\title{
Pressurized Metered-dose Inhaler (pMDI) Aerosol Deposition Measurements in Add-on Spacers
}

by

\author{
Gamal Alhegagi \\ B. Eng. Aeronautical Engineering (London University, UK) \\ B.S. in Pharmacy (Libya) \\ Medical Doctor (Libya)
}

\begin{abstract}
A Thesis submitted to
the Faculty of Graduate Studies and Research

in partial fulfilment of

the requirements for the degree of

Master of Applied Science

in Biomedical Engineering
\end{abstract}

\begin{abstract}
Ottawa-Carleton Institute for
Mechanical and Aerospace Engineering

Department of Mechanical and Aerospace Engineering

Carleton University

Ottawa, Ontario, Canada
\end{abstract}

August 1, 2009

Copyright $(\mathcal{C}$

2009 - Gamal Alhegagi 


\section{Library and Archives Canada \\ Published Heritage Branch}

395 Wellington Street Ottawa ON K1A ON4 Canada
Bibliothèque et

Archives Canada

Direction du

Patrimoine de l'édition

395 , rue Wellington

Ottawa ON K1A ON4

Canada
Your file Votre référence
ISBN: $978-0-494-60290-4$
Our file Notre référence
ISBN: $978-0-494-60290-4$

\section{NOTICE:}

The author has granted a nonexclusive license allowing Library and Archives Canada to reproduce, publish, archive, preserve, conserve, communicate to the public by telecommunication or on the Internet, loan, distribute and sell theses worldwide, for commercial or noncommercial purposes, in microform, paper, electronic and/or any other formats.

The author retains copyright ownership and moral rights in this thesis. Neither the thesis nor substantial extracts from it may be printed or otherwise reproduced without the author's permission.

\section{AVIS:}

L'auteur a accordé une licence non exclusive permettant à la Bibliothèque et Archives Canada de reproduire, publier, archiver, sauvegarder, conserver, transmettre au public par télécommunication ou par l'Internet, prêter, distribuer et vendre des thèses partout dans le monde, à des fins commerciales ou autres, sur support microforme, papier, électronique et/ou autres formats.

L'auteur conserve la propriété du droit d'auteur et des droits moraux qui protège cette thèse. $\mathrm{Ni}$ la thèse ni des extraits substantiels de celle-ci ne doivent être imprimés ou autrement reproduits sans son autorisation.
In compliance with the Canadian Privacy Act some supporting forms may have been removed from this thesis.

While these forms may be included in the document page count, their removal does not represent any loss of content from the thesis.
Conformément à la loi canadienne sur la protection de la vie privée, quelques formulaires secondaires ont été enlevés de cette thèse.

Bien que ces formulaires aient inclus dans la pagination, il n'y aura aucun contenu manquant. 


\section{Abstract}

Pressurized Metered-Dose Inhalers (pMDIs) are used in the treatment of lung diseases, such as asthma and bronchitis. Add-on spacers are attached to the pMDIs to enhance the total amount of medication delivered to the lungs in patients that cannot use pMDI properly due to incoordination. The deposition of Salbutamol Sulphate aerosol spray from Ventolin ${ }^{\circledR}$ pMDI was studied experimentally in three types of add-on spacer devices, which include OptiChamber, OptiHaler and PocketChamber, for flow rates of 30,45 and $60 \mathrm{~L} / \mathrm{min}$. A similar deposition study was carried to determine the distribution of Salbutamol Sulphate in different parts of the OptiChamber spacer. Salbutamol Sulphate deposition was assayed spectrophotometerically. The experimental results has shown that the relatively large volume OptiChamber provided lesser drug deposition in the spacer and more drug available for inhalation while, the relatively smaller OptiHaler and PocketChamber had more drug deposition in the spacer. Drug deposition in the lower half of the OptiChamber was higher than the upper half. In addition to the experimental analysis, numerical study was also carried out using RANS (Reynolds Averaged NavierStokes) equations and Eddy Interaction models (for the particulate phase) together with the SST (Shear Stress Transport) turbulence model to determine the effect of the spray angle on the deposition of Salbutamol Sulphate in the OptiChamber spacer. Numerical simulation results (using $6^{\circ}$ downward spray angle and $30 \mathrm{~L} / \mathrm{min}$ flow rate) indicate higher drug deposition in the lower half of the OptiChamber than the upper half. 


\section{Acknowledgements}

I would like to express my deepest appreciation to my supervisor Professor Edgar Matida for his advice, guidance and support throughout my research. My special thanks to Professor Metin Yaras for his strong encouragement. This thesis is dedicated to my wife

for her endless support and encouragement and to my children for their patience throughout my research work. 


\section{Table of Contents}

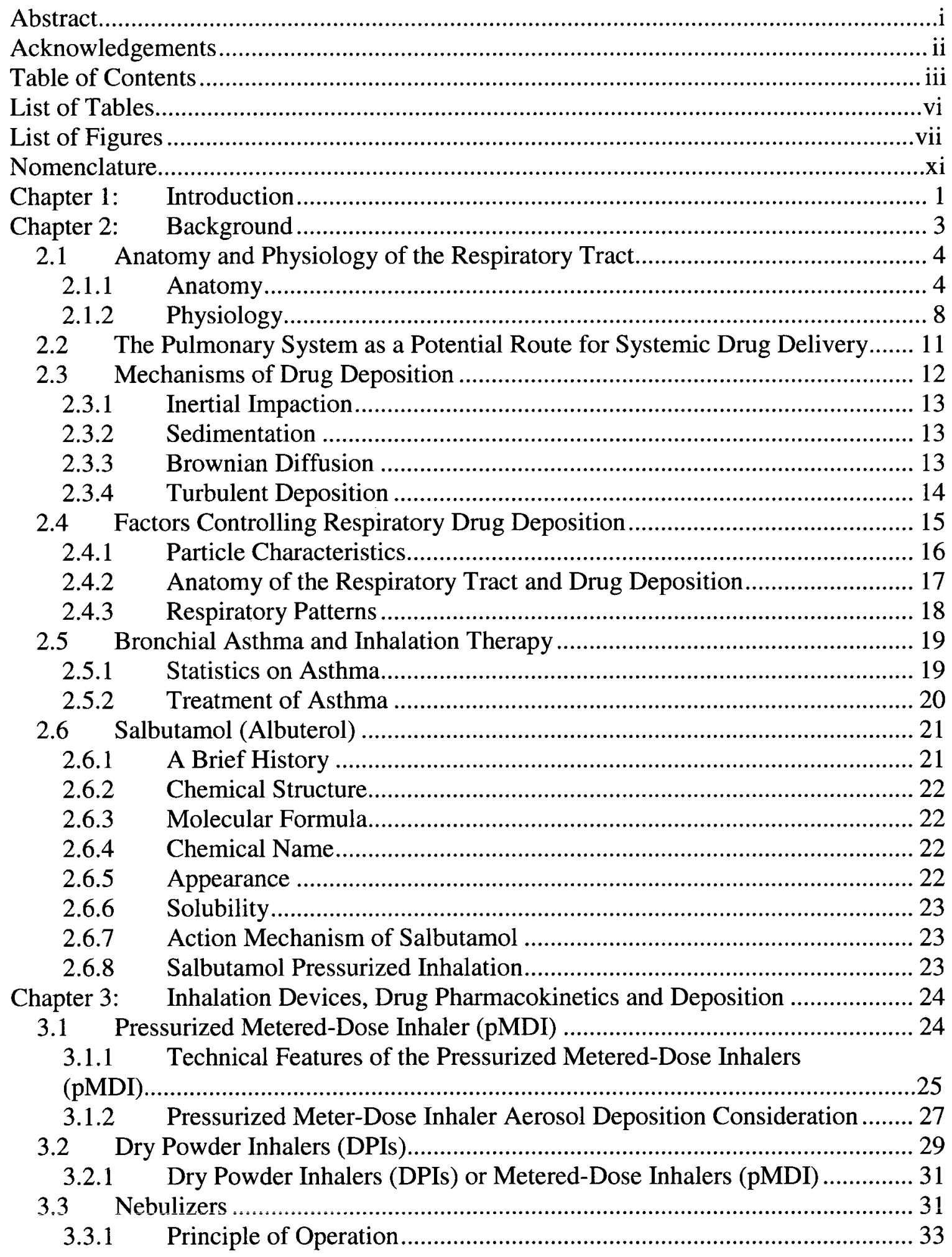


3.4 Identification of Drug Deposition in Lungs Following Inhalation ................... 33

3.4.1 Pharmacokinetic and Scintigraphic Methods.............................................. 35

3.5 Comparison of Drug Deposition by Various Inhalation Devices ...................... 37

Chapter 4: $\quad$ Add-on Devices and Drug Deposition...................................................... 39

4.1 Pressurized Metered-Dose Inhalers and Droplet Size ..................................... 41

4.1.1 Post-Nozzle Droplet Break-Up ............................................................... 41

4.1.2 Post-Nozzle Droplet Evaporation ………............................................... 41

4.1.3 Enhancing Droplet Evaporation.......................................................... 41

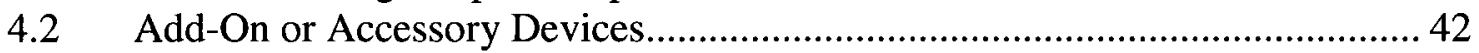

4.2.1 Characteristics of Spacer Devices........................................................... 43

4.2.2 Types of Spacers ............................................................................. 44

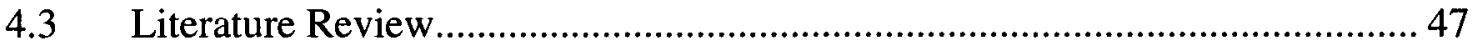

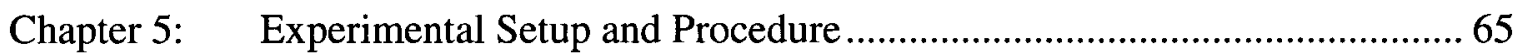

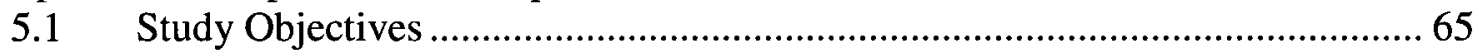

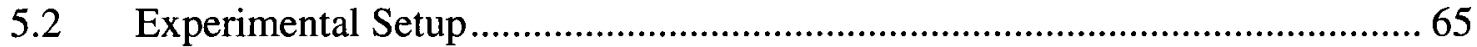

5.2.1 Propellant Driven Metered-Dose Inhaler.................................................67 67

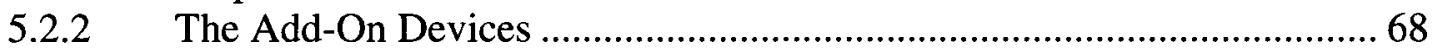

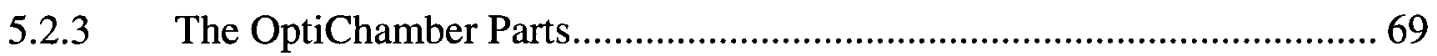

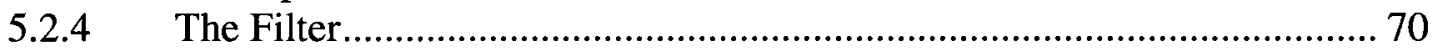

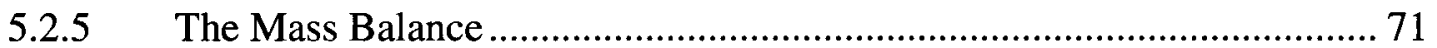

5.2.6 The Mass Flow Meter ....................................................................... 71

5.2.7 The Vacuum Pump ................................................................................. 72

5.2.8 The Spectrophotometer ........................................................................ 72

5.3 General Measurement Procedures ................................................................ 76

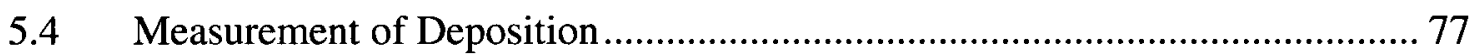

5.4.1 Assay of Salbutamol Sulphate .............................................................. 77

5.4.2 Wash Procedure ...................................................................................... 77

5.5 Procedure for the Construction of the Standard Curve ..................................... 78

5.6 Uniformity of pMDI Actuation Dose. .............................................................. 79

5.7 Determination of Salbutamol Sulphate Deposition in Different Add-On Devices

at Various Flow Rates ............................................................................................ 80

5.8 Determination of Salbutamol Sulphate Deposition in Different Parts of the

OptiChamber at Various Flow Rates ......................................................................... 80

Chapter 6: Measurement of Uncertainty................................................................. 81

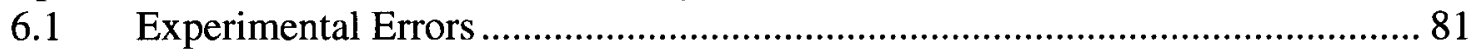

6.2 Types of Experimental Errors ................................................................... 82

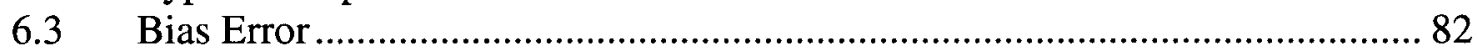

6.3.1 Estimation of Bias Error in the Deposition Fraction of Salbutamol

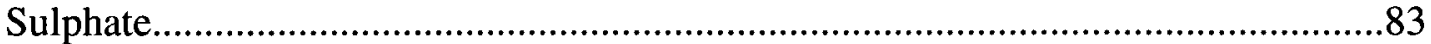

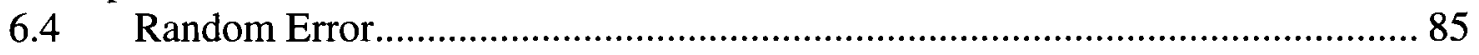

6.4.1 Estimation of the Precision Error (Random Error) in the Deposition

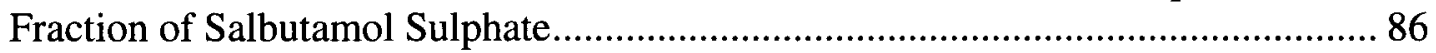

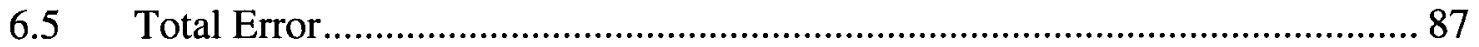

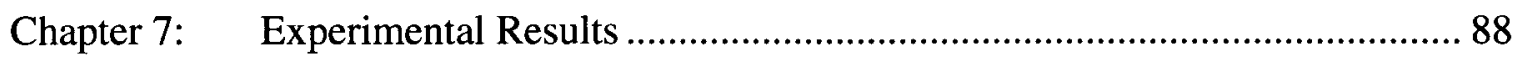

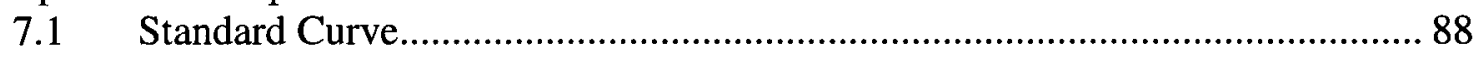

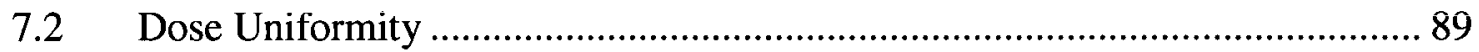


7.3 Salbutamol Sulphate deposition in Different Add-On Devices

7.4 Variation of Total Deposition Fraction (TDF) of Salbutamol Sulphate Aerosol

Spray with Flow Rate............................................................................................ 94

7.5 Deposition of Salbutamol Sulphate in Different Parts of OptiChamber........... 96

7.6 Deposition fraction of Salbutamol Sulphate in Upper and Lower Halves of

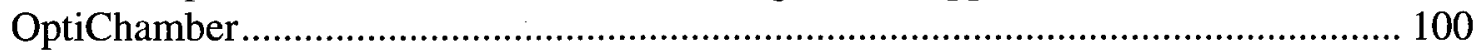

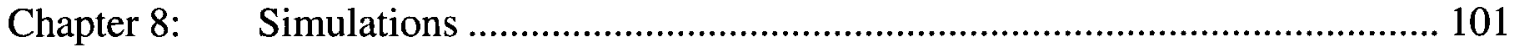

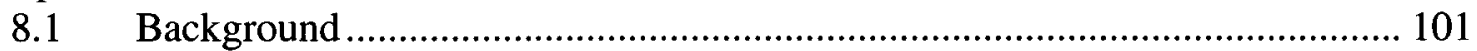

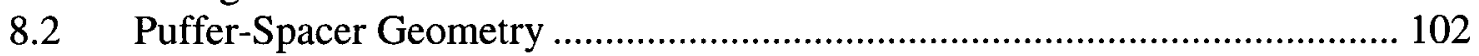

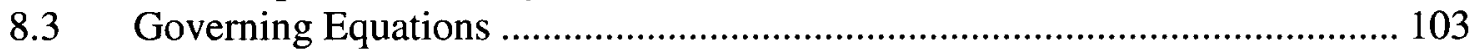

8.4 Meshing and Boundary Conditions ............................................................. 107

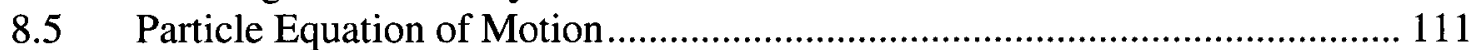

8.6 Lagrangian Particle Tracking..................................................................... 113

8.7 Fluid Flow and Particle Deposition Results.................................................... 114

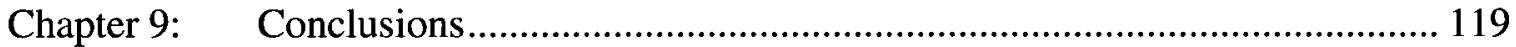

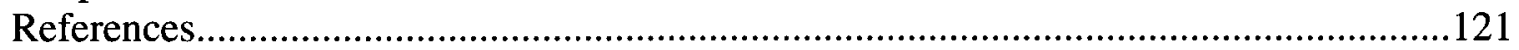

Appendix A: Standard Curve .............................................................................. 133

Appendix B: Dose Uniformity................................................................................. 133

Appendix C: Salbutamol Sulphate Deposition in Spacer and Filter at Different Flow Rates

Appendix D: Total Deposition Fraction (TDF) of Salbutamol Sulphate in Spacers at Different Flow Rates

Appendix F: Deposition Fraction of Salbutamol Sulphate in Upper and Lower Halves of OptiChamber at Different Flow Rates 


\section{List of Tables}

Table 4.1 Summary of the Studies of drug deposition in Spacers and Airways............... 64

Table 5.1 Add-on devices used and their respective dimensions and volumes ................ 69

Table 6.1: Bias error, precision error, and the uncertainty for the deposition fraction of Salbutamol Sulphate in different spacers at various flow rates. ................................ 87

Table A.1 Variation of absorption with concentration of Salbutamol Sulphate............. 133

Table B.1 Absorption and dose of eight consecutive salbutamol sulphate actuations in

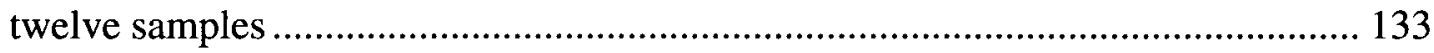

Table C.1 : Salbutamol Sulphate deposition in OptiChamber and filter at different flow

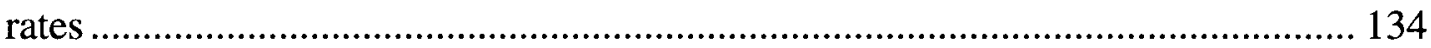

Table C.2 : Salbutamol Sulphate deposition in OptiHaler and filter at different flow rates

Table C.3 : Salbutamol Sulphate deposition in PocketChamberand filter at different flow rates

Table D.1: Total deposition fraction of Salbutamol Sulphate in OptiChamber 135

Table D.2: Total deposition fraction of Salbutamol Sulphate in OptiHaler .................... 136

Table D.3: Total deposition fraction of Salbutamol Sulphate in PocketChamber.......... 136

Table E.1: Salbutamol Sulphate deposition at $30 \mathrm{~L} / \mathrm{min}$ flow rate ................................. 137

Table E.2: Salbutamol Sulphate deposition at $45 \mathrm{~L} / \mathrm{min}$ flow rate ................................ 137

Table E.3: Salbutamol Sulphate deposition at $60 \mathrm{~L} / \mathrm{min}$ flow rate ............................... 138

Table F.1: deposition fraction of Salbutamol Sulphate in upper and lower halves of OptiChamber at $30 \mathrm{~L} / \mathrm{min}$ flow rate

Table F.2: deposition fraction of Salbutamol Sulphate in upper and lower halves of OptiChamber at $45 \mathrm{~L} / \mathrm{min}$ flow rate.

Table F.3: deposition fraction of Salbutamol Sulphate in upper and lower halves of OptiChamber at $60 \mathrm{~L} / \mathrm{min}$ flow rate. 


\section{List of Figures}

Figure 1.1: Inhalation through an add-on device (spacer) attached to pMDI .................... 1

Figure 2.1: Upper and lower respiratory tracts (National Cancer Institute, 2009)............. 5

Figure 2.2: Major bronchial subdivisions and lateral aspect of the lungs. Adapted from

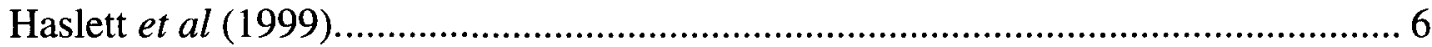

Figure 2.3 Diagrams of alveoli showing alveolar sacs with pulmonary artery and vein

(The Internet Encyclopedia of Science: Anatomy and Physiology, ......................... 7

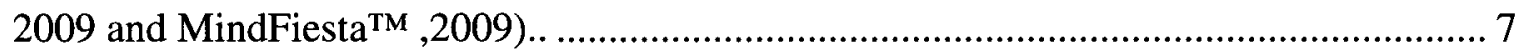

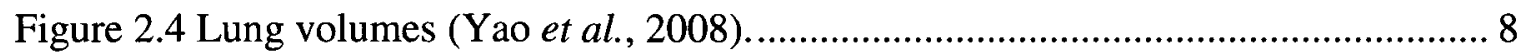

Figure 2.5 Basic gas exchange unit of the lung. Adapted from Haslett et al. (1999)...... 10

Figure 3.1 Components of the pressurized metered-dose inhaler (pMDI). Adapted from

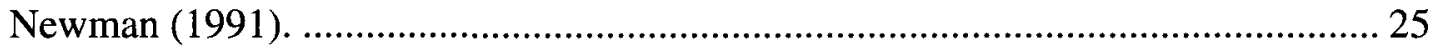

Figure 3.2 Cross-section of Easyhaler® - a new generation, multidose dry powder inhaler

Source: Juntunen-Backman et al. (2002)............................................................ 30

Figure 3.3 Valved jet nebulizer. Adapted from Newman, (1991) .................................. 32

Figure 3.4 Basic components of pneumatic nebulizer. Adapted from Newman (1991)... 33

Figure 3.5 Pharmacokinetics of an inhaled drug. Adapted from Chrystyn (1997)........... 34

Figure 3.6 Gamma image of inhaled radio-labelled drug in the lungs. Source: Newman

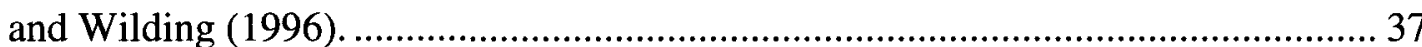

Figure 3.7 Percent of nominal dose of Salbutamol deposited in the lungs, oropharynx, apparatus, and exhaled, using dry powdered inhaler (DPI), pressurized metered-dose inhaler (pMDI), pMDI with holding chamber (pMDI/HC), and nebulizer (NEB) -

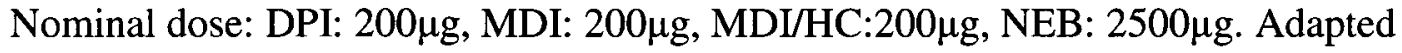

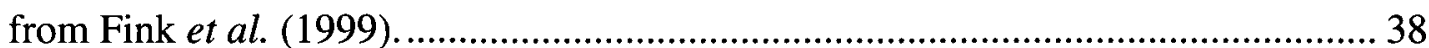

Figure 4.1 Relative sizes of a typical raindrop, a water droplet in a cloud together with a large and small aerosol particles respectively. Aerosol particles can be as small as 0.01 microns. Source: Russell (1996). 40

Figure 4.2 Types of spacers and valves holding chambers (VHC) Source: Asmus et al. (2004). 
Figure 4.3 Variation of the mean respirable dose of Fluticasone Propionate pMDI with spacers normalized per actuation. Adapted from Asmus et al. (2004). 48

Figure 4.4 Variation of the mean respirable dose of Fluticasone Propionate pMDI with valved holding chambers (VHCs) normalized per actuation. Adapted from Asmus et al. (2004).

Figure 4.5 Mean oropharynx dose normalized per actuation. Adapted from Asmus et al. (2004) 50

Figure 4.6 Disodium Chromoglycate (DSCG) as percentage of $5 \mathrm{mg}$ dose recovered in particles $<5 \mu \mathrm{m}$ aerodynamic diameter (Dae) for six different add-on devices. Adapted from Barry and O'Callaghan (1996). 51

Figure 4.7 Salbutamol as percentage of $100 \mu \mathrm{g}$ dose recovered in particles $<5 \mu \mathrm{m}$ aerodynamic diameter $\left(\mathrm{D}_{\mathrm{ac}}\right)$ for four spacer devices. Adapted from Barry and O'Callaghan (1996). 52

Figure 4.8: Budesonide as percentage of $200 \mu \mathrm{g}$ dose recovered in particles $<5 \mu \mathrm{m}$ aerodynamic diameter $\left(\mathrm{D}_{\mathrm{ae}}\right)$ for three different spacers. Adapted from Barry and O'Callaghan (1996).

Figure 4.9: Effect of spacer length and spacer diameter on the availability of respirable mass of medication. Adapted from Barry and O'Callaghan (1995 A). 54

Figure 4.10 (A): Effect of fast and slow inhalation on aerosol deposition in lung for each particle size using Albuterol doses of $30 \mu \mathrm{g}$. Adapted from Usmani et al. (2005). . 57

Figure 4.10 (B): Effect of fast and slow inhalation on aerosol deposition in oropharynx for each particle size using Albuterol doses of $30 \mu \mathrm{g}$. Adapted from Usmani et al. (2005)

Figure $4.10(\mathrm{C})$ : Effect of fast and slow inhalation on aerosol exhalation fraction for each particle size using Albuterol doses of $30 \mu \mathrm{g}$. Adapted from Usmani et al. (2005). . 58

Figure 4.11 (A): Effect of fast and slow inhalation on aerosol deposition expressed as percentage of radionuclide dose delivered for each particle size in central and intermediate, and peripheral regions of the lung. Adapted from Usmani et al. (2005).

Figure 4.11 (B): Effect of fast compared with slow on aerosol penetration into the lung. Adapted from Usmani et al. (2005). 59 
Figure 4.12: Change in $\mathrm{FEV}_{1}$ with slow and fast inhalation. Adapted from Usmani et al. (2005).

Figure 4.13 Variation of spray velocity with time at 3 selected centerline locations.

Adapted from Crosland (2008).

Figure 4.14 Geometry-based and velocity based calculations of spray direction without coflow and velocity-based calculation with coflow. Adapted from Crosland (2008).

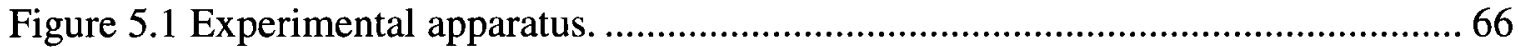

Figure 5.2 Ventolin HFA ${ }^{\mathrm{TM}}$ pressurized metered dose inhaler...................................67

Figure 5.3 Inhalers used in the experiments (OptiChamber®), Optihaler ${ }^{\circledR}$,

PocketChamber ${ }^{\mathrm{TM}}$ ).

Figure 5.3 Photograph showing different parts of the OptiChamber (two halves, MDI inlet piece, valve and mouthpiece that fit together)......................................... 70

Figure 5.4 Schematic diagram of a spectrophotometer. .......................................... 73

Figure 5.5 Agilent 8453 UV-visible Spectroscopy System....................................... 75

Figure 7.1 Variation of absorption with standard concentrations of Salbutamol Sulphate.

Figure 7.2 Dose uniformity in eight consecutive MDI actuations of Salbutamol sulphate.

Figure 7.3 Deposition of Salbutamol Sulphate aerosol from pMDI in three types of spacers and their filters at $30 \mathrm{~L} / \mathrm{min}$ flow rate.

Figure 7.4 Deposition of Salbutamol Sulphate aerosol from pMDI in three types of spacers and their filter at $45 \mathrm{~L} / \mathrm{min}$ flow rate.

Figure 7.5 Deposition of Salbutamol Sulphate aerosol from pMDI in three types of spacers and their filter at $60 \mathrm{~L} / \mathrm{min}$ flow rate. 92

Figure 7.7 Linear variation of the total deposition fraction (TDF) with flow rate for each type of spacer used.

Figure 7.8 Deposition of Salbutamol Sulphate aerosol spray in various parts of the OptiChamber at different flow rates.

Figure 7.9 Deposition of Salbutamol Sulphate Spray in the upper and lower halves of an OptiChamber. 
Figure 7.10 Variation of Salbutamol Sulphate deposition fraction in upper and lower halves of OptiChamber with flow rate.................................................................. 100

Figure 8.1 View of the puffer attached to the spacer...................................................... 102

Figure 8.2 View of the canister and the lower part of the spacer. ................................. 103

Figure 8.3: Unstructured grid at the mid-plane of the geometry. (The 3-D geometry has approximately 3,000,000 elements).

Figure 8.4: Details of the unstructured grid near the canister and nozzle. (The 3-D geometry has approximately 3,000,000 elements). 108

Figure 8.5: The vertical and horizontal lines at the mouthpiece outlet (inlet of the add-on spacer). 109

Figure 8.6: Horizontal distribution ( $\mathrm{z}$ direction) of streamwise mean velocities, $U$, for three different grid sizes. 110

Figure 8.7: Vertical distribution (y direction) of streamwise mean velocities, $U$, for three different grid sizes.

Figure 8.8 Example of meanflow tracking trajectories (20 particles carrying information of the distance travelled by the particles).

Figure 8.9: Magnitude of mean velocities at the midplane of the geometry.

Figure 8.10: Turbulence kinetic energy at the midplane of the geometry. 116

Figure 8.11: 2-D vector plot superimposed to the magnitude of mean velocities at the mouthpiece outlet.

Figure 8.12: Particle deposition distribution (10,000 particles). 


\section{Nomenclature}

A Cross-sectional area $\left(\mathrm{m}^{2}\right)$ or spectrophotometeric absorbance of a sample

C Concentration of analyte in the sample $(\mu \mathrm{g} / \mathrm{mL}$ or $\mathrm{mol} / \mathrm{L})$

$C_{C}$ or $C_{0} \quad$ Cunningham's slip correction factor

$C D \quad$ Drag coefficient

CFC Chlorofluorocarbon

CFD Computational fluid dynamics

$C_{\mu} \quad$ A constant in the eddy diffusivity formula

$D \quad$ Particle diameter $(\mu \mathrm{m})$ or characteristic dimension $(\mathrm{m})$ in the fluid flow

$D_{a e} \quad$ Aerodynamic diameter $(\mu \mathrm{m})$

DF Deposition Fraction

$d f \quad$ Degree of freedom

$d_{p} \quad$ Particle diameter $(\mu \mathrm{m})$

DPI Dry powder inhaler

DSCG Disodium chromoglycate

$\frac{D}{d t}$ or $\frac{d}{d t} \quad$ Total time derivative for a fluid particle or for an aerosol particle

EIMs Eddy Interaction Models

EVM Eddy Viscosity Model

$F \quad$ A function in the turbulence model

$F E V_{l} \quad$ Forced expiratory volume in one second $(\mathrm{mL})$

$g \quad$ Gravitational acceleration constant $\left(\mathrm{m} / \mathrm{s}^{2}\right)$

HFA Hydrofluoroalkane

$I_{0} \quad$ Light intensity (cd) entering the sample

$I \quad$ Light intensity (cd) leaving the sample

$K \quad$ Constant for a particular sample at a certain wavelength $\left(\mathrm{L} \mathrm{mol}^{-1} \mathrm{~cm}^{-1}\right)$

$k \quad$ Boltzmann's constant or turbulence kinetic energy $(\mathrm{J} / \mathrm{K})$

$L \quad$ Length of the light path in glass sample cuvette $(\mathrm{cm})$

$L_{e} \quad$ Eddy length scale (percentage of inlet diameter in turbulent flow) 


\begin{tabular}{|c|c|}
\hline$L E S$ & Large Eddy Simulation \\
\hline$m$ & Mass $(\mathrm{kg})$ or mean \\
\hline$\dot{m}$ & Mass flow rate of air $(\mathrm{kg} / \mathrm{s})$ \\
\hline$M M A D$ & Mass median aerodynamic diameter $(\mu \mathrm{m})$ \\
\hline$n$ & Number of experiments carried out for each sample \\
\hline$n m$ & Nanometer \\
\hline$N_{i}$ & Random number \\
\hline$P$ & Air pressure $\left(\mathrm{N} / \mathrm{m}^{2}\right)$ \\
\hline$p M D I$ & Pressurized metered-dose inhaler \\
\hline$Q$ & Volume flow rate of air $\left(\mathrm{m}^{3} / \mathrm{s}\right.$ or $\left.\mathrm{L} / \mathrm{min}\right)$ \\
\hline RANS & Reynolds average Navier-Stokes \\
\hline $\operatorname{Re}_{P}$ & Reynolds number of aerosol particle \\
\hline$R M S$ & Root-mean square \\
\hline$S D$ & Standard Deviation \\
\hline Stk & Stokes number \\
\hline SST & Shear Stress Transport \\
\hline$t$ & time(s) \\
\hline$T D F$ & Total deposition fraction \\
\hline$T$ & Transmitted light for a sample in the spectrophotometer \\
\hline$u$ & Velocity component in the r-direction, or the $\mathrm{x}$-direction $(\mathrm{m} / \mathrm{s})$ \\
\hline$u_{e}$ & Eddy velocity scale $(\mathrm{m} / \mathrm{s})$ \\
\hline$U$ & Bias error (subscript denote device used) or streamwise mean velocities \\
\hline$U_{0}$ & Velocity of the aerosol particles $(\mathrm{m} / \mathrm{s})$ \\
\hline$\vec{V}$ & Velocity of air $(\mathrm{m} / \mathrm{s})$ \\
\hline$v$ & Velocity component in the $\alpha$-direction, or the y-direction $(\mathrm{m} / \mathrm{s})$ \\
\hline$V$ & Local speed $(\mathrm{m} / \mathrm{s})$ \\
\hline$V H C$ & Valved holding chamber \\
\hline Vol & Volume (mL) of wash solution (subscript denotes part washed) \\
\hline$w$ & Velocity component $(\mathrm{m} / \mathrm{s})$ in the $\theta$-direction, or the $\mathrm{z}$-direction \\
\hline$x, y, z$ & Rectangular coordinates (m) \\
\hline
\end{tabular}




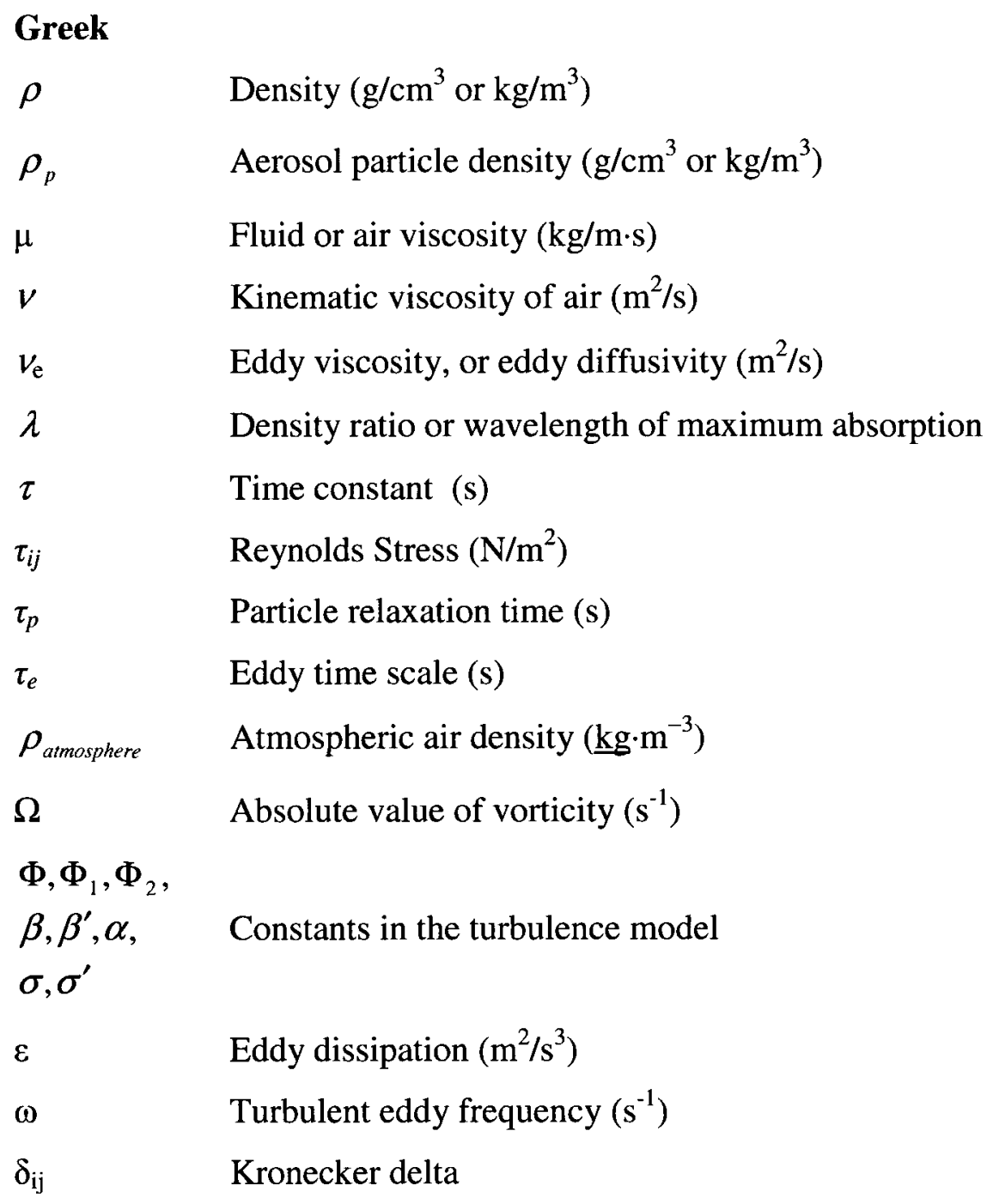

\section{Subscripts}

$\begin{array}{ll}f & \text { Fluid } \\ p & \text { Particle } \\ e & \text { Eddy } \\ x, y, z & \mathrm{x}, \mathrm{y}, \mathrm{z} \text { components } \\ \text { spacer } & \text { Spacer } \\ \text { filter } & \text { Filter } \\ \text { flow meter } & \text { Flow meter } \\ \text { flow rate } & \text { Flow rate }\end{array}$




$\begin{array}{ll}\text { Gauge } & \text { Gauge } \\ m & \text { Time mean values } \\ K & \text { Kolmogorov }\end{array}$

\title{
Medical and Latin Terminology
}

\author{
Bioavailability Fraction of an administered dose of drug reaching \\ systemic circulation unchanged \\ Bronchodilator Drug that relaxes bronchial smooth muscle, dilating \\ the bronchi. \\ Drug clearance Ability of the body to remove the drug from the general \\ circulation by the kidneys or other body organs. \\ Dysphonia Hoarseness or other phonation disorders of the \\ voice. \\ Emphysema COPD due to the destruction of elastic tissue in the \\ Lung, increasing lung compliance. \\ First pass effect Drug metabolism causing the a drug concentration to \\ be greatly reduced before it enters the systemic \\ circulation. \\ Hypokalemia Level of potassium ions in blood serum below \\ normal \\ In vivo \\ A medical procedure carried out in the living \\ organism \\ In vitro \\ A medical procedure carried outside the living \\ organism \\ Lag time \\ Time required for a drug administered orally to be \\ absorbed into the systemic circulation. \\ Lipophilicity The ability of a drug to dissolve in a non-polar or lipid solvent \\ Nasopharynx The area of the throat that lies behind the nose.
}


Oral thrush Growth of Candida on the mucous membranes of the mouth.

Oropharynx The part of the throat that lies at the back of the mouth

Oropharyngeal Related to the oropharynx

Palpitations Awareness of irregular and/or forceful heart beat.

Pharmacokinetics The process in which a drug undergoes absorption, distribution, metabolism and elimination by the body.

Pharmacological Related to drug action on the tissue.

Radionuclide Unstable radioactive form of an element that decays resulting in the release of nuclear radiation.

Receptor Site on or inside of a cell that binds with substrates such as hormones, drugs and others to produce a physiologic or pharmacologic action

Systemic therapy Treatment through the bloodstream reaching all cells of the body

Tracheobronchial Tubular structure within the neck consisting of the trachea, bronchi and bronchioles that provides air to lungs

Tremors Involuntary, alternating, rhythmical movement that may involve any muscles of the body. 


\section{Chapter 1: Introduction}

Pressurized Metered-Dose Inhalers (pMDIs) or "puffers" are normally used in the treatment of lung diseases, such as asthma and bronchitis. According to statistics from the Canadian Lung Association, 10\% of the population may have some respiratory illness requiring treatment in part of their lives. Pressurized MDIs require actuation/inhalation coordination and are normally not recommended for children or seniors. Considerable amounts of aerosol medication generated from the pMDIs are deposited and lost on the walls of the upper airways (mouth-throat-trachea) before reaching the target (or the lungs), resulting in up to approximately $91 \%$ losses from a single dosage (Fink, 2000), i.e., only $9 \%$ are delivered to the lungs. Add-on spacers are devices that are attached to the pMDIs (Figure 1.1) to enhance the total amount of medication delivered to the lungs (losses are decreased to approximately $80 \%$, Fink, 2000). Spacers available on the market have cylindrical shapes and may or may not contain valves (at the mouthpiece) that will open after a certain threshold pressure. Spacers tend to reduce velocity and turbulence levels of the aerosol created by the pMDIs, thus decreasing the amount of medication lost in the airways (mainly in the mouth).

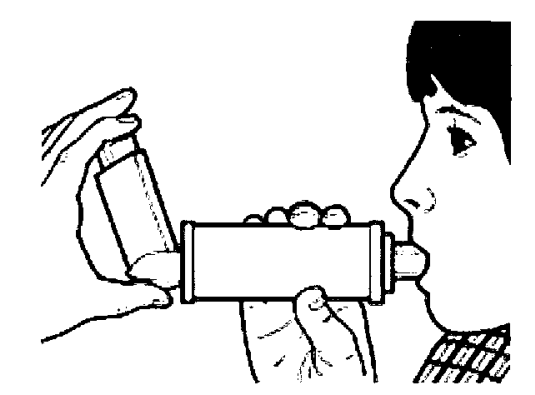

University of Michigan Health System (2009)

Figure 1.1: Inhalation through an adj-on device (spacer) attached to pMDI 
Based on previous PIV (Particle Image Velocimetry) measurements of spray velocities (Crosland, 2008), which indicated that the spray angle and velocities coming from the pMDI vary in time, the present thesis is focusing on the measurement of pMDI nonsymmetrical aerosol deposition on the walls of add-on spacers. An additional numerical simulation was also performed and described in the present work. By better understanding the physics involved in this aerosol deposition, new design concepts for add-on spacers may be developed in the future.

Concerning the thesis outline, the following chapter introduces the background of aerosol drug delivery, the anatomy of the respiratory tract, the physiology and pathology of the respiratory system, aerosol medication deposition mechanisms in the lungs, and some aspects of medication used in the treatment of lung diseases. Chapters 3 and 4 describe inhaler devices and provide discussions concerning aerosol deposition results found in the literature. The experimental setup, the uncertainty analysis, and the experimental results are shown in Chapters 5, 6, and 7, respectively. Chapter 8 provides the details of the numerical analysis and Chapter 9 depicts the final conclusions and recommendations for future work. 


\section{Chapter 2: Background}

Localized drug delivery to the respiratory tract has become a very important and effective therapeutic procedure for the treatment of a number of respiratory tract disorders including, asthma, bronchitis, and other lung disease such as cystic fibrosis. Although it has been used for more than two thousand years, its use has only become important in the last 30 to 40 years with the introduction of efficient devices in terms of pulmonary drug deposition (Suarez and Hickey, 2000).

Several studies have demonstrated the clinical advantage of inhalation aerosols over systemic therapy (drug reaching and affecting cells and organs of the entire body) for the treatment of lung disorders (Clark, 1972, Neville et al., 1977, Newman, 1985). Compared with other drug delivery systems, relatively small doses are required for effective treatment hence, reducing systemic exposure to drug and thus minimizing adverse effects. Lower dosage delivered from one inhaler may produce a response that differs from that produced by a different inhaler and vice-versa. Dose regimens may provide considerable cost savings, especially with expensive therapeutic agents. An effective inhalation device should produce an aerosol of medication with a dose having particle size in the respirable range, in other words, able to reach the lower region of the respiratory tract. Inhalation devices should be simple to use, portable and durable (Chapman, 1995). The efficacy and adverse effects of inhaled medication depends on the device, the medication being used and the patient's use of the device (improper use due to lack of coordination). 


\subsection{Anatomy and Physiology of the Respiratory Tract}

The respiratory tract has a combined surface area of over $100 \mathrm{~m}^{2}$ and is in direct contact with the external environment (Haslett et al., 1999). Each anatomical segment of the respiratory tract posses a wide range of physiological functions. These physiological functions vary with the state of health of the body. The respiratory tract is a complicated system and its malfunction may occur as a result of a number of disease processes.

\subsubsection{Anatomy}

The respiratory system consists of a number of elements namely, the respiratory tract, the pulmonary circulation, the chest wall, as well as the central nervous system. The respiratory tract can be divided into four anatomical segments, these include, the nasooropharynx, the conducting airways, the respiratory bronchioles, and the alveoli (see Figure 2.1). The lungs form part of the conducting units and the respiratory units. The conducting units consist of the trachea and bronchi, and bronchioles concerned with the conduction of air from outside the body and deliver it to the respiratory units or the alveoli. The unicellular epithelial walled blood capillaries surrounding the alveolar sac result in the exchange of carbon dioxide for oxygen required by the body for metabolism and therefore energy production. Respiratory dysfunction may result from malfunction of one or more of these segments.

The "upper respiratory tract" (also depicted in Figure 2.1) consists of the nasooropharynx, which includes the nasal and oral cavities, nasal passages, and the larynx (Haslett et al., 1999). The upper respiratory tract walls are lined by vascular mucous membrane and a surface containing ciliated epithelium. The function of the naso- 
oropharynx is the warming, humidification, and filtration of large particles from the inspired air. The larynx contains the epiglottis and muscles that divert the passage of food to the oesophagus and air to the trachea (Person and Mintz, 2006).

\section{Conducting Passages}

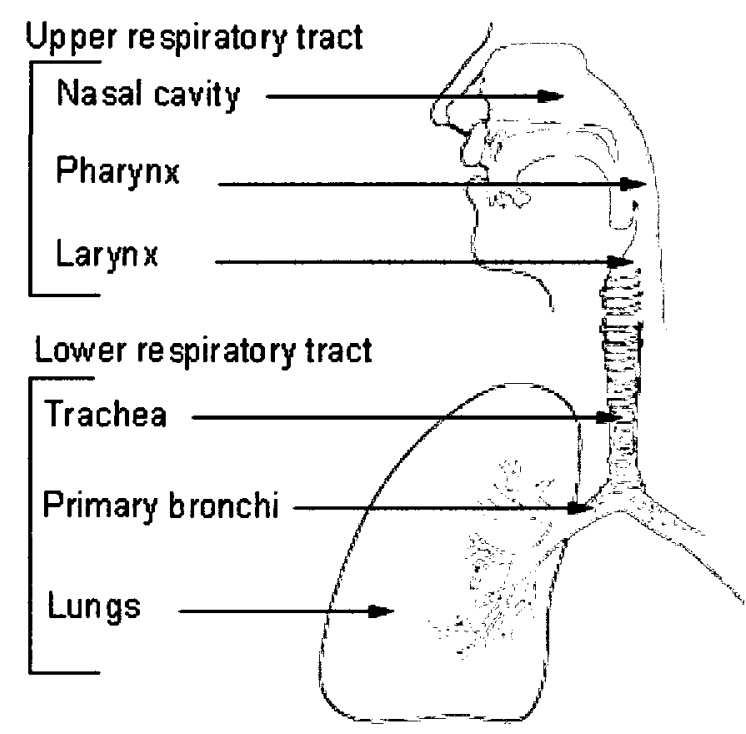

Figure 2.1: Upper and lower respiratory tracts (National Cancer Institute, 2009).

The "lower respiratory tract" consists of the trachea and the bronchi (see Figure 2.1). The trachea bifurcates at the carina into the right and left main bronchi, which branch repeatedly into smaller bronchi and bronchioles, forming about 14 generations of conducting airways (Figure 2.2) reaching all the segments in each lobe of the lungs respectively (Reynolds, 2004). The last segment of the bronchioles terminates in the respiratory bronchioles before reaching the alveoli. 

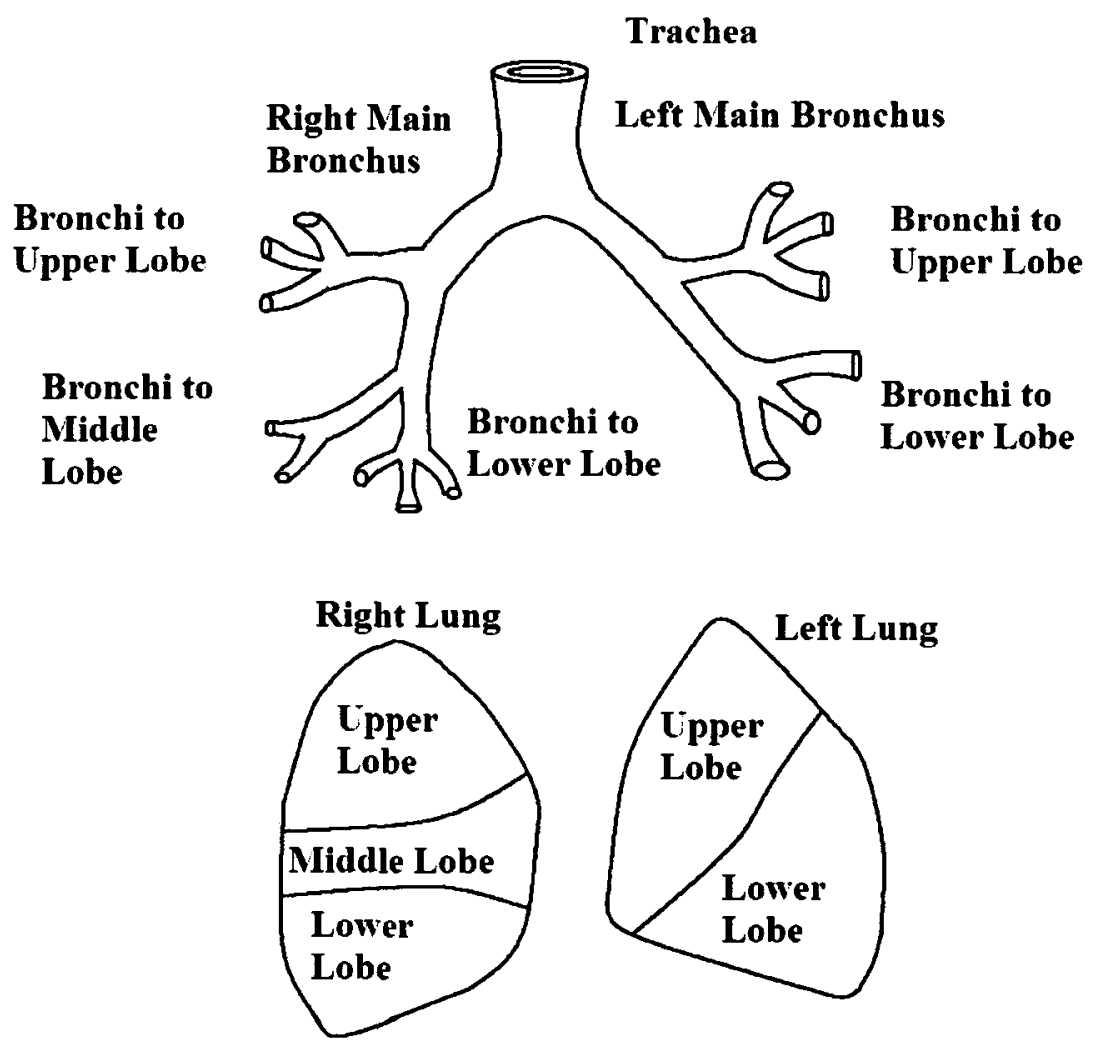

Figure 2.2: Major bronchial subdivisions and lateral aspect of the lungs. Adapted from Haslett et al., 1999.

The alveoli are lined by type I epithelial cells, a mono-cellular layer that permits gaseous exchange (Person and Mintz, 2006). The millions of alveoli present cover a total surface area of about $100 \mathrm{~m}^{2}$. A network of blood capillaries forming an air-blood interface surrounds each alveolar sac (Figure 2.3). 


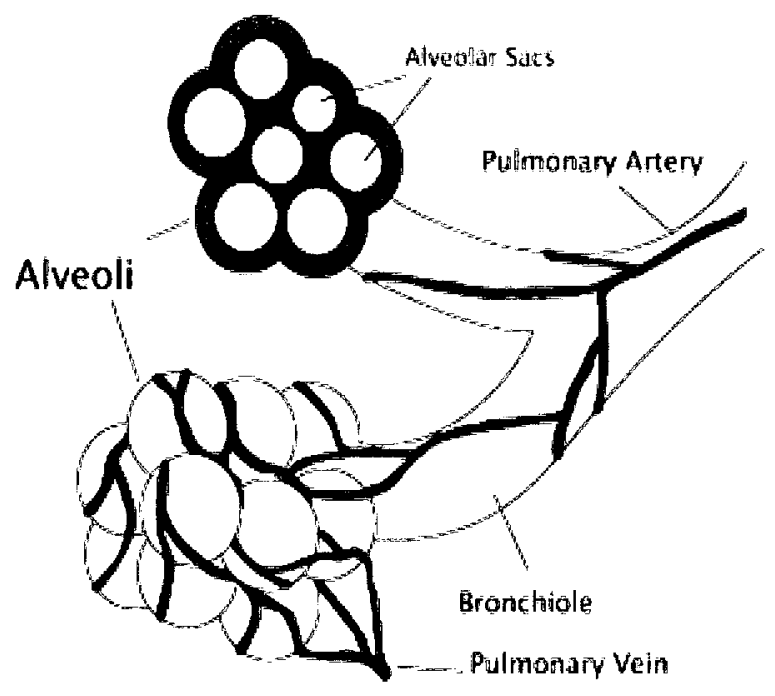

The Internet Encyclopedia of Science: Anatomy and Physiology (2009)

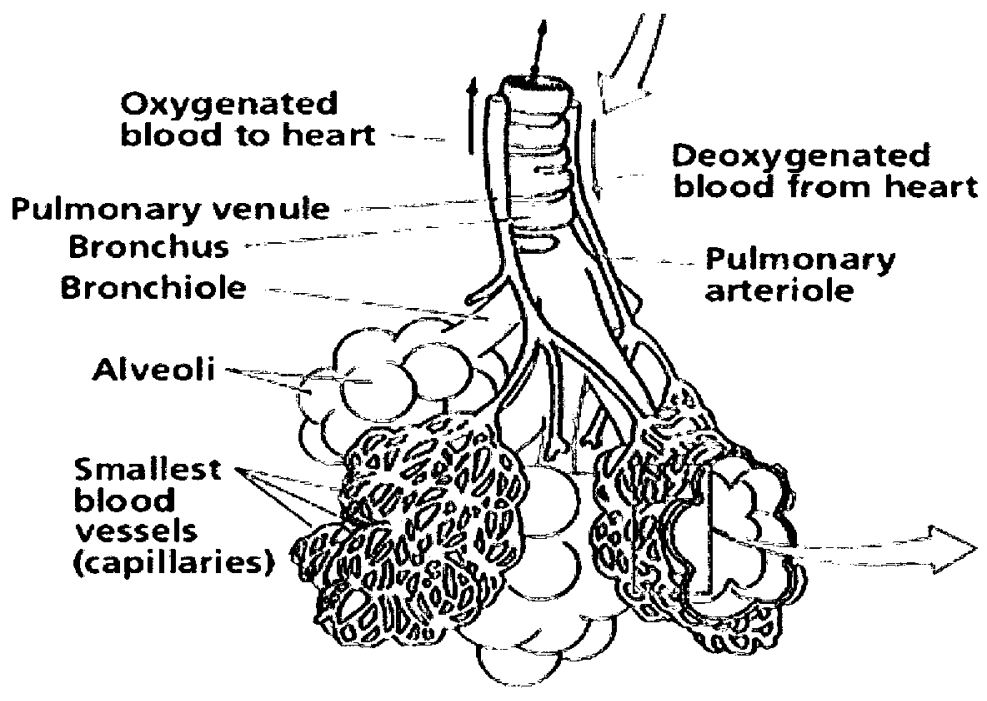

MindFiesta $^{\mathrm{TM}}(2009)$

Figure 2.3 Diagrams of alveoli showing alveolar sacs with pulmonary artery and vein (The Internet Encyclopedia of Science: Anatomy and Physiology, 2009 and MindFiesta ${ }^{\mathrm{TM}}, 2009$ ). 


\subsubsection{Physiology}

Tidal volume (Figure 2.4) is the volume of air breathed in or out in a normal breath of a healthy adult, it ranges between 500 to $800 \mathrm{~mL}$ of air (Person and Mintz, 2006). The vital capacity of the lungs is the maximum volume of air that can be expired from the lungs after a maximum inspiration (Reynolds, 2004).

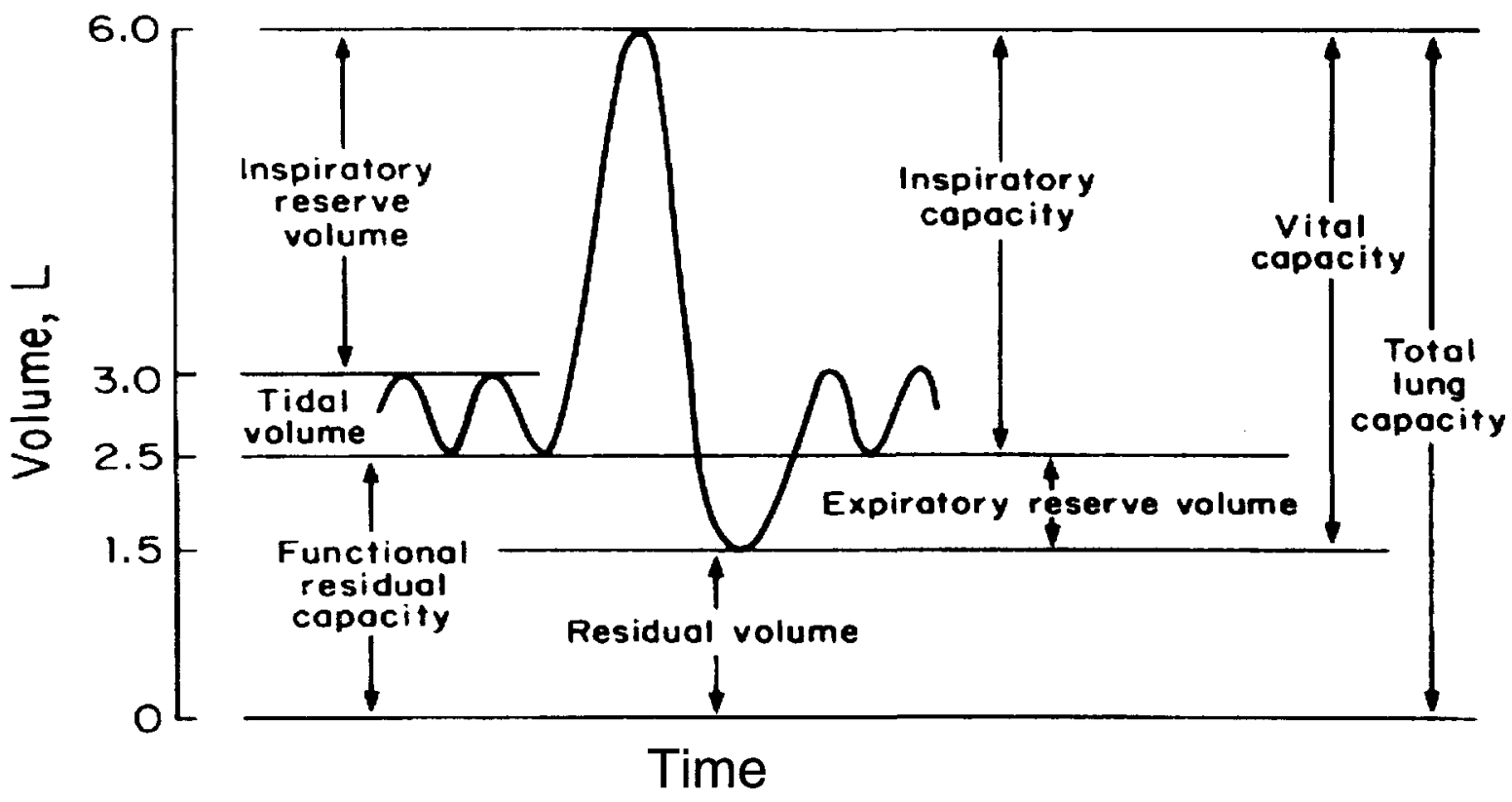

Figure 2.4 Lung volumes (Yao et al., 2008).

There are three important physiological functions of the respiratory tract. These include, ventilation, perfusion and diffusion. Ventilation is the process by which air-containing oxygen is transported in the lungs from outside the body through inspiration to reach the alveoli. The process also involves the expulsion of air containing carbon dioxide outside the body through expiration (Figure 2.5). Inspiration and expiration occur because of the pressure difference between the inside and outside of the lungs caused by the elastic nature of the lungs (Person and Mintz, 2006). Positive internal pressure is exerted by the airways and alveoli causing lung distension, while negative external pressure is caused by 
pressure outside the lungs (Reynolds, 2004). The elastic nature of the chest wall allows it to move whenever pressure is exerted on it, during breathing.

Respiration is controlled by the central nervous system; mainly the medulla and pons. These neural organs constantly receive neural inputs from several sources or receptors including, the carotid bodies which detect changes in the partial pressures of oxygen $\left(\mathrm{PaO}_{2}\right)$ and carbon dioxide $\left(\mathrm{PaCO}_{2}\right)$ as well as the $\mathrm{pH}$ of the blood, and the medullary chemoreceptor which monitors $\mathrm{PaCO}_{2}$ and $\mathrm{pH}$ alone (Haslett et al., 1999). Stretching of the chest wall muscles are monitored by the muscle spindles and Golgi tendon organs, which are embedded in these muscles. This combined information controls the ventilatory needs of the individual. Increased ventilatory needs occur during exercise and other physiological or pathological state where the body tissues require increased oxygen needs (Haslett et al., 1999). Although, the ventilatory drive is stimulated by $\mathrm{PaO}_{2}$ and $\mathrm{PaCO}_{2}$ blood levels, the receptors tend to be more sensitive to the partial pressure of carbon dioxide, $\mathrm{PaCO}_{2}$ than that of oxygen, $\mathrm{PaO}_{2}$. The normal arterial $\mathrm{PaO}_{2}$ is over $90 \mathrm{mmHg}$ and $\mathrm{PaCO} 2$ is about $40 \mathrm{mmHg}$ in a normal healthy adult individual (Haslett et al., 1999). A slight increase in $\mathrm{PaCO}_{2}$ (to about $42 \mathrm{mmHg}$ ), a condition known as hypercapnia, will rapidly stimulate an increase in the rate of ventilation, while a similar response (hypoxemic response) is obtained only when $\mathrm{PaO}_{2}$ is decreased to about $65 \mathrm{mmHg}$, a condition known as hypoxemia (Haslett et al., 1999) . Therefore, ventilation is driven primarily by hypercapnia.

Perfusion is the process by which oxygen in the alveoli is transported into the pulmonary artery capillaries surrounding the alveolar sacs and into the main blood stream. Perfusion also involves the removal of carbon dioxide from these capillaries into 
the lungs to be expelled outside of the body. Gas exchange in the lungs is a passive process. Gases diffuse across the tissue from air to blood and vice versa by diffusion driven by concentration gradients (Haslett et al., 1999).

Clinically, the consequences of impaired gas exchange are hypoxemia and hypercapnia. Ventilation-perfusion mismatch is thought to be responsible for the hypercapnia seen in certain pathological conditions that include chronic obstructive pulmonary disease (COPD) and severe asthma. COPD includes chronic bronchitis and emphysema. In chronic bronchitis, the walls of the airways are inflamed with increased mucus secretion in the airways resulting in their mechanical obstruction. In emphysema, inflammation commonly involves the respiratory bronchioles, alveolar ducts, and those alveoli that are centrally located. The airflow obstruction may partially respond to bronchodilator therapy (Haslett et al., 1999).

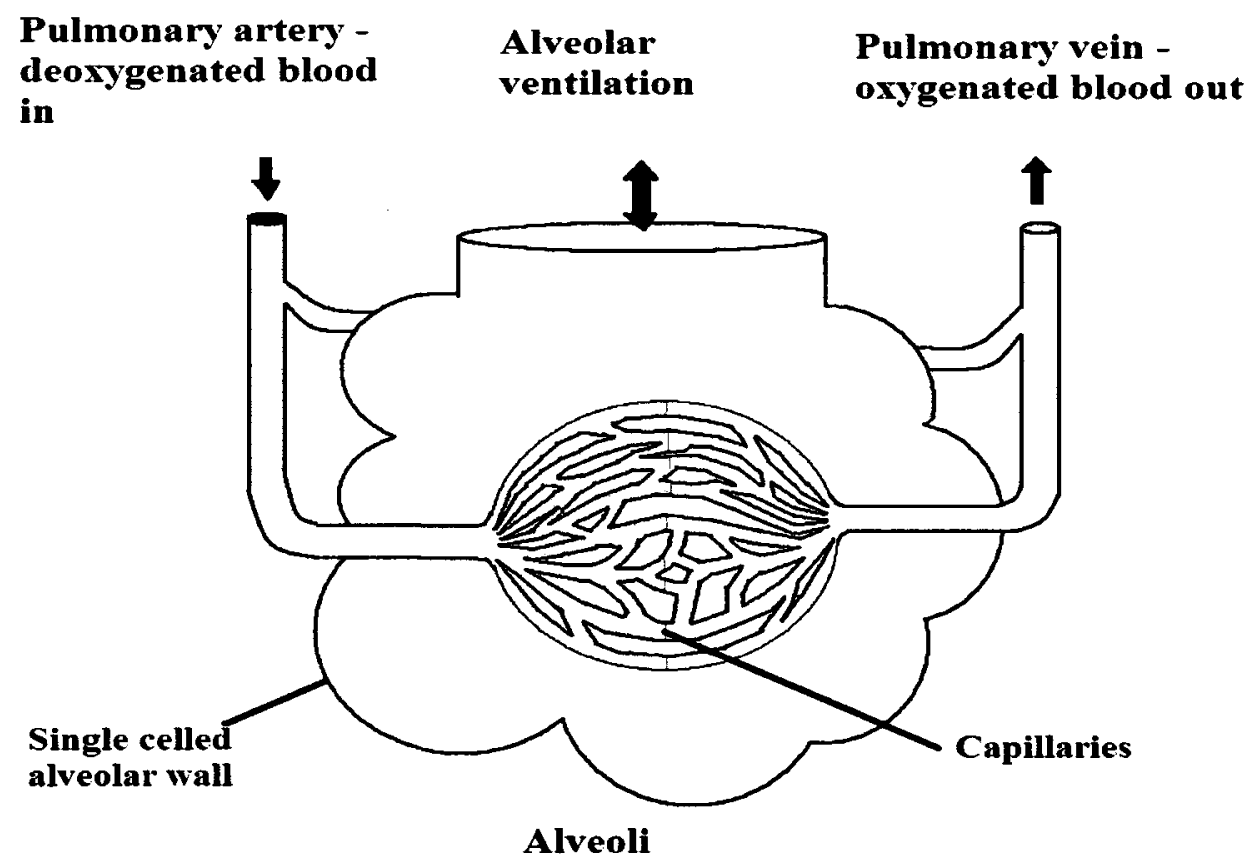

Figure 2.5 Basic gas exchange unit of the lung. Adapted from Haslett et al., 1999. 


\subsection{The Pulmonary System as a Potential Route for Systemic Drug $\underline{\text { Delivery }}$}

The lungs with a combined surface area of more than $100 \mathrm{~m}^{2}$ together with a low metabolic activity (Lourenco and Cotroman, 1982, Clarke and Newman, 1984) makes them an ideal site for drug absorption and a potential route for the systemic administration of certain drugs that cannot be delivered by other means. Many studies have shown that greater bioavailability has been achieved for macromolecular drugs than any other route of administration to the systemic circulation (Patton and Platz, 1992, Byron and Patton, 1994).

The inhaled route of administration for drugs such as bronchodilators and corticosteroids is considered as the ultimate procedure for treating patients with obstructive airway diseases. When compared with systemic administration, the inhalation route provides a faster onset of action and high in-situ drug concentrations. The efficacy of a therapeutic aerosol is mainly determined by its ability to provide a satisfactory dose of the drug at the target site. Naturally, the human lung has evolved to prevent the entry of atmospheric particulates to the body. Therefore, delivering a certain dose of a drug to the site of action via inhalation requires a multidisciplinary scientific effort. Research is being focused on particle technology as well as on the design of drug delivery devices as means to increase the fraction of drug reaching the periphery of the respiratory tract. 


\subsection{Mechanisms of Drug Deposition}

An aerosol is a suspension of fine particles of liquid or solid dispersed in a gas. Drugs in aerosol form are used for inhalation therapy. The efficacy of an aerosolized drug is its ability to reach the peripheral portions of the lung. The anatomy and physiology of the lungs play a major role in preventing the entry of particulate matter. The redistribution of the drug particles in the airways is determined by the efficiency of the regional pattern of deposition (Schlesinger, 1985).

Lung diseases such as COPD and asthma affect aerosol lung deposition with increased central (tracheobronchial) deposition and a decreased deposition at the

peripheral airways (Anderson et al., 1990). Aerosol particles deposit in the respiratory tract is affected by a number of mechanisms, which include impaction (inertial deposition), sedimentation (gravitational deposition), Brownian diffusion, interception, electrostatic precipitation (Carpenter and Miller, 1993; Yu and Chien, 1997, Carpenter, 1999) and turbulent deposition (Dekker, 1961).

The role of each mechanism depends on a number of factors, which include the characteristics of the inhaled aerosol particles, the breathing pattern of the patient and the anatomy of the respiratory tract. Some of the mechanisms are more important than the others. Impaction and sedimentation play an important role in the deposition of large aerosol particles with a mass median aerodynamic diameter (MMAD) between $1 \mu \mathrm{m}$ and $10 \mu \mathrm{m}$ while diffusion is more important in the deposition of smaller aerosol particles in the lung periphery (Yu and Chien, 1997). 


\subsubsection{Inertial Impaction}

Inertial impaction occurs when a large particle is unable to rapidly adjust to sudden changes in streamline direction. Due to its inertia, the particle will continue along its original direction and may impact in an obstacle in its path. Deposition of aerosol drug particles in the upper airways and at bronchial branching points occurs mainly by inertial impaction. The rate of inertial impaction is directly proportional to the velocity of the streamline, the breathing frequency and the diameter of the aerosol drug particle (Schlesinger, 1985, Carpenter, 1999).

\subsubsection{Sedimentation}

Sedimentation describes the motion of molecules in solutions or particles in suspensions in response to an external force such as gravity overcoming the total force of the air resistance. Under gravitational effect, inspired aerosol drug particles will leave the air stream and fall down at a constant rate (Brain and Valberg, 1979).

Sedimentation occurs mainly in small airways with low air velocity. The likelihood of aerosol drug particles to undergo sedimentation is proportional to the residence time of the particle in the airways and to the particle size but inversely proportional to the breathing rate.

\subsubsection{Brownian Diffusion}

Brownian motion occurs because of gas molecules in continuous motion collide with small aerosol drug particles causing discrete non-uniform pressures at the particles' surfaces. Such particle motion exists in still air even in the absence of gravity (Brain and 
Valberg, 1979). Aerosol drug particle deposition due to Brownian motion occurs mainly in the bronchioles, alveoli, and bronchial airways. The deposition is inversely proportional to those particles with diameters less than $50 \mu \mathrm{m}$ (Lippmann, 1977).

\subsubsection{Turbulent Deposition}

Laminar flow in the respiratory tract causes small particles with a mass median aerodynamic diameter (MMAD) of $0.3 \mu \mathrm{m}$ or less to deposit uniformly on the tracheal wall by Brownian diffusion. The presence of non-uniform deposition pattern of small particles indicates departure from ideal laminar flow. The inhomogeneity in deposition increases with increase in flow rate (Martin and Jacobi, 1972). One of the most important factors affecting tracheal deposition is the flow field caused by the entry of the inspired air jet from the larynx towards the posterior wall of the trachea causing turbulence (Dekker, 1961). Turbulence produces inhomogeneous deposition patters involving particles of all sizes but the effect is more apparent in particles of smaller size (Schlesinger and Lippmann, 1976). Therefore, changes in flow pattern tend to affect the deposition of small particles more than larger particles where their motion is mainly determined by inertial forces (Olson et al., 1973). Particle deposition within the trachea tends to increase in turbulence. Submicron particles are injected into the laminar boundary layer by turbulent eddies, where they may deposit by Brownian diffusion (Owen, 1969). Eddies may cause larger particles to be projected towards the tracheal wall at a local rate higher than would occur in the absence of any secondary flow thus enhancing their inertial deposition (Davies, 1966). In relatively high turbulent flow 
regimes, particles very close to the wall may acquire considerable velocities, causing them to deposit by inertia (Fuchs, 1964).

\subsection{Factors Controlling Respiratory Drug Deposition}

Studies have shown that the distribution and deposition of drugs in the respiratory tract depends on:

(1) The characteristics of the inhaled drug particles including the particle diameter, size distribution, shape, electrical charge, density, and the hygroscopicity of the formulation (Schlesinger, 1985, Hickey, 1993 Atkins, 1994).

(2) The anatomy of the respiratory tract (Lippmann and Schlesinger, 1984). This includes the diameter of the bronchi and brochioles.

(3) The patterns of breathing which include, frequency, tidal volume, and flow (Byron, 1986, Stahlhofen, 1989, Anderson, 1995, Svartengren, 1996).

(4) The design and characteristics of the aerosol-delivering device.

The ideal site of drug deposition along the respiratory tract for local drug delivery is not well understood. Effective therapy may depend on targeting specific autonomic receptors in the respiratory tract with different drugs. The location of these receptors varies along the respiratory tract (Barnes et al., 1993).

Because of the variable thickness of the bronchial epithelial cells in the central portion of the lung, the rate of drug absorption is $50 \%$ that of the peripheral portions of the lung, which contain alveolar epithelial cells (Brown et al., 1983).

For maximum drug bioavailability for systemic delivery, drug delivery should be targeted to the periphery of the lungs. The onset and duration of action of the drug is 
proportional to the rate of pulmonary absorption and pulmonary clearance. Several factors determine the pharmacokinetics of the inhaled drug. These include, the physicochemical properties of the drug such as the dissolution rate, the molecular weight, the partition coefficient and the particle charge (Effros and Mason, 1983, Byron, 1986, Byron and Phillips, 1990). An ideal inhalation aerosol for local delivery should have a relatively slow rate of pulmonary absorption and clearance. It has been shown that the lung residence time of the drug may be increased by increasing the lipophilicity (Johnson, 1996) of the drug, maximizing the particle size (Byron, 1986, Gonda, 1988) and release rate (Byron, 1986, Gonda, 1988, Suarez et al., 1998). The pharmacologic effect and the duration of action of a drug can also be determined by drug-drug interactions that may occur at the drug receptor site and/or during drug disposition.

\subsubsection{Particle Characteristics}

The particle size determines the extent of penetration of the particle into the lungs and is therefore an important parameter that affects its deposition site (Zainudin, 1993).

The aerodynamic diameter $\left(\mathrm{D}_{\mathrm{ae}}\right)$ is used to express the aerosol particle size. It is used to characterize drug particles for pulmonary drug delivery as an alternative to the geometric diameter. It can be described as the diameter of a sphere of unit density (1 $\mathrm{g} / \mathrm{cm}^{3}$ ) and has a similar gravitational settling velocity from an air stream as the particle in question (Schlesinger, 1985). The settling velocity of the drug particle is proportional to the aerodynamic diameter. Therefore, those particles with more than a unit density have an aerodynamic diameter more than the geometric diameter while, particle with a density less than one will have an aerodynamic diameter smaller than the geometric 
diameter. Aerosol size distributions may be classified as being highly monodisperse, having uniform sizes and a geometric standard deviation of less than 1.2 or polydisperse, having nonuniform sizes and a geometric standard deviation of more than or equal to 1.2.

Inhaled particles tend to be filtered off in the upper airways and the branches of the tracheobronchial tree. Therefore, aerosol particles over $100 \mu \mathrm{m}$ are filtered off in the naso-opharynx while particles over $10 \mu \mathrm{m}$ cannot pass through the tracheobronchial tree. Particles reaching the alveolar space must be less than $5 \mu \mathrm{m}$ (Brain and Valberg, 1979, Zainudin, 1993, Byron and Patton, 1994). Particles with diameter less than $0.5 \mu \mathrm{m}$ tend to reach deep into the lungs but are exhaled without deposition although, some studies show that exhalation of these particles can be minimized through breath-holding (Byron, 1976, 1987) .

\subsubsection{Anatomy of the Respiratory Tract and Drug Deposition}

Particle deposition is affected by the geometry of the airways. The air velocity for a given flow is determined by the cross-section of the airway at the same time, changes in the diameter of the airways and the branching pattern of the bronchi and bronchioles causes mixing between the tidal and reserve air (Schlesinger, 1985).

The large lungs with a more symmetrical upper bronchial airway pattern in humans cause more particle deposition in the upper bronchial region than other animal species (Lippmann and Schlesinger, 1984). 


\subsubsection{Respiratory Patterns}

Regional deposition of inhaled aerosol is affected by the pattern of respiration. The mean flow rates in each region of the respiratory tract are determined by the breathing volume and frequency and thus influence the effectiveness of the deposition mechanism (Schlesinger, 1985, Byron, 1986, Gonda, 1990, Hakkinen et al., 1999).

Particle deposition increases with turbulent flow and particle size. Increased deposition of large particles in the upper respiratory tract occurs with rapid breathing. Increased penetration of particles to the lung periphery occurs with slow steady inhalation (Valberg et al., 1982).

Slow breathing with or without breath holding maximizes particle deposition in the traheobronchial region (Byron, 1986). With breath holding, maximum pulmonary deposition occurs between $1.5 \mu \mathrm{m}$ and $2.5 \mu \mathrm{m}$ and without breath holding, this occurs between $2.5 \mu \mathrm{m}$ and $4 \mu \mathrm{m}$. Rapid inhalation produces a similar picture, but decreased maximum tracheobronchial deposition occurs between $3 \mu \mathrm{m}$ and $6 \mu \mathrm{m}$. With breath holding, maximum pulmonary deposition occurs between $1.5 \mu \mathrm{m}$ and $2 \mu \mathrm{m}$ and without breath holding this occurs between $2 \mu \mathrm{m}$ and $3 \mu \mathrm{m}$ (Byron, 1986). Therefore, the ideal use of an aerosol should involve:

(1) The use of an aerosol with an aerodynamic diameter (Dae) between $2-5 \mu \mathrm{m}$ to minimize deposition in the oropharynx.

(2) The patient should inhale slowly and steadily.

(3) The patient should hold his/her breath for a few seconds after completion of aerosol inhalation. 


\subsection{Bronchial Asthma and Inhalation Therapy}

Asthma is defined as a chronic inflammatory disorder of the airways, characterised by reversible airflow obstruction causing cough, wheeze, chest tightness and shortness of breath (Haslett et al., 1999). Inflammation of the bronchial wall involves various types of inflammatory cells including eosinophils, mast cells and lymphocytes together with cytokines and inflammatory products of these cells. This induces hyper-responsiveness of the bronchi so that they constrict more readily in response to a wide range of stimuli (Haslett et al., 1999). The airflow obstruction, which characteristically fluctuates markedly, increases the work of breathing. A constricted bronchus can no longer be effectively cleaned by coughing up the mucus formed by the disease process and many of the bronchi become obstructed by mucus plugs (Haslett et al., 1999).

\subsubsection{Statistics on Asthma}

- Over 30 million Americans suffer from asthma (Asthma Prevalence, 2000-2001).

- In 2000, 12 million individuals in the United States experienced an asthmatic attack and accounted for 10.4 million outpatient visits, 1.8 million emergencies, 465,000 inpatients, and 4,487 deaths (Asthma Prevalence, 2000-2001 and MMWR 2003).

- Direct and indirect annual economic losses as a result of asthma are estimated to be over $\$ 14$ billion (Morbidity \& Mortality: 2002). 


\subsubsection{Treatment of Asthma}

This is condensed from Davidson's Principle and Practice of Medicine (Haslett et al., (1999). The procedure involves five steps depending on the condition of the patient. All five steps require the use of inhalation therapy:

Step 1: patient with minor symptoms treated by occasional use of inhaled shortacting $\beta_{2}$-adrenoceptor agonist bronchodilator such as Salbutamol Sulphate.

Step 2: patient with increased daytime attacks is treated by short-acting $\beta_{2^{-}}$ adrenoceptor agonist inhaler as required together with an inhaled steroid such as Fluticasone Propionate.

Step 3: Asthma disrupting patient's sleep. Patient treated with short-acting $\beta_{2}$ adrenoceptor agonist inhaler plus high dose of inhaled corticosteroid that requires the use

of a large volume spacer (holding chamber). The spacer decreases the gastrointestinal absorption of swallowed drug and to lower the risk of developing the local side effects such as oropharyngeal candidiasis.

Step 4: Severe asthmatic attacks during daytime. Patient treated with high dose of inhaled corticosteroid together with short-acting $\beta_{2}$-adrenoceptor agonist inhaler as required plus a sequential therapeutic trial of inhaled long-acting $\beta 2$ adrenoceptor agonist such as Salmeterol.

Step 5: Severe asthmatic attacks day and night. Treatment as step 4 with the addition of regular oral corticosteroid therapy such as Prednisolone. 


\subsection{Salbutamol (Albuterol)}

\subsubsection{A Brief History}

Salbutamol is widely used for the symptomatic treatment of asthma. During an asthmatic episode, muscles around the airways constrict hence decreasing the airway diameter causing difficulties in breathing. Salbutamol relaxes the constricted bronchial smooth muscles relieving the respiratory distress caused by asthma. The following is a brief history on Salbutamol which has been condensed from the British Pharmaceutical Society:

- In 1903: Bullowa \& Kaplan reported that adrenaline can be used to treat asthma but had unwanted side effects on the cardiovascular system.

- In 1910: Barger \& Dale named agents similar to adrenaline as "sympathomimetic" as they stimulated the sympathetic nervous system.

- In 1940: Konzett identified isoprenaline, a sympathomimetic that had no effect on the blood pressure but stimulated the heart.

- In 1948: Ahlquist classified adrenoceptors into two types, $\alpha$ and $\beta$.

- In 1967: Lands separated $\beta$ receptors into $\beta_{1}$ and $\beta_{2}$ subtypes. $\beta_{1}$ receptors are present mainly in the heart, whereas $\beta_{2}$ receptors are present on the bronchial smooth muscle.

- In 1969: Salbutamol was the first $\beta_{2}$ selective agent used to treat asthma. It is administered by inhalation and provides short bronchodilation effect for 4-6 hours. 


\subsubsection{Chemical Structure}

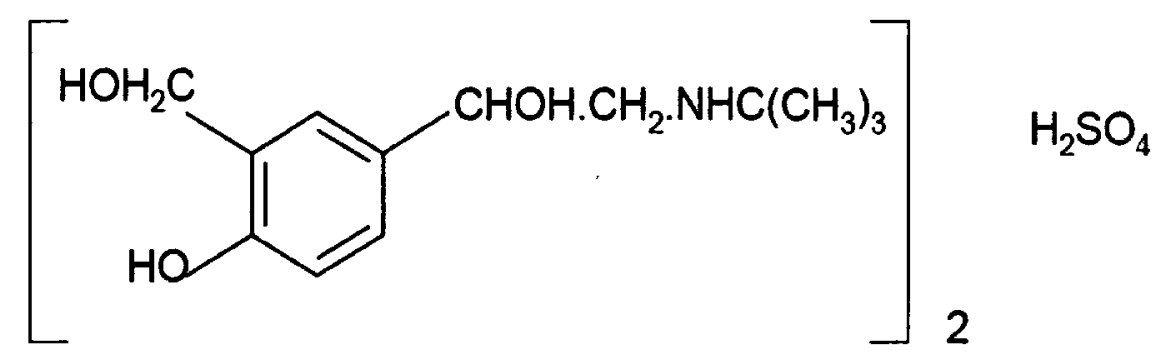

(British Pharmacopoeia, 2007).

\subsubsection{Molecular Formula}

\section{$\left(\mathrm{C}_{13} \mathrm{H}_{21} \mathrm{NO}_{3}\right)_{2} \mathrm{H}_{2} \mathrm{SO}_{4}$}

(British Pharmacopoeia, 2007).

\subsubsection{Chemical Name}

(1 RS)-2_[(1,1-Dimethylethyl)amino]-1-[4-hydroxy-3

(hydroxymethyl)phenyl]ethanol.

(British Pharmacopoeia, 2007).

\subsubsection{Appearance}

White or almost white crystalline powder

(British Pharmacopoeia, 2007). 


\subsubsection{Solubility}

Salbutamol Sulphate is sparingly soluble in water and soluble in $96 \%$ ethanol.

(British Pharmacopoeia, 2007).

\subsubsection{Action Mechanism of Salbutamol}

$\beta_{2}$ - agonists activate adenylate cyclase causing the formation of intracellular cyclic adenosine monophosphate (cAMP) which activates intracellular phosphokinase. This causes the bronchial smooth muscle cells to relax and the airways to dilate. $\beta_{2}$ - agonists also prevent the mast cells from releasing bronchoconstriction substances and alters the composition of the mucus secretion thus increasing mucocillary transport (Katzung, 1989) Side effects of $\beta_{2}$ - agonists include hypokalemia which can occur with excessive doses as well as tremor, palpitations, nervous tension, headache and peripheral vasodilatation (BNF, 1999).

\subsubsection{Salbutamol Pressurized Inhalation}

This is defined as a suspension of either Salbutamol or Salbutamol Sulphate in a suitable liquid in a suitable pressurized container (British Pharmacopoeia, 2007). The pressurized inhalation complies with the requirements stated by the British Pharmacopoeia. 


\section{Chapter 3: Inhalation Devices, Drug Pharmacokinetics}

\section{and Deposition}

This chapter provides a brief description and comparison of the various types of therapeutic inhalation devices present in the world market. A more detailed description is given on the pMDI as it forms part of the apparatus and experimental procedure of the research presented in this thesis.

\subsection{Pressurized Metered-Dose Inhaler (pMDI)}

Pressurized metered dose inhalers (pMDI) are considered as the most widely prescribed aerosol delivery system because of their effectiveness and ease of use by a large number of patients (Terzano, 2001). The main components of the pMDI (Figure 3.1) include an actuator, a metering valve, and a pressurized container that holds the micronized drug suspension or solution, propellant, and surfactant (Newman, 1991).

The high vapour pressure propellant supplies the energy for dispersion in these delivery systems. Despite being effective, cheap and easy to use, pMDI have a number of limitations. One limitation includes the pMDI spray which consists of large propellant droplets moving at a velocity of over $30 \mathrm{~m} / \mathrm{s}$ that readily impact on the oropharyngeal wall. When a pMDI used correctly, such an impact results in about $80 \%$ loss in the emitted dose (Finlay et al., 1997) while 10-20\% deposit in the lungs (Newman, 1985).

Another limitation of the pMDI is improper use of the device by many patients, estimated to be $50 \%$ in adult patients and a higher proportion in young children resulting in some patients receiving little or no medication (Crompton, 1982). The poor 
coordination between pMDI actuation and inhalation especially seen in elderly patients and the "cold Freon" effect where some patients cease inhaling as a result of the cold propellant striking the back of the throat causes a large part of the drug to be lost. Reduced aerosol deposition in lungs will result in reduced clinical benefits.

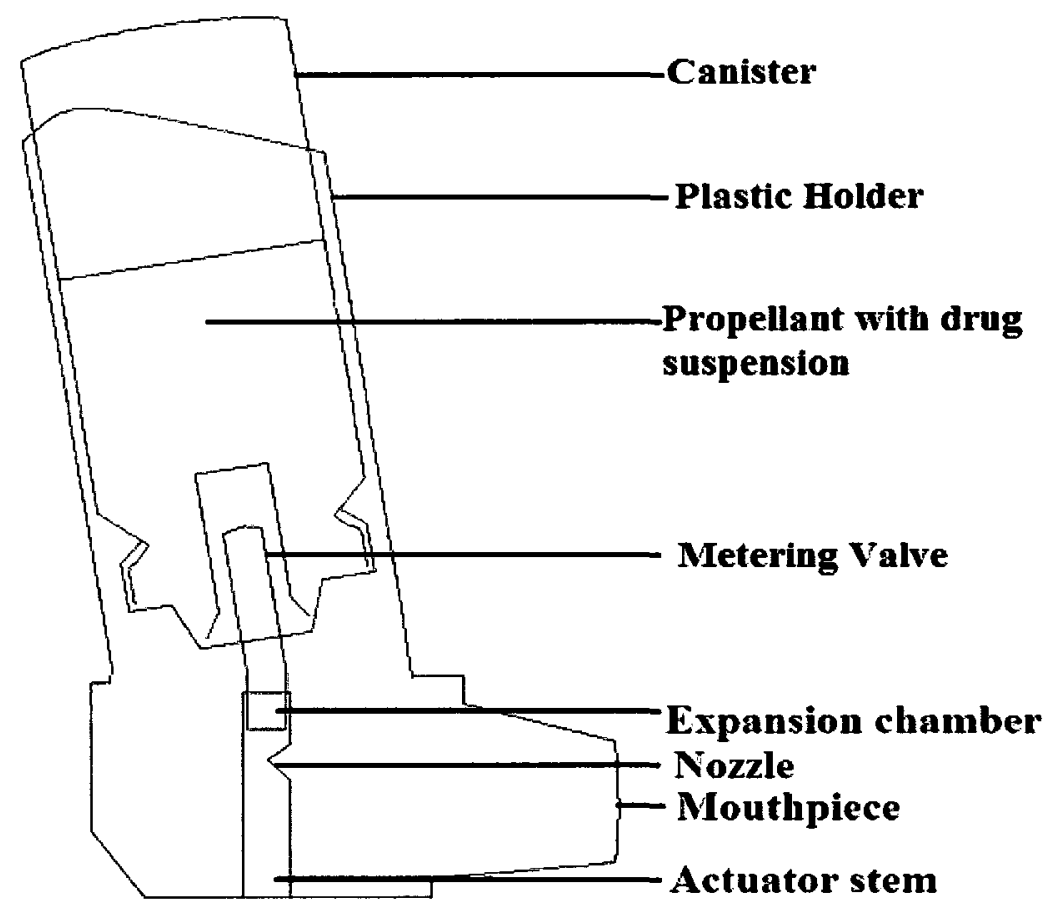

Figure 3.1 Components of the pressurized metered-dose inhaler (pMDI). Adapted from Newman, 1991.

\subsubsection{Technical Features of the Pressurized Metered-Dose Inhalers (pMDI)}

The particle size distribution of the pMDI aerosols is affected by

(i) The aerosol formulation.

(ii) The pressure in the MDI canister. 
(iii) The physicochemical properties of the propellants and other added chemicals such as surfactants. Physicochemical properties include density, viscosity, surface tension, vapour pressure, heat of vaporization, etc.

(iv) The design of the pMDI's valve and actuator orifice.

The formulation is formed of either a suspension or a solution. The suspension consists of a micronized powder of the active agent suspended in a liquid propellant. The solution consists of the active agent in a solvent added to the propellant. Actuation of the pMDI causes the release of the formulation in the expansion chamber from the pressurized canister resulting in a mixture of gas and liquid which is discharged to the outside from the orifice of the device. As the liquid stream leaves the orifice, it is broken down into droplets by the high-speed gas flow. Very high pressure causes a high atomization force that produces a large number of small particles that may undergo coagulation (Fuchs, 1964).

The pressure required to break-up the droplets is proportional to the viscosity and surface tension of the formulation. Both, the viscosity and the surfactant in pMDI formulations are low. The surfactant is used to promote droplet dispersion and to stop coagulation of solid particles. The effective particle size depends on the rate of evaporation of the droplets released from the pMDI. The droplet consists mainly of the propellant that undergoes rapid vaporization as it leaves the orifice. Propellants in pMDI are made of two or more agents mixed at various proportions to obtain the desired pressure and volatility (Wiener, 1958).

Small droplets produce small particles. Once released from the orifice, the mass median aerodynamic diameter (MMAD) of the droplet ranges between $20 \mu \mathrm{m}$ and $50 \mu \mathrm{m}$. 
As the propellant vaporizes rapidly, the droplet mass falls by $30 \%$, thus decreasing the droplet diameter by $12 \%$. Droplet vapourization then slows down producing the final particle size which ranges between $2.4 \mu \mathrm{m}$ and $5.5 \mu \mathrm{m}$ in dry air as measured with a cascade impactor (Kim et al., 1985). Increasing the diameter of the orifice of the pMDI canister increases the size of the droplets while decreasing the orifice diameter lowers the discharge efficiency (Kim et al., 1985).

The volume of aerosol released from the pMDI as well as the diameter and the design of the actuator housing of the pMDI together with other factors influence the particle size and the jet pattern (Sackner and Kim, 1985). Reduction in the metered volume of the pMDI, results in a short broken aerosol jet with the forward jet velocity being reduced more. The reduced quantity of propellant results in a smaller jet expansion and therefore less aerosol loss because of impaction. On the other hand, a very smallmetered volume may adversely affect accuracy and reproducibility of the dose (Sackner and Kim, 1985).

\subsubsection{Pressurized Meter-Dose Inhaler Aerosol Deposition Consideration}

The aerosol particle impaction theory predicts that aerosol particle $10 \mu \mathrm{m}$ or more traveling at the normal pMDI jet velocity should impact on an obstacle at a distance of 10 $\mathrm{cm}$ away from the actuator orifice, which is equivalent to the distance between the pMDI orifice and the posterior pharyngeal wall (Rance, 1974). Impaction loss is minimized if droplets vaporize completely to their final size before reaching the oropharyngeal wall. Nevertheless, some studies (Pengilly and Keiner, 1977, Moron and Anderson, 1980) have demonstrated that between 50 and 65 percent of delivered pMDI aerosol is lost in the oral 
cavity indicating that the droplets in the oropharynx do not have enough residence time for complete vaporization. Using an oropharyngeal model, Kim et al., (1985), demonstrated that a higher fraction of large particles were lost in the oropharynx in one type of aerosol while a lower fraction was lost in two other types. Using the predictions from impaction theory, it was suggested that the aerosol particles in the first aerosol probably had a diameter larger than $10 \mu \mathrm{m}$ upon approaching the oropharyngeal wall compared with the smaller fraction of these large particles in the other two. The difference in particle size fraction may be due to the difference in formulations between the aerosols. The formulation of the first aerosol consists of a solvent containing a large amount of slowly vaporizing alcohol while the suspension-type formulations contain no alcohol. It has been found that spray droplets containing 15 percent alcohol by weight had MMAD of about $30 \mu \mathrm{m}$ at $28 \mathrm{~cm}$ from the actuator (Pengilly and Trujillo, 1977) while a pMDI spray containing a mixture of propellants produced $14 \mu \mathrm{m}$ droplets at 10 $\mathrm{cm}$ from the actuator (Sciarra and Curie, 1978). Pressurized metered-dose inhaler (pMDI) therapeutic aerosols that penetrate the oropharynx, larynx and in turn the trachea have MMAD in the range of 2.5 to $2.8 \mu \mathrm{m}$ (Sackner and Kim, 1985). During tidal breathing, $60 \%$ of this particle size range deposit in the lung. Therefore, it is expected that the pMDI aerosols will have a maximum effective deposition in the lung of approximately 20 percent of the initial dose delivered (Lippmann, 1977, Yu and Diu, 1983).

In vivo, the oropharyngeal deposition lowers the actual deposition in the lung to values even lower than those obtained using in vitro models or mouth-washing techniques. When using radionuclide-tagged aerosol in patients suffering from chronic obstructive pulmonary disease (COPD), it was found that only 9 percent of the dose was 
deposited in the lung while 80 percent was deposited in the mouth, 1 percent expired and 10 percent deposited in the aerosol actuator (Newman et al., 1981).

\subsection{Dry Powder Inhalers (DPIs)}

Aerosols in dry powder inhalers (DPIs) shown in Figure 3.2 are formed by drawing air through a fixed dose of dry powder medication (Fink, 1999). The powder consists of a mixture of micronized drug particles ( $<5 \mu$ m MMAD) together with lactose or glucose particles (diameter $30 \mu \mathrm{m}$ ) or micronized drug particles loosely bound together forming aggregates (Ganderton, 1992). The function of the large lactose or glucose carrier particles is to reduce the strong coherent forces between the micronized particles themselves (deaggregation) such that these can be easily separated into individual respirable particles. When the drug dose is very small, the carrier particles add bulk to the powder. The drug particles are loosely held to the carrier particles and therefore can be released easily by a relatively high inhalation flow rate of $30-120 \mathrm{~L} / \mathrm{min}$ (Engel et al., 1990, Dolovich et al., 1996). The high inhalation flow rate causes the large carrier particles that form the bulk of the aerosol to impact on the oropharyngeal wall thus the sweet taste of the carrier particles gives a sensation to the patient that the dose has been inhaled. 


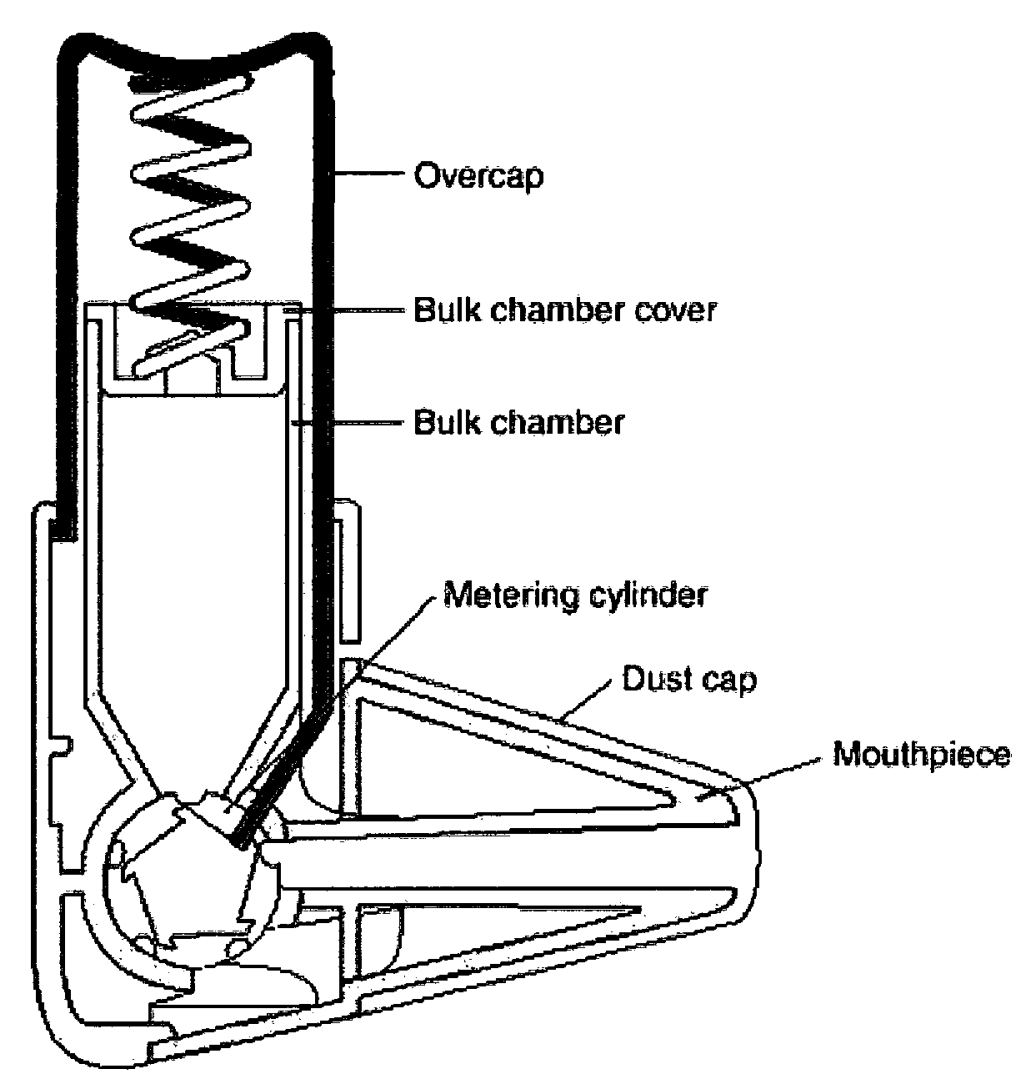

Figure 3.2 Cross-section of Easyhaler ${ }^{\circledR}$ - a new generation, multidose dry powder inhaler Source: Juntunen-Backman et al., 2002.

The resistance to inspiration and the inspiratory flow required to deaggregate and aerosolize the medication depends on the geometry of the DPI device. High resistance DPI devices require a high inspiratory flow rate thus providing a higher drug delivery to the lower respiratory tract compared to pMDI (Thorsson et al., 1994, Svartengren et al., 1995).

It has not been shown that high resistance DPIs produce more lung deposition or bronchodilation than low resistance DPIs (Svartengren et al., 1995). When using DPIs, 
priming of the device is important to ensure aerosolization of the drug powder (Hill and Slater, 1998). Most of the drug particles produced by the DPIs are in the respirable range although the particle size distribution differs significantly between different DPIs (Dhand and Fink, 1999). Clumping of the powder occurs as a result of high ambient humidity forming large particles that cannot be effectively aerosolized (Rajkumari et al., 1995). Drug particle size is increased in aerosols in humid air and thus may decrease the delivery of the drug to the lung. Therefore, DPIs require cool dry storage conditions.

\subsubsection{Dry Powder Inhalers (DPIs) or Metered-Dose Inhalers (pMDI)}

DPIs are more expensive than pMDIs at the same time there are limited number of respiratory drugs available in DPI dosage form. In addition, the effect of humidity reduces the commercial availability of DPIs. Clinically, the high inspiratory flow required by DPIs for maximum drug delivery makes them ineffective in patients suffering from severe airway obstructive disease and those children under the age of six years (Fink, 2000).

\subsection{Nebulizers}

Nebulizers are devices that are used to produce aerosols from liquids for inhalation into the lower respiratory airways. Atomization is the process of pneumatically converting a liquid into small droplets (Figure 3.3). Baffles are placed in the pneumatic nebulizers such that the size of most droplets produced are within the respirable range of $1-5 \mu \mathrm{m}$. 


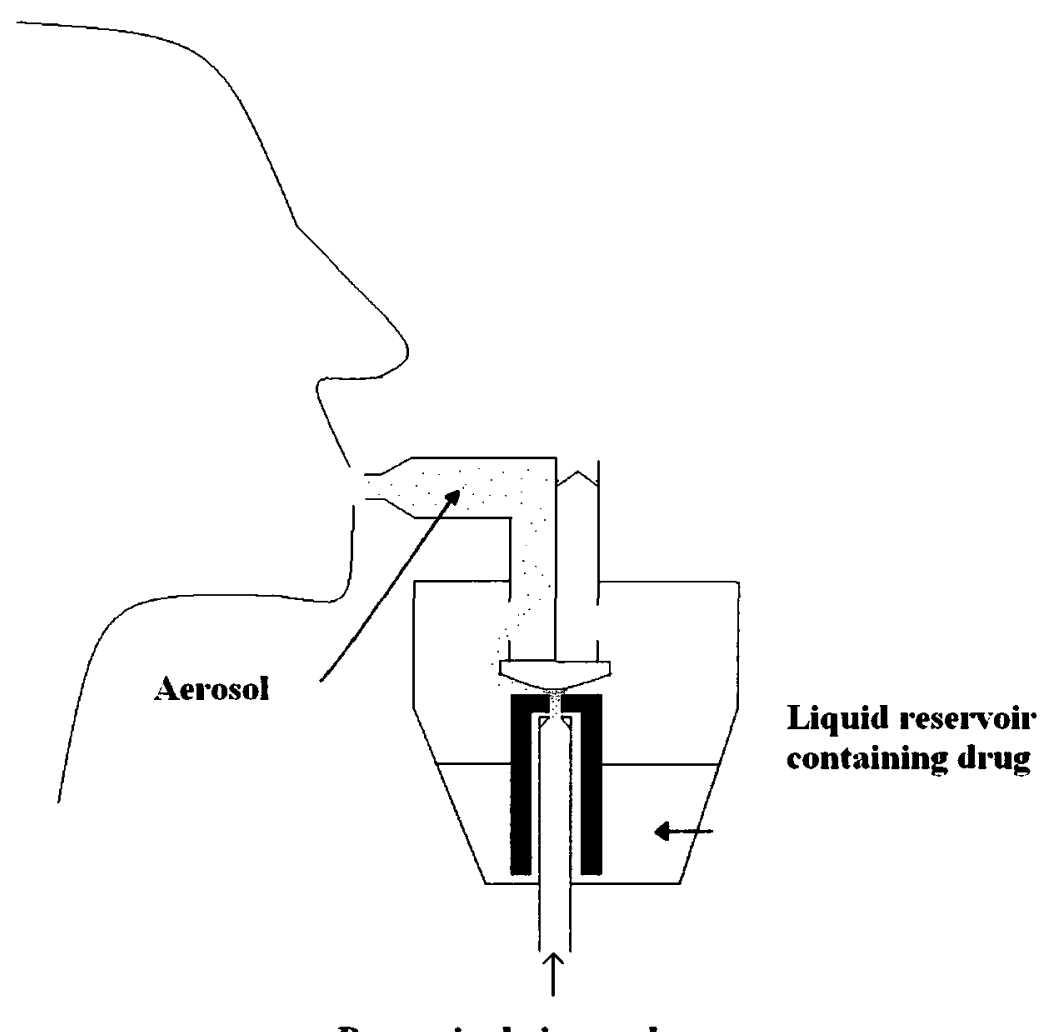

Pressurized air supply

Figure 3.3 Valved jet nebulizer. Adapted from Newman, 1991 .

Generally, the pMDI is the first choice for aerosol delivery of bronchodilators and steroids (AARC, 1992, O'Donohue, 1996) but nebulizers continue to be useful since some inhalant drugs are present only in solution form, also some patients cannot master pMDI use while others prefer using nebulizers over other inhalers. Both the pMDIs and the nebulizers are equivalent in terms of physiologic benefits (Turner et al., 1996, Cates, 1999). The choice of the inhaler device depends on the clinician or patient preference. 


\subsubsection{Principle of Operation}

A pressurized gas supply is needed to act as a driving force for the process of liquid atomization (Newman, 1991, Dalby et al., 1996). A negative pressure region is created by delivering compressed air through a jet (Figure 3.4). The drug solution is sheared into a liquid film as it passes into the gas stream. The surface tension forces cause the film to break into droplets. Smaller particles are formed by a baffle placed in the aerosol stream where they are delivered into the patient's inspiratory air stream (Smye et al., 1991).

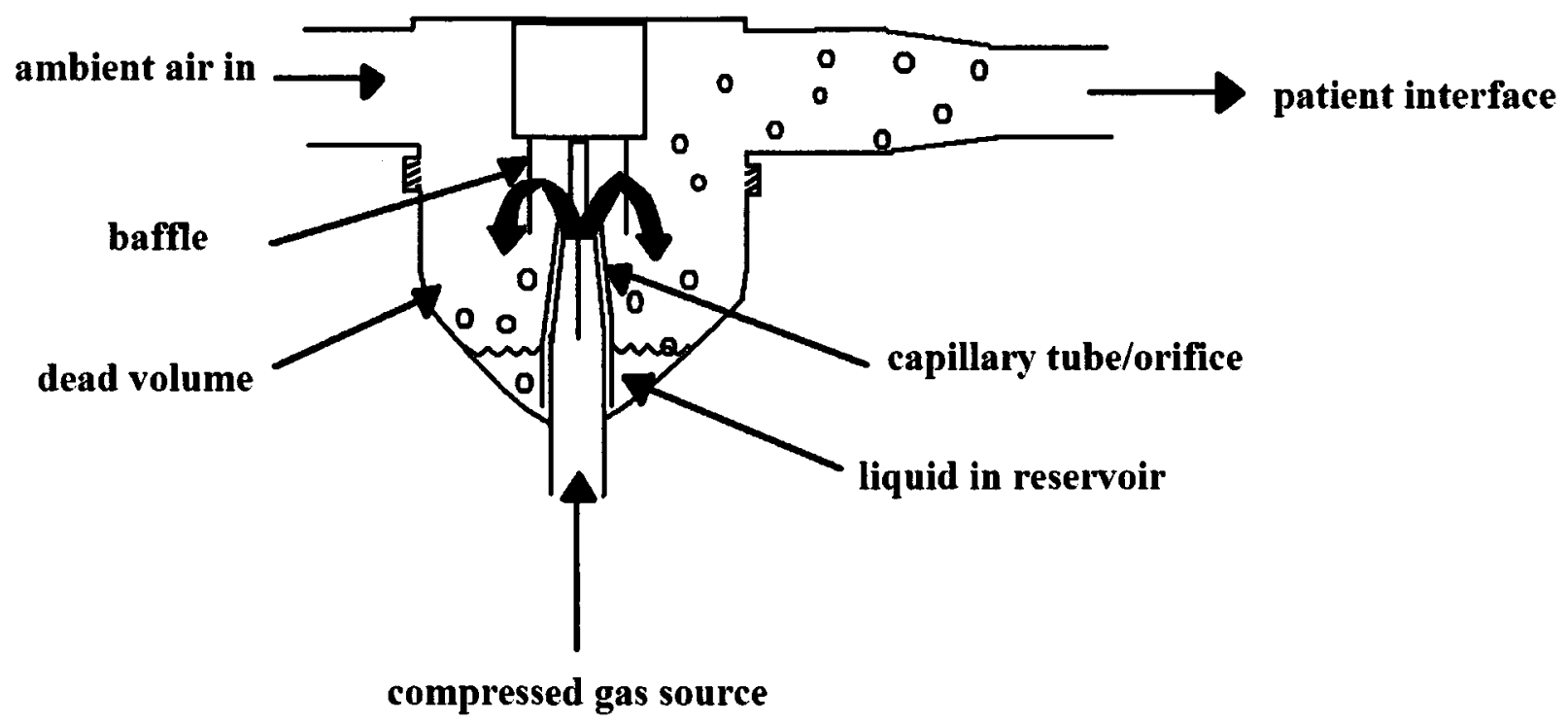

Figure 3.4 Basic components of pneumatic nebulizer. Adapted from Newman, 1991.

\subsection{Identification of Drug Deposition in Lungs Following Inhalation}

Inhalation of bronchodilator drugs such as $\beta$-adrenergic agonists (e.g Salbutamol) and anti-inflammatory agents such as corticosteroids (e.g. Fluticasone) for the treatment of 
asthma and chronic obstructive pulmonary disease (COPD) allows direct delivery of these pharmacological agents to the therapeutic sites in the airways.

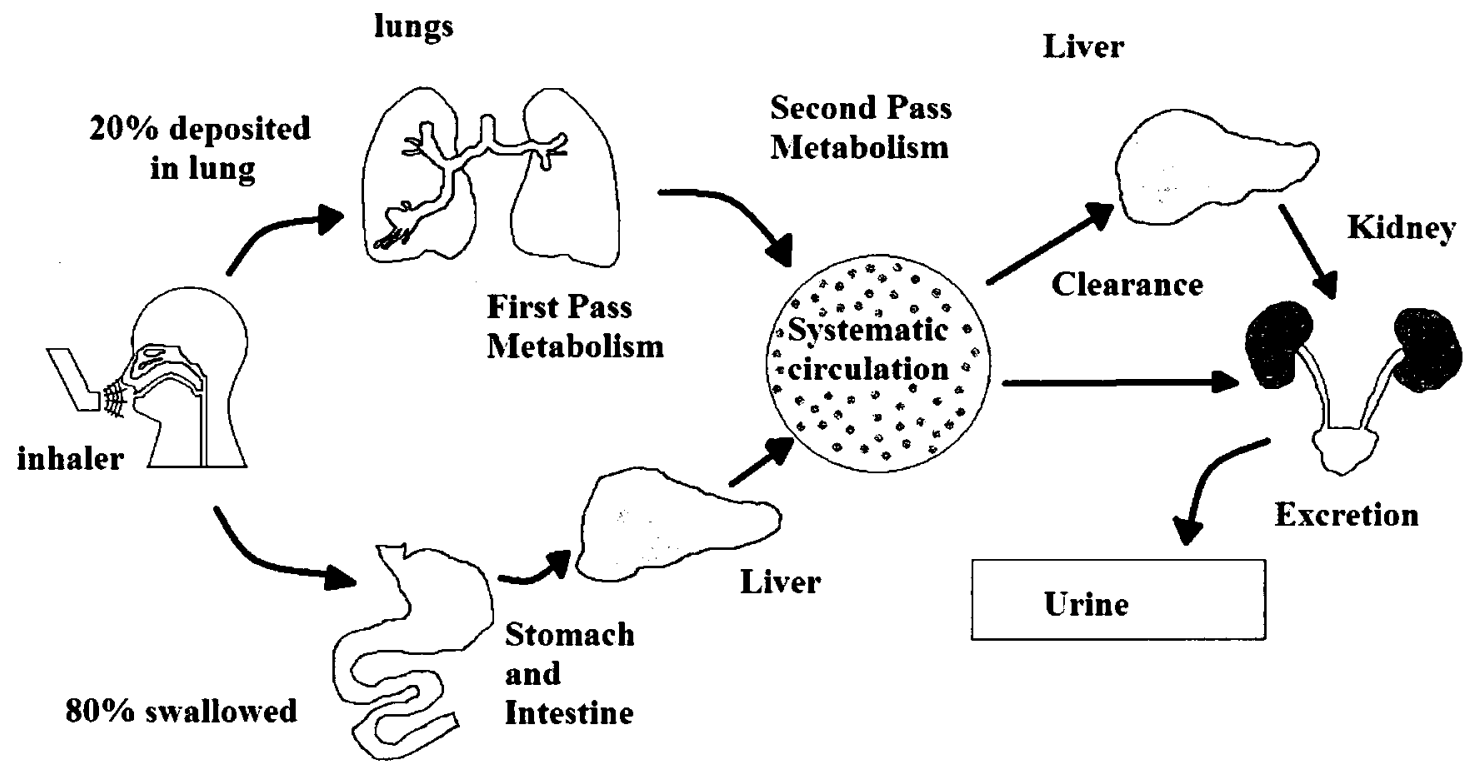

Figure 3.5 Pharmacokinetics of an inhaled drug. Adapted from Chrystyn, 1997.

After inhalation, approximately $20 \%$ of the dose is delivered directly to the lungs while most of the drug is swallowed (Melchor et al., 1993, Chrystyn, 1997). The drug delivered to the lungs will either undergo clearance by the mucocillary process present in walls of the airways or undergo absorption from the airway wall into the systemic circulation. The amount of drug in the circulation represents the fraction of the dose that will exert the pharmacological effect within the airway wall (Figure 3.5).

Those drug particles with the highest probability of depositing in the lung are less than $5 \mu \mathrm{m}$ in size (Rees et al., 1982) while particles less than $2 \mu \mathrm{m}$ in size deposit mostly in the alveoli (Zanen et al., 1994, 1996). The dose from the released aerosol contains a 
large amount of particles having a size within the range of $2-5 \mu \mathrm{m}$ resulting in an even distribution of these particles in the lung tissue (Chrystyn, 1997). When comparing inhalation devices, emphasis is placed on the aerodynamic particle size measured in-vitro using cascade impactor. These procedures are important for quality-control purposes and for equivalence, such that focus is placed on the amount of drug delivered to the lungs and the rest of the body.

\subsubsection{Pharmacokinetic and Scintigraphic Methods}

Both pharmacokinetic and scintigraphic methods can be used to determine the amount of drug that can be delivered to the lungs following inhalation. Pharmacokinetic methods measure the amount of drug in the serum that has been absorbed by the body (Newnham et al., 1993, Seale and Harrison, 1998, Derendorf et al., 1998) or urine that has been excreted by the body (Borgström and Nilsson, 1990, Hindle and Chrystyn, 1992). Figure 3.5 shows how the inhaled drug is delivered to the systemic circulation via the lung and the gastrointestinal tract. Therefore, procedures must be used to differentiate between these two routes of absorption. These procedures include the pharmacokinetic methods and the gamma scintigraphic methods. These methods do not determine the distribution of the inhaled drug in different zones of the lungs but do provide an index concerning the relative amount of inhaled dose of the drug which can produce a clinical effect in the airways. These methods can be used to compare the equivalence between two inhaled devices containing the same drug. When inhaled, a drug becomes distributed to every part of the airway and the clinical effect is due to the total dose rather than that caused by the pulmonary distribution (Chrystyn, 1997). 
Pharmacokinetic methods can be used to estimate the total systemic delivery of the inhaled drug via the oral and inhaled routes and thus provide valuable data, which predict extra pulmonary effects. Estimation of delivery can be achieved by comparing areaunder-the-curve data or urinary drug excretion (to infinity) for inhaled products. To identify the effective lung dose, methods, which differentiate between drug delivered to the systemic circulation via the oral and pulmonary routes, are needed. This approach is not necessary if oral absorption is poor (e.g. sodium cromoglycate) or when the first pass effect is substantial (e.g. Fluticasone). To separate systemic delivery via the gastrointestinal and pulmonary routes, oral charcoal is used to block all gastrointestinal absorption or sampling the urine during the lag time of the absorption phase. A lag time is the time required for drugs administered orally to be absorbed into the systemic circulation and after which they are excreted in the urine (Figure 3.5). In comparison, inhaled drugs reaching the lungs are instantly absorbed (Shenfield et al., 1976) and undergo very rapid urinary excretion. After oral absorption, the amount of drug excreted in the urine is negligible in the first 30 minutes while a significant amount of drug is excreted in the urine in the first few minutes after pulmonary absorption (Hindle and Chrystyn, 1992).

Scintigraphic methods are direct procedures for determining lung drug deposition after inhalation. The techniques are described by Snell and Ganderton (1999) can determine the zones where the drug has been deposited in the lungs but these methods cannot differentiate the drug being removed from the lungs by systemic absorption and that removed by mucociliary clearance. The Gamma scintigraphy involves the reformulation of the original inhaled drug such that a radiolabeled drug is used in the 
formulation (Chrystyn, 2000). In vitro studies are carried out to ensure that the aerodynamic particle size characteristics of the radiolabeled drug are similar to those of the unlabeled drug. The amount of drug inhaled is determined by inhaling the radiolabeled drug (Chrystyn, 2000) and determining the amount of radioactivity obtained from images taken by gamma camera (Figure 3.6).

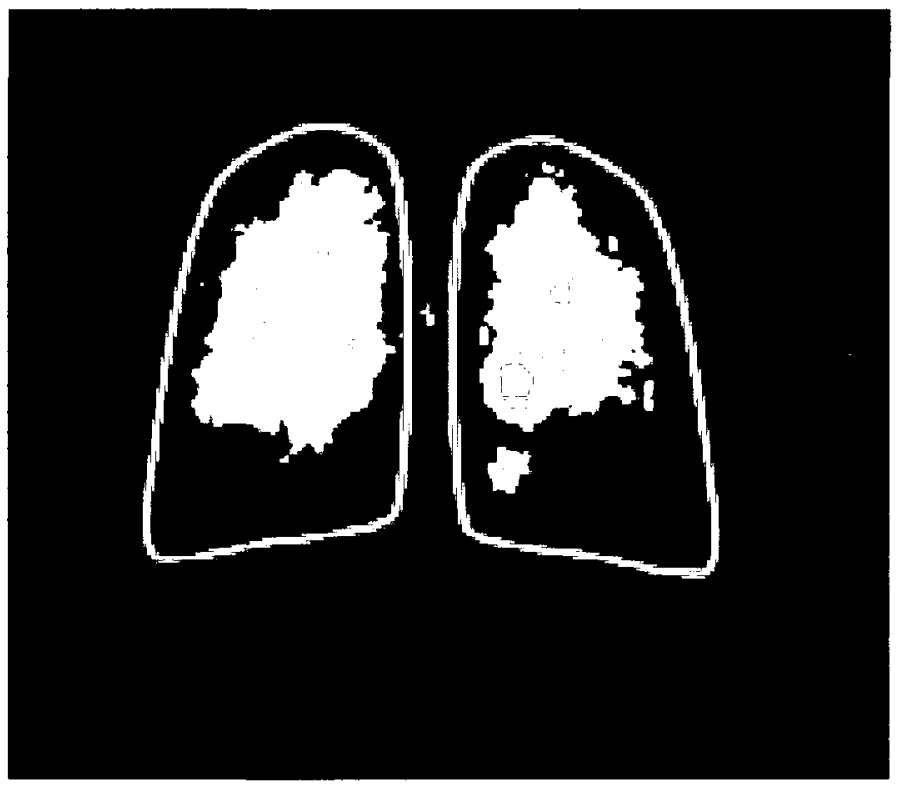

OPharmaceutical Profiles

Figure 3.6 Gamma image of inhaled radio-labelled drug in the lungs. Source: Newman and Wilding, 1996.

\subsection{Comparison of Drug Deposition by Various Inhalation Devices}

Fink and colleagues (1999) demonstrated the difference in drug deposition between various types of inhalation devices using Salbutamol as a bronchodilator therapy in mechanically ventilated patients. Figure 3.7 shows the percentage of nominal dose of 
Salbutamol deposited in the lungs, oropharynx, apparatus, and that expired from the respiratory tract.

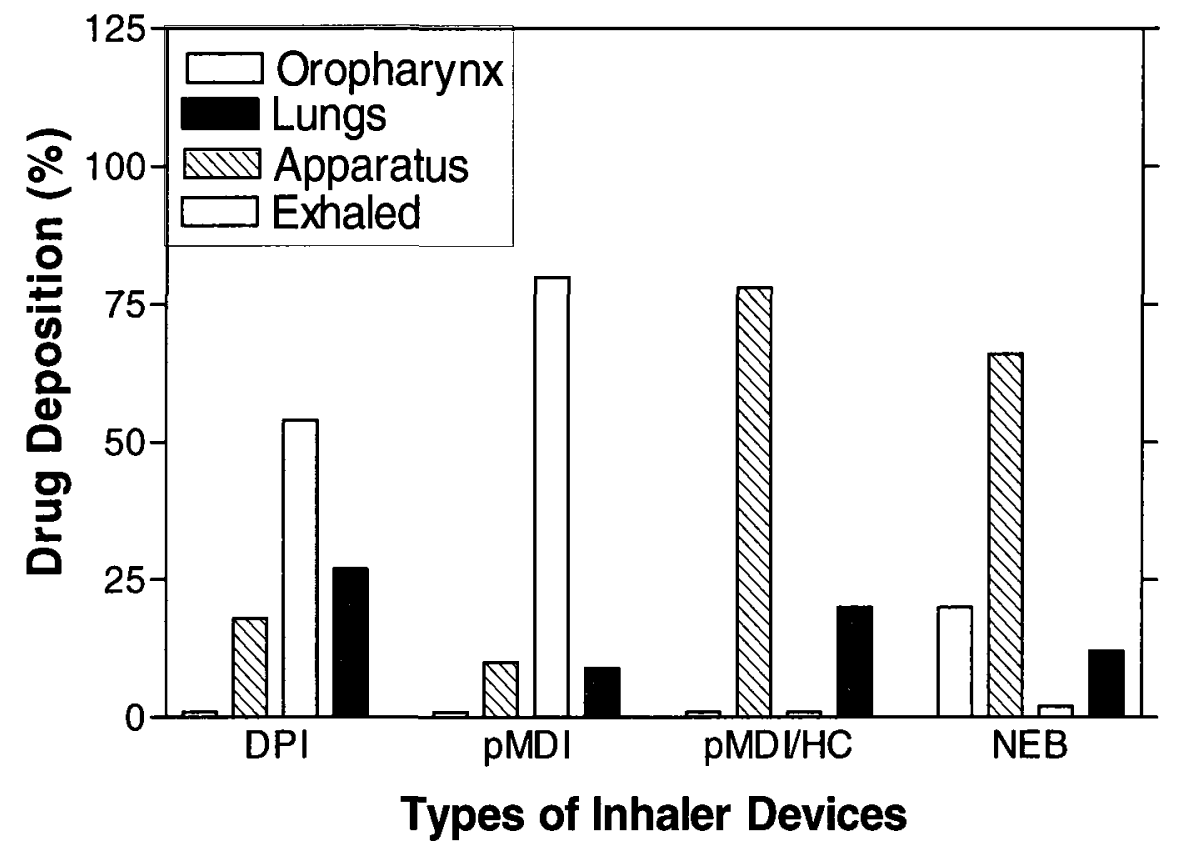

Figure 3.7 Percent of nominal dose of Salbutamol deposited in the lungs, oropharynx, apparatus, and exhaled, using dry powdered inhaler (DPI), pressurized metered-dose inhaler (pMDI), pMDI with holding chamber (pMDI/HC), and

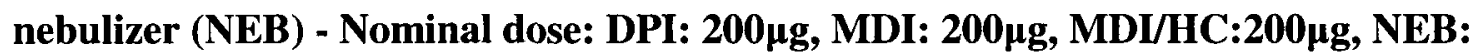

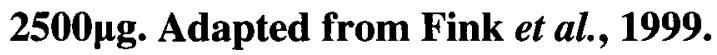

Typical inhaler devices used include a dry powder inhaler (DPI), a pressurized metereddose inhaler (pMDI), a pMDI with holding chamber (pMDI/HC), and a nebulizer (NEB). Figure 3.7 shows that a high oropharyngeal deposition occurred when using the dry powder inhaler (DPI) and the pressurized metered-dose inhaler (pMDI). Drug deposition in both of these devices was over $50 \%$ of the nominal dose of Salbutamol. 
The high velocity and dispersion of the jet released from the pMDI causes approximately $80 \%$ of the dose to impact and deposit in the oropharynx especially when the spray is released inside the oral cavity (Wiener, 1958, Newhouse and Dolovich, 1991). The aged aerosol particles released from the pMDI have a mass median aerodynamic diameter (MMAD) ranging from 2-6 $\mu \mathrm{m}$ resulting in lung deposition of approximately $10-20 \%$ depending on the technique used by the individual (Newman, 1991). The $80 \%$ of the drug dose deposited in the oral cavity may undergo systemic absorption through the mucous.

When compared with the pressurized metered-dose inhaler with holding chamber (pMDI/HC) and the nebulizer (NEB), most of the drug deposition occurred in the apparatus itself with $78 \%$ of the nominal dose depositing in the pMDI/HC and $66 \%$ in the NEB. When using proper technique and an accessory device, the percentage of the nominal dose of medication delivered by the pMDI to the lung is much higher (20\%) than that delivered by a standard small volume nebulizer (12\%), see Figure 3.7.

Although, the nominal dose with the nebulizer (NEB) is much higher than that of the other inhalation devices (Fig. 3.7), the percentage of nominal dose of Salbutamol expired is more than 20 -fold in the nebulizer compared with the other devices.

\section{Chapter 4: Add-on Devices and Drug Deposition}

Deposition of particles in the respiratory tract from inhaled aerosols is very strongly affected by the particle size. Droplets from pharmaceutical aerosols tend to change size as a result of condensation or evaporation from the droplet surface. Nebulizers containing 
aqueous drug formulation deliver water droplets that may undergo condensation or evaporation. Similarly, in propellant-driven metered-dose inhaler, evaporation of the propellant from the droplets determines their delivery. Optimizing deposition of inhaled pharmaceutical aerosols in the respiratory tract requires the prediction of the particle size changes in aerosol droplets that occur during inhalation (Finlay, 2001).

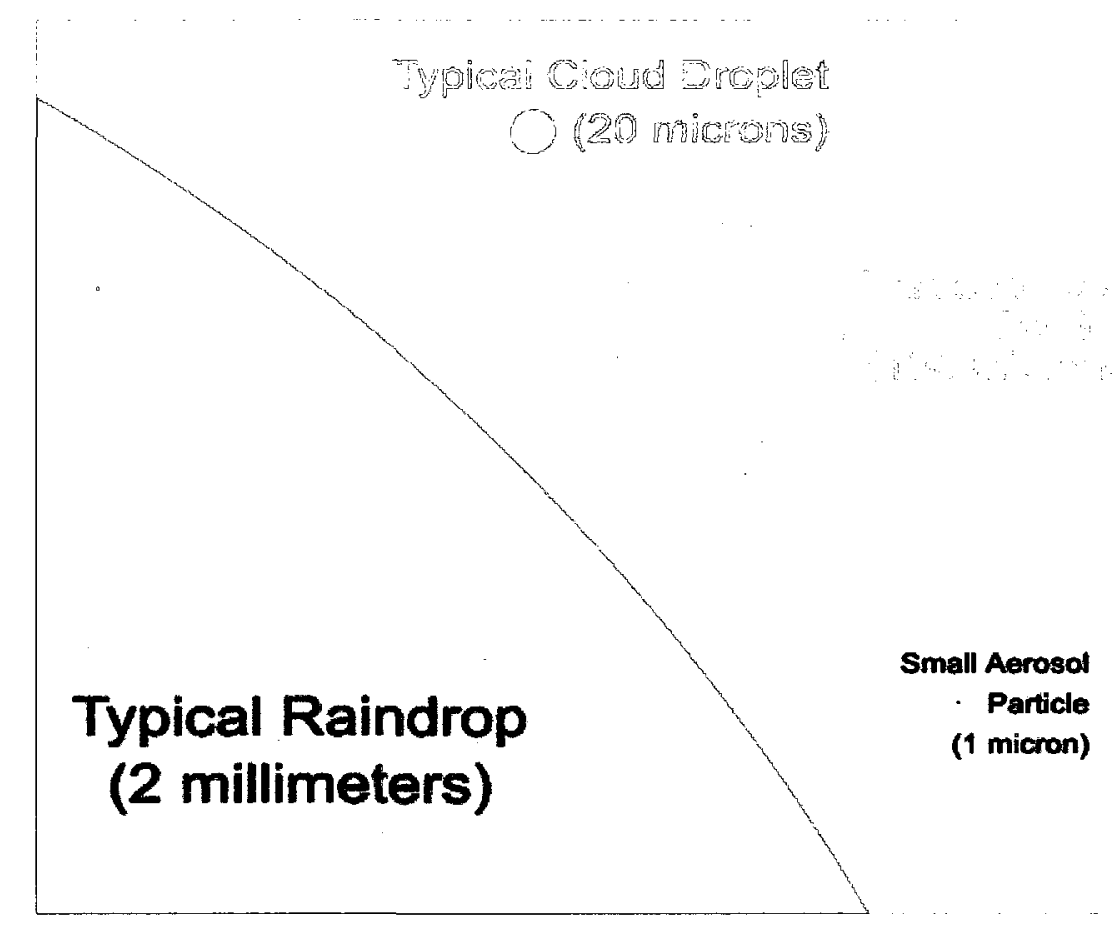

Figure 4.1 Relative sizes of a typical raindrop, a water droplet in a cloud together with a large and small aerosol particles respectively. Aerosol particles can be as small as 0.01 microns. Source: Russell, 1996. 


\subsection{Pressurized Metered-Dose Inhalers and Droplet Size}

\subsubsection{Post-Nozzle Droplet Break-Up}

Propellant droplets leave the nozzle exit in the pMDI at high speed to join the air stream being inhaled by the patient. The high relative velocity of the droplets causes them to undergo gradual aerodynamic loading. These aerodynamic forces may result in the breakup of these droplets into smaller secondary droplets (Shraiber et al., 1996).

\subsubsection{Post-Nozzle Droplet Evaporation}

Downstream of the pMDI nozzle, the evaporation of the droplet in the aerosol plume is considered as two-way coupled. This is because the evaporation of the droplet alters the surrounding gas and vice-versa. The coupling results from the droplets themselves, cooling the air around them and affecting their evaporation rate rather than the evaporation of the propellant from the particles. Therefore, to reduce droplet impaction in the oropharynx, the droplet evaporation rate should be increased downstream of the nozzle (Finlay, 2001).

\subsubsection{Enhancing Droplet Evaporation}

Enhancing droplet evaporation can be achieved by allowing the droplet more time before being inhaled by the patient. More evaporation leads to smaller inhaled particles and therefore, reduction in oropharyngeal deposition. Reduction in the particle deposition in the oropharynx can also be achieved by lowering the Stokes number (Stk) thus reducing particle impaction on the oropharynx (Finlay, 2001). . 


$$
S t k=\frac{U_{0} \rho_{p} d_{p}^{2} C_{0}}{18 \mu D},
$$

where

$U_{0}$ is the velocity of the aerosol particles

$\rho_{p}$ is the aerosol particle density

$d_{p}$ is the diameter of the particle

$C_{0}$ is the Cunningham slip factor (a correction factor to predict drag force on a particle)

$\mu$ is the fluid viscosity

$D$ is a characteristic dimension in the fluid flow

Particles having a Stokes number (Stk) $<<1$ will continue to follow the direction of the fluid stream line while, particles with Stk $>>1$ will continue moving in a straight line even after rapid change in the flow direction, resulting in inertial impaction of the particles (Finlay, 2001).

According to the above equation, a low Stk can be achieved by decreasing the velocity $\mathrm{U}_{0}$ of the aerosol particles. Increasing the distance from the pMDI nozzle to the oropharynx results in reduction of the aerosol particle velocity $\mathrm{U}_{0}$ (Finlay, 2001).

\subsection{Add-On or Accessory Devices}

These include spacers, which act to increase the distance between the pMDI nozzle and the oropharynx, and valved holding chambers (VHC) which function as a reservoir holding the aerosol spray into the chamber, allowing the particles to slowly settle for the patient to inhale through a valve in the device. 
The aerosol mechanics in these devices are governed by the equations of motion, droplet evaporation and the Navier-Stokes equations governing the fluid motion of a turbulent gas jet consisting of propellant and air actuated in such device (Finlay, 2001).

\subsubsection{Characteristics of Spacer Devices}

Spacers or add-on devices consist of a chamber where a pMDI is attached at one end while the other end is fitted with a mouthpiece. The pMDI is actuated into the chamber and the patient inhales the required dose of the drug through the mouthpiece. The procedure does not require the coordination of the two manoeuvres by the patient (Selroos and Halme, 1991). The chamber functions as a reservoir for the aerosol released from the pMDI. It reduces the velocity of the aerosol and increases the distance between the pMDI nozzle and the patient's oral cavity. The add-on device therefore, prolongs the transit time of the released aerosol particles between the pMDI nozzle and the oral cavity enhancing propellant evaporation (Terzano, 2001) thus, reducing the particle size. This results in an increase in the respirable fraction of the aerosol particles hence decreasing oropharyngeal impaction of the drug particles thereby increasing drug deposition in the lung periphery. Large aerosol particles constitute about $80 \%$ of the aerosol dose; spacers tend to trap a large portion of these particles with a small fraction being deposited in the oropharynx hence reducing the local and systemic side effects of the drug. Depending on the medication being used, local side effects may include throat irritation, dysphonia and oral thrush caused by using pMDI alone. Some spacers as InspireEase ${ }^{\circledR}$ contain valves that produce an audible sound alerting the patient when the inspiratory flow rate exceeds a certain threshold value. Inspiratory flow rate above such value causes turbulent flow 
condition in the spacer resulting in increased impaction of the aerosol particles and therefore, more drug deposition in the upper airways.

\subsubsection{Types of Spacers}

Today, many different types of spacers are present in the market. They may differ in volume, length, shape, construction material (plastic or metal), rigidity (rigid or collapsible), valved (valved holding chamber or VHC) or non-valved (Figure 4.2). Spacers can be classified into three categories (Lavorini et al., 2006) these include:

(a) Open tube spacers: these act to increase the distance between the pMDI nozzle and the patient's oropharynx.

(b) Holding chambers: these contain a one-way inhalation valve in the mouthpiece that functions to retain the sprayed aerosol within the device until the patient inhales it.

(c) Reverse-flow devices: in these devices, the spray is introduced into a collapsible bag or a small volume container through which outside air is entrained.

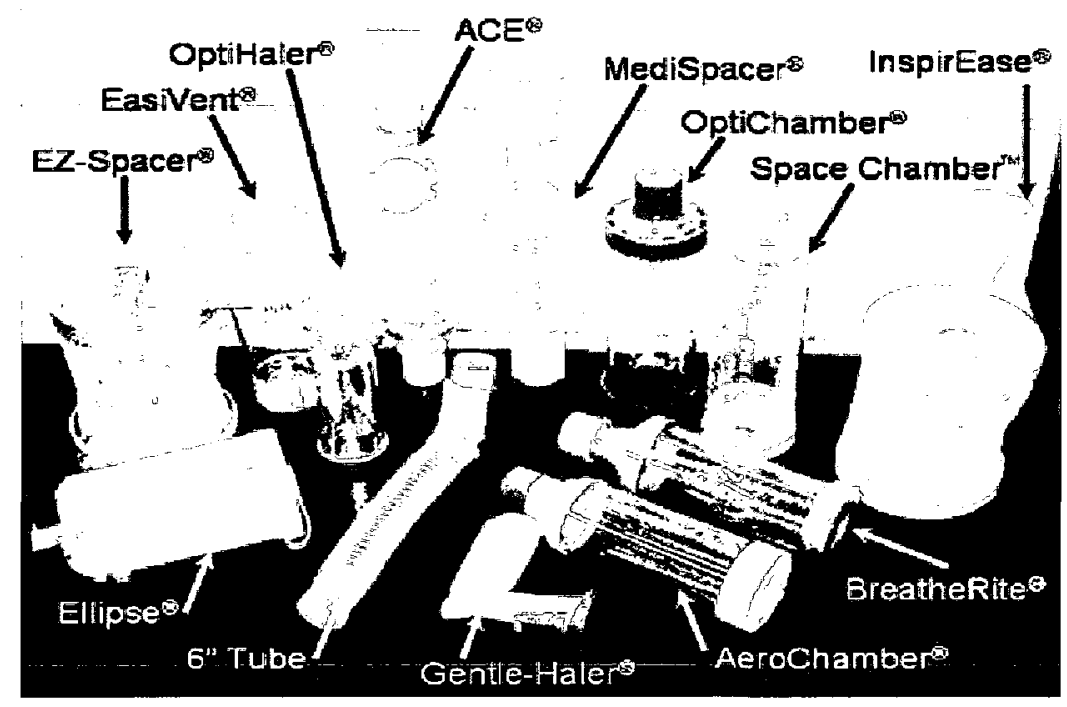

Figure 4.2 Types of spacers and valves holding chambers (VHC) Source: Asmus et al., 2004. 
Some of the disadvantages of spacer devices include their bulkiness, which makes them difficult to carry around, and many do not appeal to many patients especially the young. Certain spacers fit only one type of pMDI making their use very limited.

Errors in pMDI inhalation technique cannot be eliminated by using spacer devices. Today, a wide range of spacer devices are present in the market with different designs therefore, optimal inhalation technique probably differs from one spacer to another altering the dose of drug available for inhalation. Laboratory studies, (Barry et al., 1993, Barry et al., 1995A, O'Callaghan et al., 1994, Barry et al., 1994, Everard et al., 1992) supported by emerging pharmacokinetic evidence and radiolabelled deposition studies, (Clarke and Lipworth, 1995, Hindle and Chrystyn, 1994, Kenyon et al., 1996) have shown that when spacers are used incorrectly, the amount of drug delivered to the lungs can be affected significantly. There are general techniques that have to be trained and followed by each patient whenever using a pMDI with a spacer. Such techniques include, an inhalation flow rate of $30 \mathrm{~L} / \mathrm{min}$ or less and breath holding for about 10 seconds immediately after aerosol inhalation. Delaying inhalation immediately after actuation of the pMDI causes loss of a large portion of the respirable dose into the spacer device. Repeated multiple actuations of the pMDI into the spacer by the patient just before inhalation results in turbulent conditions in the spacer. This causes the small aerosol particles to coalesce into large particles, which deposit on the walls of the spacer reducing the respirable dose (Barry et al., 1993, Barry et al., 1995A, O'Callaghan et al. 1994, Barry et al., 1994).

Static electricity is another problem with plastic spacers. Charge tend to accumulate on the surface of the spacer causing some of the aerosol droplets to be 
attracted to the spacer wall resulting in their suspension thereby cannot be inhaled. Static electric charge can be reduced by washing the spacer with detergent, rinsing with water and drying in air (Wildhaber et al., 1996), producing a similar effect on drug delivery as that of antistatic paint (Barry et al., 1995A, Clarke and Lipworth, 1995). The cleared static charge may re-accumulate. Reduction in static electricity on spacer surface increase drug availability for lung deposition and therefore the clinical effect of the inhaled drug. Spacer made metal or antistatic material reduces static charge accumulation in the spacer (Bisgaard et al., 1995).

Depending on the drug prescribed, the size of the spacer may affect the amount of drug available for inhalation (Barry and O'Callaghan, 1995B, Agertoft and Pedersen, 1994). Aerosol clouds that differ in speed and volume may deliver different amount of drug from different spacers (Barry and O'Callaghan, 1995C).

The breathing pattern in children has an important effect on the drug dose inhaled by the patient and the size of the spacer in such a case is of less importance (Everard $e t$ al., 1992, Clarke and Lipworth, 1995).

Replacing the older propellant Chlorofluorocarbons (CFCs) with Hydrofluoroalkanes (HFAs) to reduce ozone depletion, may produce very different results in spacers. A study on Salbutamol pMDI with HFAs propellant delivered more drug compared with the conventional pMDI using the same spacer (Barry and O'Callaghan, 1997). Most of the information about spacers is based on experimental studies where filters or particle sizing apparatus was used to collect the drug. The experimental findings are now supported by recent pharmacokinetic studies. 
Although, there is an increase in the number of spacers being used worldwide, information concerning the amount of drug made available from the different types of spacers is limited (O'Callaghan and Barry, 1997).

\subsection{Literature Review}

Do all add-on devices provide similar dose of drug for inhalation or does the dose differ according to the type of device? Aerosol deposition characteristics of several commercially available add-on devices including spacers and valved holding chambers (VHC) were compared in an in vitro study carried out by Asmus and colleagues in 2004. The study involved the use of Fluticasone Propionate pressurized metered-dose inhaler (pMDI) where the respirable dose of the drug with a particle size ranging between 1-5 $\mu \mathrm{m}$ was obtained using a cascade impactor. High performance liquid chromatography (HPLC) was used to determine the drug washed from the cascade impactor.

Figure 4.3 shows the respirable dose obtained from different spacers. The Ellipse Spacer had the highest respirable dose while the Gentle-Haler and the MediSpacer had a respirable dose similar to that of the pMDI alone. The lowest respirable dose was obtained from both the OptiHaler and Aerosol Cloud Enhancer (ACE). 


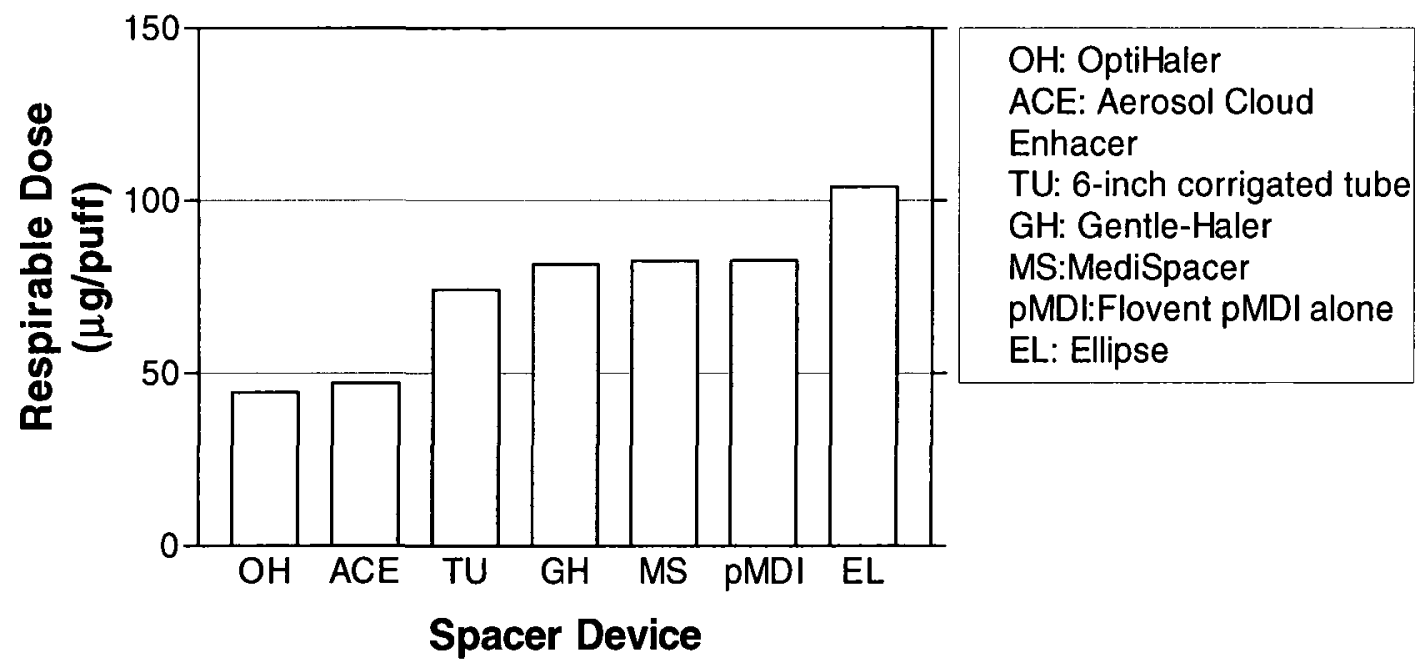

Figure 4.3 Variation of the mean respirable dose of Fluticasone Propionate pMDI with spacers normalized per actuation. Adapted from Asmus et al., 2004.

Even the VHC did not all produce similar respirable doses of the drug as illustrated in Figure 4.4. The respirable dose from the EasyVent, the AeroChamber, the InspirEase, The OptiChamber and the Space Chamber all had similar inspirable dose but for the Breathrite and the E-z Spacer, the respirable doses were smaller. 


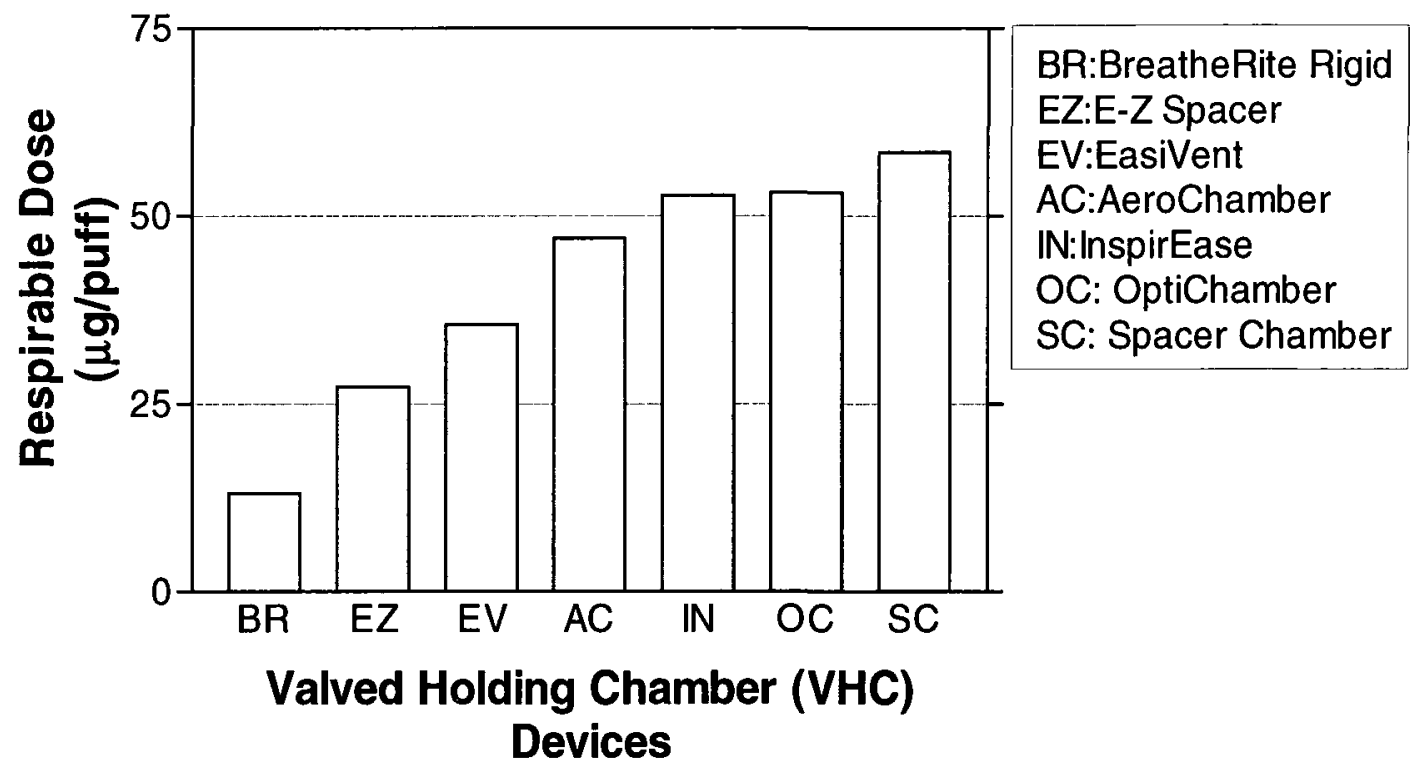

Figure 4.4 Variation of the mean respirable dose of Fluticasone Propionate pMDI with valved holding chambers (VHCs) normalized per actuation. Adapted from Asmus et al., 2004.

Figure 4.5 shows the mean oropharyngeal dose of Fluticasone Propionate with and without the add-on devices. The results show that the oropharyngeal dose from the pMDI alone is much higher than the dose produced when the pMDI was used in combination with the add-on devices. An important function of the add-on devices is the reduction of the oropharyngeal drug impaction thus minimising the systemic side effects of the drug. 


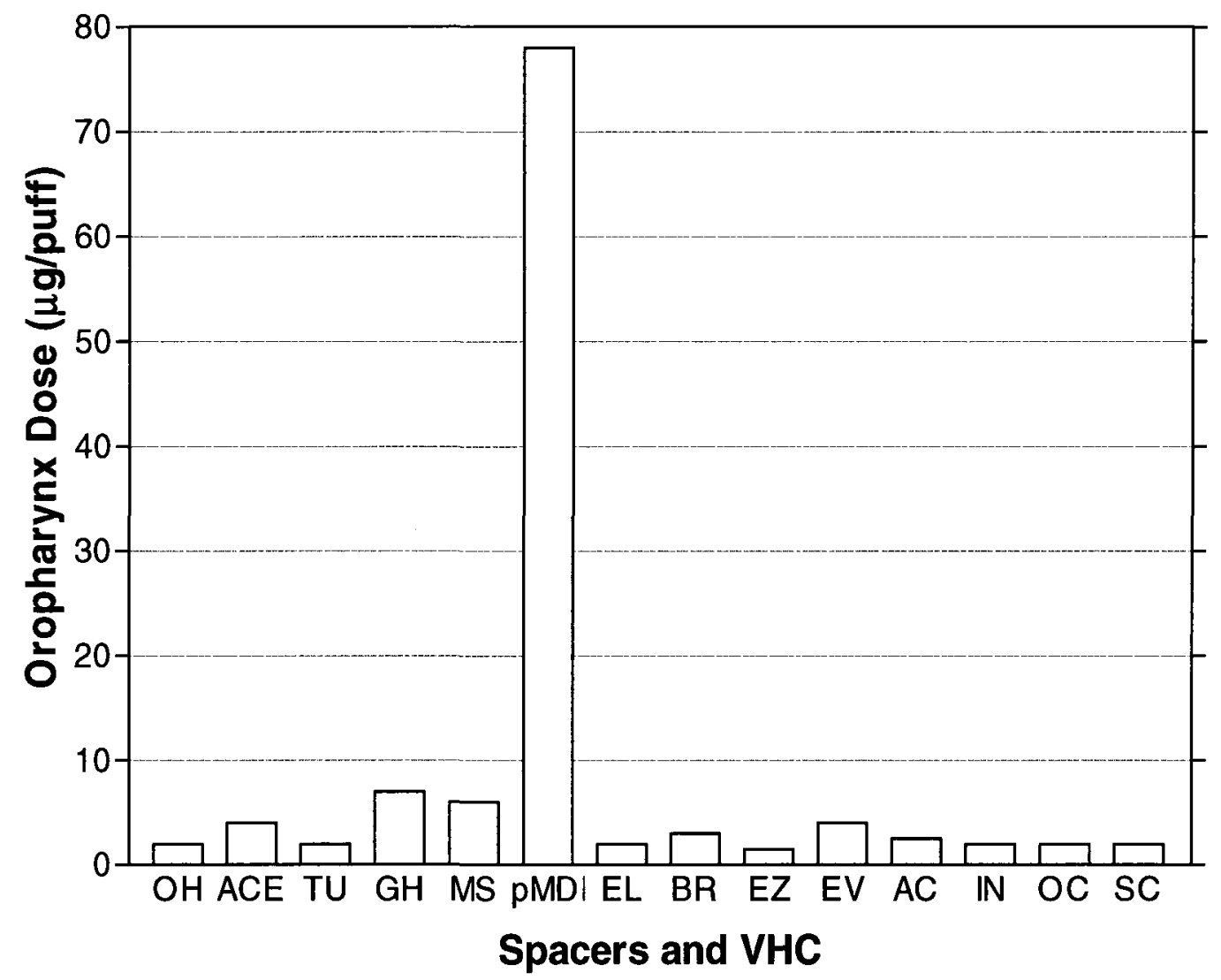

Figure 4.5 Mean oropharynx dose normalized per actuation. Adapted from Asmus et al., 2004.

The results for the add-on devices do not show equivalent in vitro performance of Fluticasone Propionate pMDI. The difference between the highest and lowest respirable dose shown by the devices indicates that most differences exist in the amount of Fluticasone Propionate inhaled by the patient.

Do similar add-on devices provide similar drug output from different drugs with similar range of particle size? Barry and O'Callaghan (1996) carried out an in vitro study to determine the drug output from various spacer devices using different types of inhalation drugs. The drugs used include Disodium Chromoglycate (DSCG, $5 \mathrm{mg}$ ), 
Salbutamol $(100 \mu \mathrm{g})$, and Budesonide $(200 \mu \mathrm{g})$. Various particle sizes of the drugs used were obtained from their respective pressurized metered dose inhalers. The pMDIs were actuated directly into a glass multistage impinger (MLSI) to determine the amount of drug released or via one of the different add-on devices. Add-on devices used include, Fisonair, Nebuhaler, Volumatic, Inspirease, Aerochamber, Aerosol Cloud Enhancer (ACE), and Dynahaler.

The results in Figure 4.6 show that for particles with diameter less than $5 \mu \mathrm{m}$, the DSCG dose recovered from the Fisonair and Nebuhaler respectively was more than that recovered from the pMDI alone. The dose recovered from Inspirease was similar to that of the pMDI alone. Doses lower than the pMDI were recovered from the Aerochamber, the Aerosol Cloud Enhancer and the Dynahaler respectively.

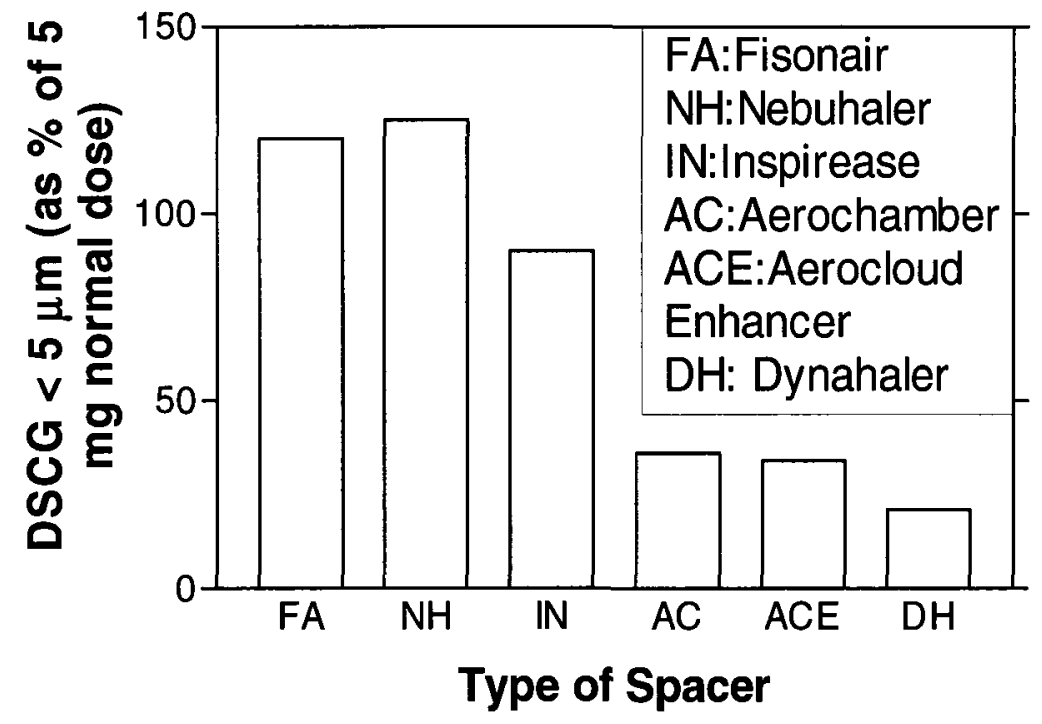

Figure 4.6 Disodium Chromoglycate (DSCG) as percentage of $5 \mathrm{mg}$ dose recovered in particles $<5 \mu \mathrm{m}$ aerodynamic diameter (Dae) for six different add-on devices. Adapted from Barry and O'Callaghan, 1996. 
When a different drug such as Salbutamol was used, the recovered dose for particles less than $5 \mu \mathrm{m}$ diameter was more from the Volumatic spacer than that from the pMDI alone. The picture was different for the Inspirease where the recovered dose was 50\% less than that from the pMDI alone but similar to that from the Aerochamber (Fig. 4.7).

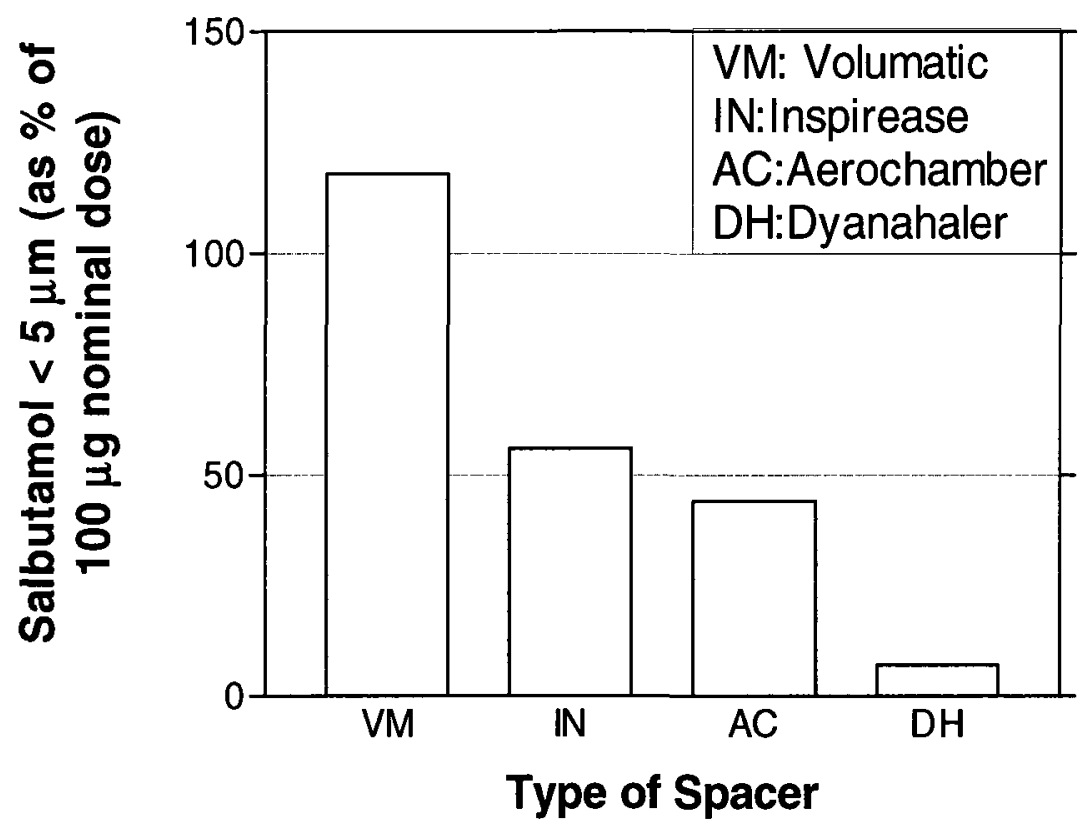

Figure 4.7 Salbutamol as percentage of $100 \mu \mathrm{g}$ dose recovered in particles $<5 \mu \mathrm{m}$ aerodynamic diameter $\left(D_{a e}\right)$ for four spacer devices. Adapted from Barry and O'Callaghan, 199.6.

When Budesonide was used, the recovered dose of the small particles changes with the drug used. The recovered dose from the Inspirease was similar to that of the pMDI alone while the recovered dose from the Nebuhaler was slightly less than that of the pMDI alone but low in case of the Aerochamber (Figure. 4.8). 


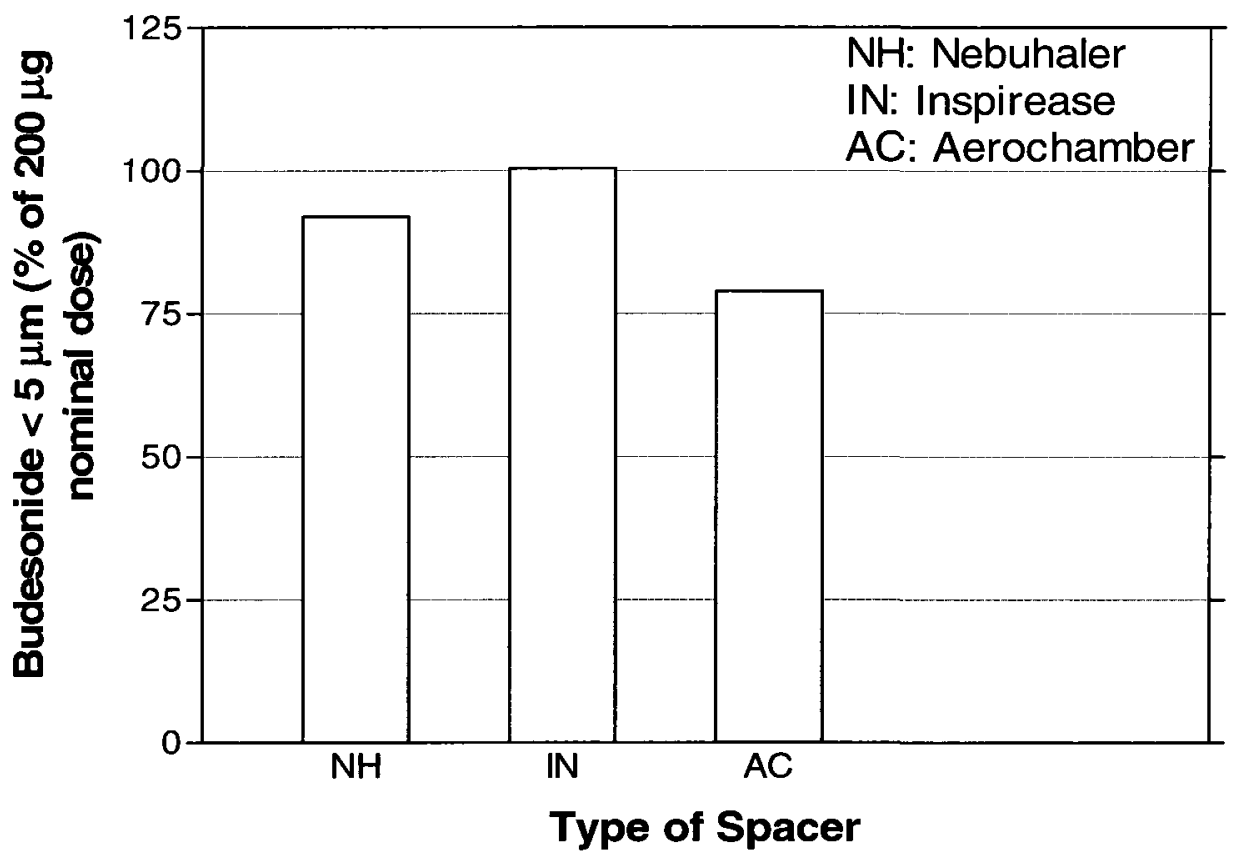

Figure 4.8: Budesonide as percentage of $200 \mu \mathrm{g}$ dose recovered in particles $<5 \mu \mathrm{m}$ aerodynamic diameter $\left(\mathrm{D}_{\mathrm{ae}}\right)$ for three different spacers. Adapted from Barry and O'Callaghan, 1996.

The results show that the recovery of certain drugs is influenced not only by the drug itself but also by the volume of the add-on device. Significant dose of DSCG and Salbutamol was recovered from the relatively large volume add-on devices (Fisonair, Nebuhaler, and Volumatic) compared with the smaller add-on devices tested. For Budesonide, the differences between the add-on devices were less significant. The study demonstrates that significant differences exist in the dose of drugs available for inhalation when various drugs are used with different add-on devices. Different add-on devices should therefore be evaluated for each inhalation drug prescribed to ensure efficient drug delivery. 
Is there an ideal size and/or shape of an add-on device to provide an efficient inhaled drug delivery to the patient? Barry and O'Callaghan (1995A) carried out an in vitro study to investigate whether add-on devices have an optimum size and shape for inhalation drug therapy. Generally speaking, increasing the volume of the add-on device increases the availability of the inhaled drug as illustrated in Figure 4.9. The Figure shows that by increasing the length and diameter of the add-on device, the respirable mass of Cromolyn is increased. Therefore, small volume add-on devices, especially those with less than $200 \mathrm{~mL}$, tend to have reduced drug availability for inhalation. This occurs as a result of the relatively high velocity aerosol droplets impacting on the internal walls of the small volume add-on device. Deposition as a result of droplet impaction is less in case of large volume add-on devices with volumes over $500 \mathrm{~mL}$ (Zak et al., 1999).

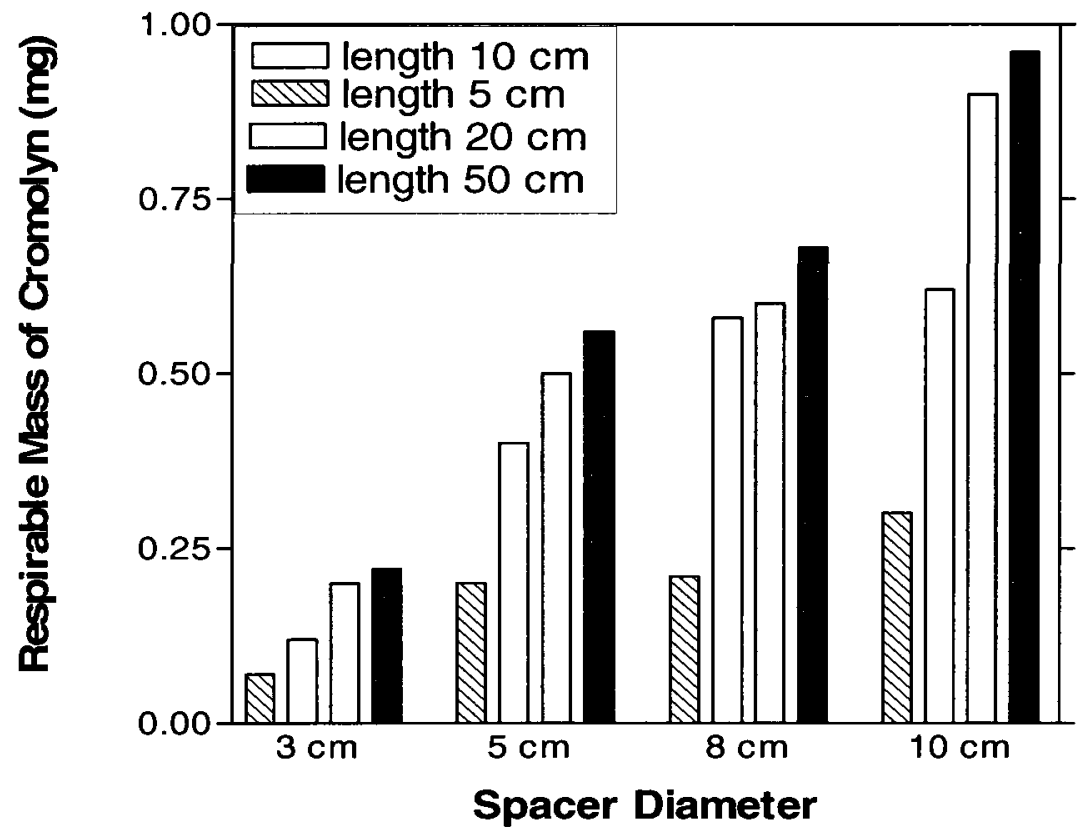

Figure 4.9: Effect of spacer length and spacer diameter on the availability of respirable mass of medication. Adapted from Barry and O'Callaghan, $1995 \mathrm{~A}$. 
For large volume add-on devices, $750 \mathrm{~mL}$ or more, the amount of fine drug particles released by the pMDI per dose is small but is considered large in case of small volume add-on devices (Barry and Callaghan, 1996). Those add-on devices with volumes of one liter or more are considered to be ineffective as very few patients are capable of inhaling completely such large volume. There are a number of factors that influence the amount of drug inhaled by the patient, including the design of the add-on device and the spray characteristics. Therefore, it is difficult to envisage the pulmonary deposition of an inhaled drug since each pMDI/add-on device combination is unique (Newman and Newhouse, 1996). Pulmonary drug deposition may also be affected by the new generation of propellants used nowadays. The replacement of the Chlorofluorocarbon (CFCs) with Hydrofluoroalkanes (HFAs) propellants to reduce the depletion of the ozone layer may affect drug delivery to the patient. Although relatively few studies have been carried-out to assess drug delivery using HFAs pMDI with different add-on devices, one study by Mitchell et al., (1999) using HFA-Salbutamol found that the difference in respirable dose between the relatively large and the relatively small volume add-on devices was not apparent.

Certain pulmonary diseases influence the mode of inhalation of the patient thus affecting the pulmonary drug deposition and therefore the therapeutic outcome of the inhaled drug. In vivo studies by Newman and colleagues (1981) evaluated the effects of different modes of inhalation on airway deposition of Terbutaline Sulphate pMDI aerosol spray and changes in forced expiratory volume in one second $\left(\mathrm{FEV}_{1}\right)$. The studies have shown that a slow inhalation rate of $30 \mathrm{~L} / \mathrm{min}$ of $500 \mu \mathrm{g}$ Terbutaline Sulphate resulted in an increase in $\mathrm{FEV}_{1}$ by approximately $30 \%$ while a fast inhalation flow rate of $80 \mathrm{~L} / \mathrm{min}$ 
produced only $15 \%$ increase in $\mathrm{FEV}_{1}$. The results were compared with similar studies by Newman (1982) and a correlation between airway drug deposition from the pMDI and the percentage increase in $\mathrm{FEV}_{1}$ was determined. Other similar studies were carried out by Lawford and McKenzie (1983) using Fenoterol pMDI have demonstrated that a slow inhalation rate of $64 \mathrm{~L} /$ min caused an increase in $\mathrm{FEV}_{1}$ by $45 \%$, while a fast inhalation of $192 \mathrm{~L} /$ min caused an increase in $\mathrm{FEV}_{1}$ by $35 \%$. Therefore, a slow inhalation flow rate from a pMDI produced a better clinical response in terms of $\mathrm{FEV}_{1}$ when compared to a fast inhalation flow rate.

The design of the add-on device as well as the mode of inhalation and aerosol particle size plays an important role in drug deposition in the respiratory tract. The effect of aerosol particle size on lung drug deposition at different modes of inhalation and consequential pharmacological outcome has been studied by Usmani and colleagues in 2005. The in vivo study investigated the regional lung deposition and bronchodilator response as a function of $\beta 2$-agonist particle size. Technetium-99-labeled monodisperse Albuterol aerosol (30 $\mu \mathrm{g}$ dose) with mass median aerodynamic diameter (MMAD) of 1.5, 3.0 and $6.0 \mu \mathrm{m}$ respectively were inhaled by a group of asthmatic patients (forced expiratory volume in one second, $\mathrm{FEV}_{1}$ of $76.8 \pm 11.4 \%$ predicted) at slow inhalation flow rates of $30-60 \mathrm{~L} / \mathrm{min}$ and a fast inhalation flow rate of over $60 \mathrm{~L} / \mathrm{min}$. A planar scintigraphy was used to quantify lung and extra-thoracic radioaerosol deposition. The results show that the smaller particles of $1.5 \mu \mathrm{m}$ had the highest total lung deposition (Figure 4.10A) and the highest amount of particles expired for both slow and fast inhalation flow rates, this is followed by $3 \mu \mathrm{m}$ particles (Figure 4.10C). Particles of $6 \mu \mathrm{m}$ size produced the highest oropharyngeal deposition at fast inhalation (Figure 4.10B) and 
the least amount of particles expired for both fast and slow inhalation rates (Figure 4.10C).

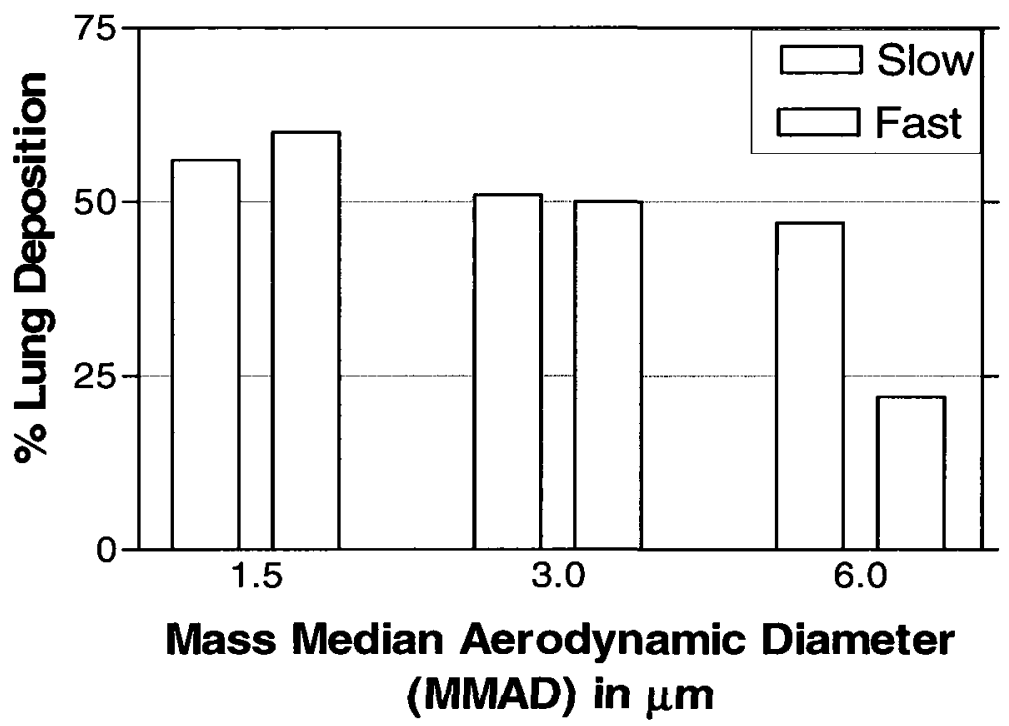

Figure 4.10 (A): Effect of fast and slow inhalation on aerosol deposition in lung for each particle size using Albuterol doses of $30 \mu \mathrm{g}$. Adapted from Usmani et al., 2005.

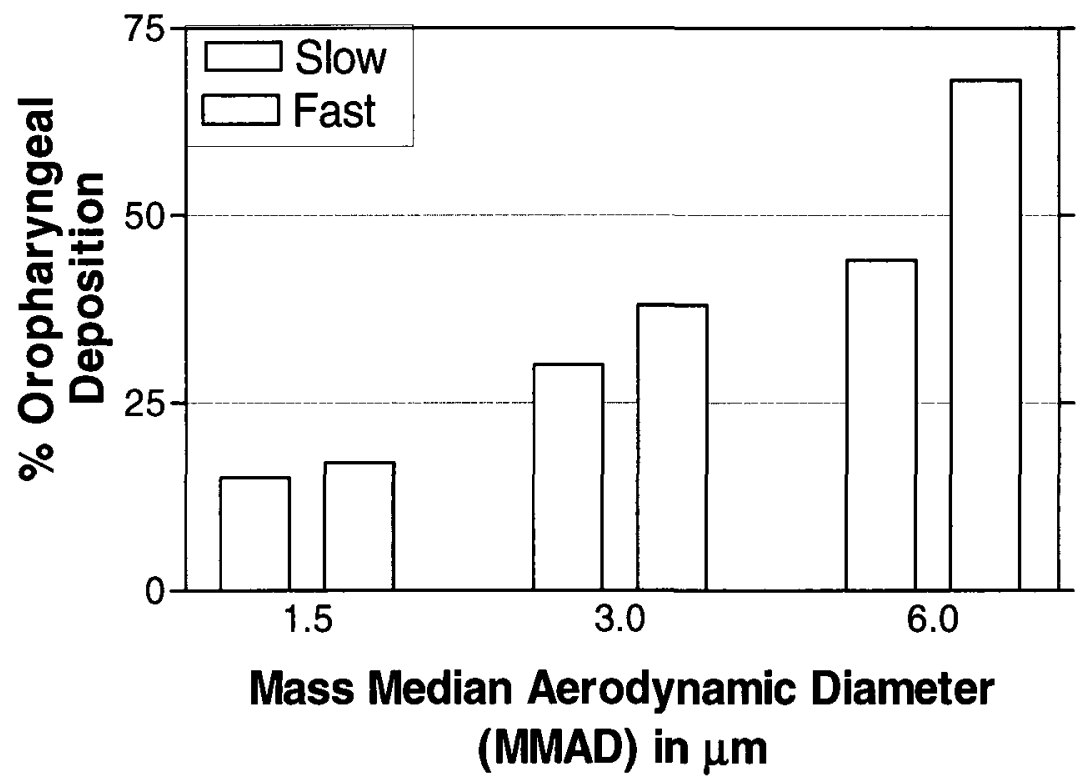

Figure 4.10 (B): Effect of fast and slow inhalation on aerosol deposition in oropharynx for each particle size using Albuterol doses of $30 \mu \mathrm{g}$. Adapted from Usmani et al., 2005. 


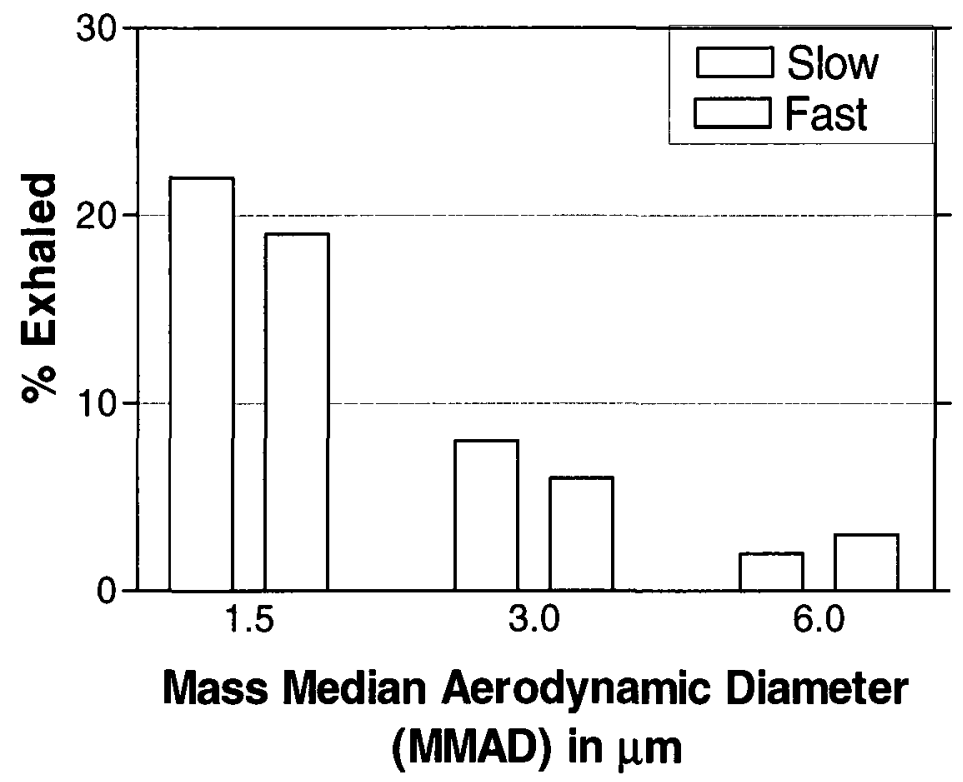

Figure 4.10 (C): Effect of fast and slow inhalation on aerosol exhalation fraction for each particle size using Albuterol doses of $30 \mu \mathrm{g}$. Adapted from Usmani et al., 2005.

The results show that the smaller particles produced a higher peripheral lung deposition than the other particle sizes (Figure 4.11A) and a higher lung penetration index (Figure 4.11B). 


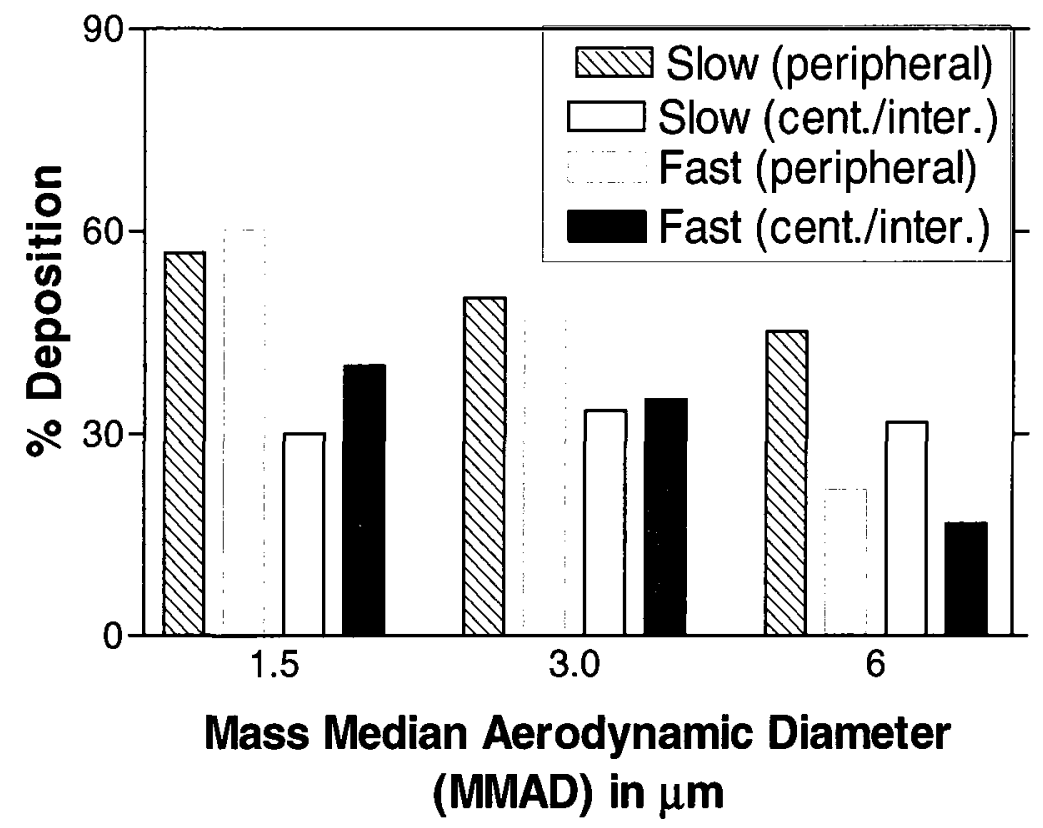

Figure 4.11 (A): Effect of fast and slow inhalation on aerosol deposition expressed as percentage of radionuclide dose delivered for each particle size in central and intermediate, and peripheral regions of the lung. Adapted from Usmani et al. (2005).

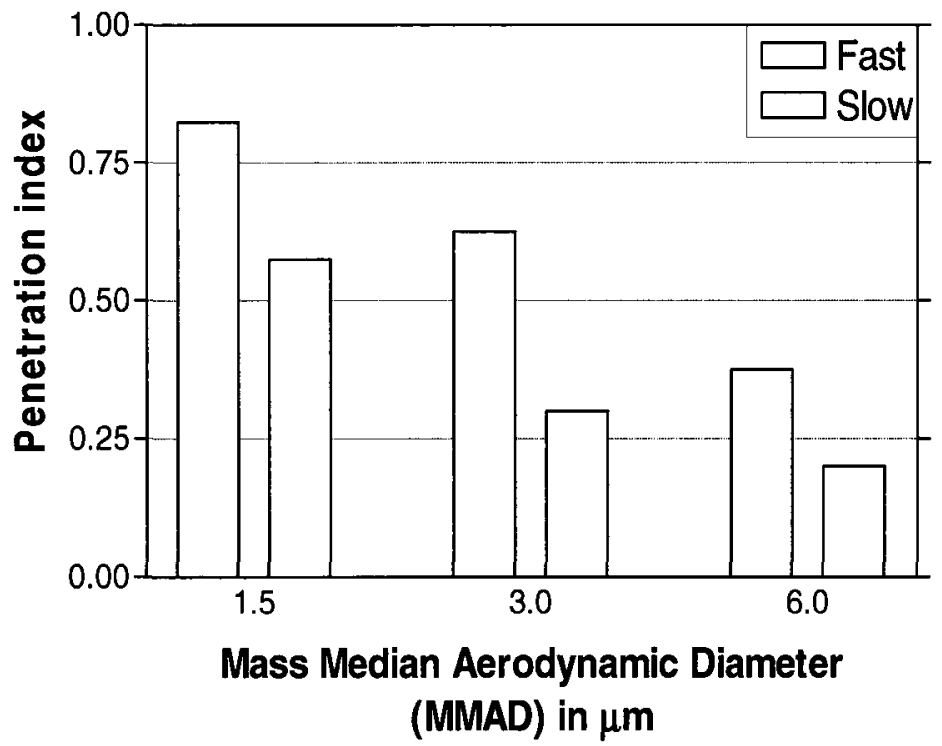

Figure 4.11 (B): Effect of fast compared with slow on aerosol penetration into the lung. Adapted from Usmani et al., 2005. 
The results also show that in slow inhalation, the largest particles produced more bronchodilation in terms of the change in $\mathrm{FEV}_{1}$ than the other particle sizes (Figure 4.12). Fast inhalation decreased total lung deposition and increased oropharyngeal deposition for the larger particles $(3.0$ and $6.0 \mu \mathrm{m})$ as shown in Figure $4.10 \mathrm{~B}$, with less bronchodilation effect (Figure 4.12). Although, Figure $4.11 \mathrm{~A}$ shows that the $\beta_{2}$-agonist deposition in the central and intermediate regions of the lung is less than those in the peripheral region, the response to the $\beta_{2}$-agonist is more in the central and intermediate regions of the lung as illustrated in Figure 4.12. This shows that deposition of inhaled $\beta_{2^{-}}$ agonist in the proximal airways is more potent than that in the distal airways. Enhancing inhaled drug therapy can be achieved by altering intrapulmonary deposition through aerosol particle size.

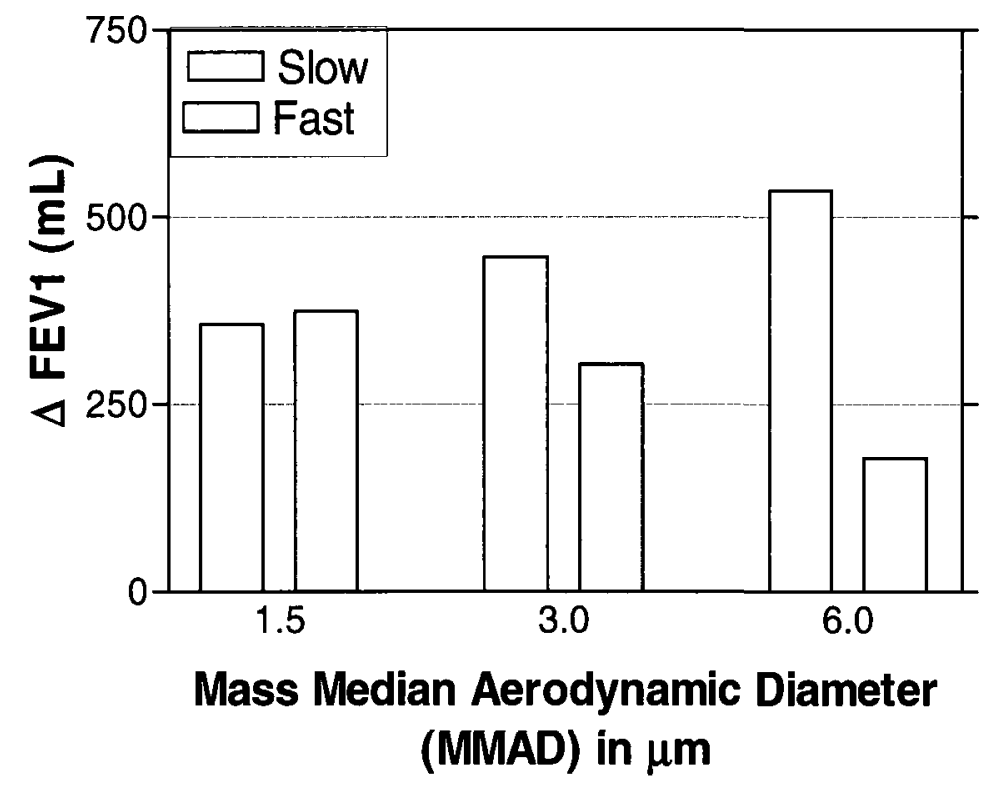

Figure 4.12: Change in $\mathrm{FEV}_{1}$ with slow and fast inhalation. Adapted from Usmani $e t$ al., 2005. 
Does the spray velocity in the aerosol released from a pressurized metered-dose inhaler decline gradually with time as is expected and does the spray direction follows a similar path as that of the spray velocity. Crosland and colleagues (2009) studied the spray characteristics of Ventolin ${ }^{\circledR}$ pressurized metered-dose inhaler. The experimental procedure involved the use of an optically triggered particle image velocimetry (PIV) to measure the spatially resolved velocity of the pMDI spray. Measurement of the spray direction was carried out using (a) Velocity-based method in which the average velocity profile of the spray at four streamwise locations was defined with the edge of the spray being at the point where the velocity is half of its peak value. The angle which the peak line makes with the horizontal represents the spray direction. (b) Geometry-based method where a commercial spray analysis software in which the intensity of two spray images was used to determine the spray direction. The coflow is the flow of air that enters between the pMDI canister and its container and mixes with the pMDI spray. Figure 4.13 shows the variation of spray velocity with time at three chosen centreline locations. The velocity at each point tends to be bimodal having two velocity peaks at the same location. Wigley and colleagues (2002) used the numerical models by Fletcher (1975) and Clark (1991) to explain this bimodal phenomenon. A mass flow imbalance occurs because of the flow moving into and out of the expansion chamber. A pressure rise in the expansion chamber causes the vapour mass fraction to decrease reducing the flow velocity out of the nozzle orifice. A decrease in the mass flow rate in the expansion chamber also occurs because of increased pressure in the chamber. A reduction in mass flow rate accelerates outflow again thus producing a second peak. The velocity thereafter decreases with time. 


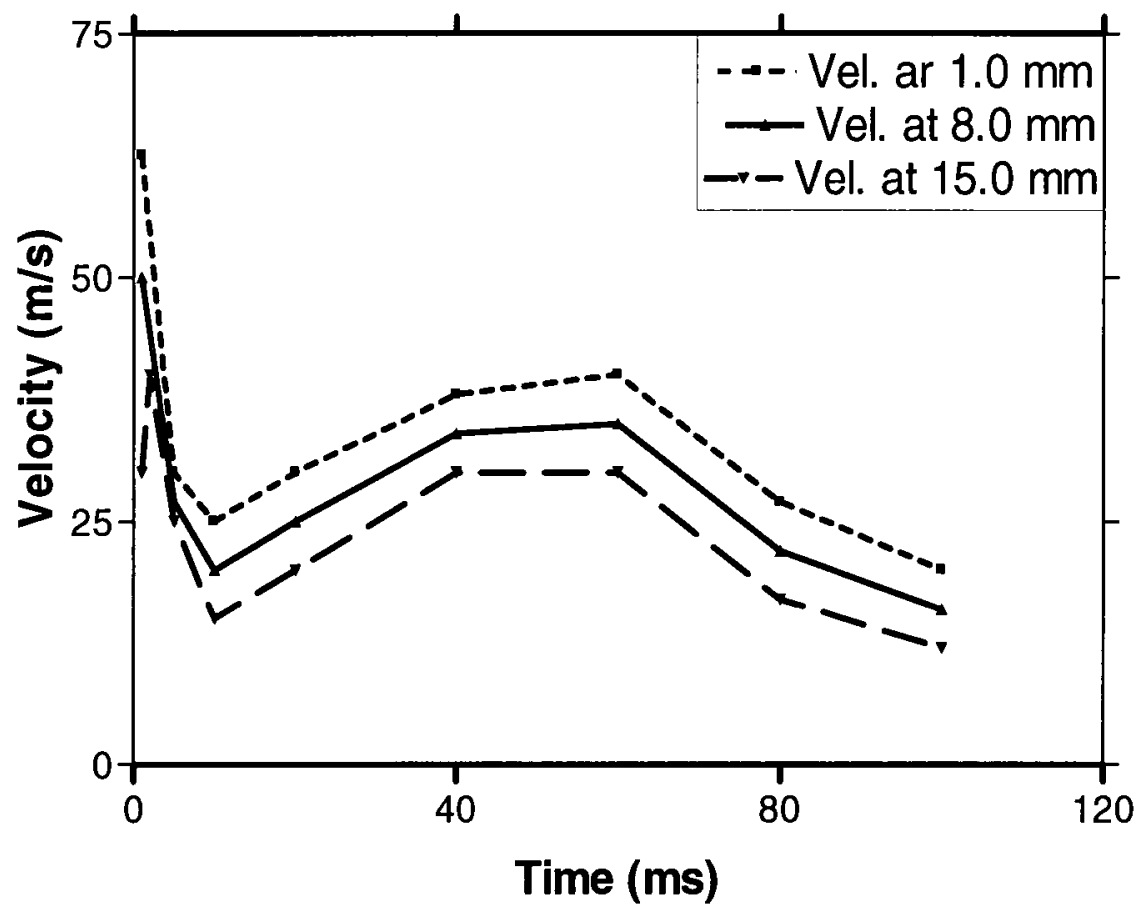

Figure 4.13 Variation of spray velocity with time at 3 selected centerline locations. Adapted from Crosland, 2008.

Figure 4.14 shows the variation in spray direction with time using the velocity based calculation method with and without the coflow and the geometry based calculation method without the coflow. Both methods produced a downward deflection of the spray direction between $2^{\circ}$ and $5.5^{\circ}$ below the horizontal plane with the velocity based method producing more downward deflection than the geometry based method. The asymmetric velocity profile of the coflow produced a further increase in downward deflection of the velocity based spray direction. 


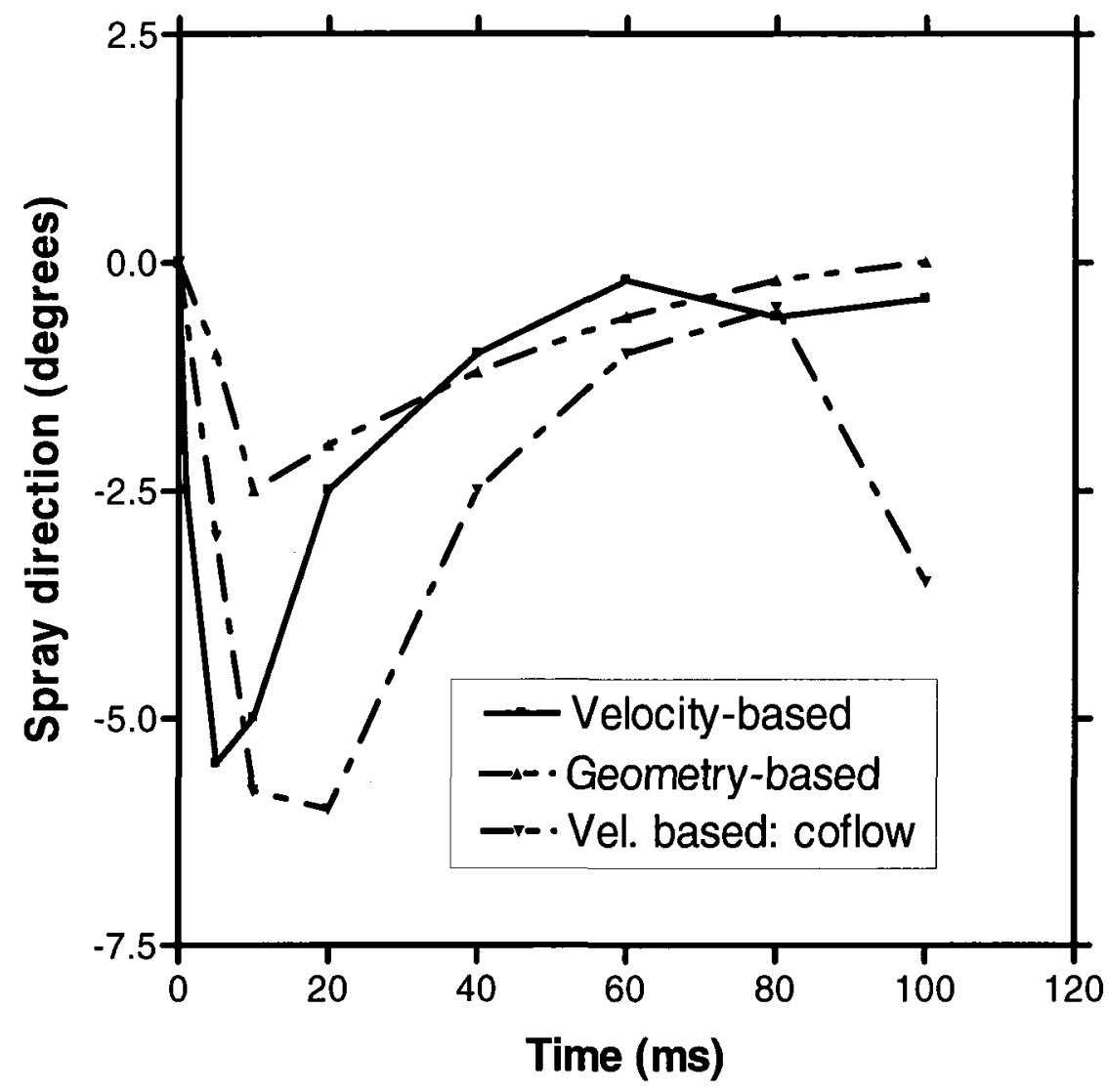

Figure 4.14 Geometry-based and velocity based calculations of spray direction without coflow and velocity-based calculation with coflow. Adapted from Crosland, 2008. 
Table 4.1 Summary of the Studies of drug deposition in Spacers and Airways

\begin{tabular}{|c|c|c|}
\hline Investigator & \begin{tabular}{|l|} 
Study \\
\end{tabular} & Outcome \\
\hline $\begin{array}{l}\text { Norman et al. } \\
(1980,1983)\end{array}$ & $\begin{array}{l}\text { In vivo determination of the effect of } \\
\text { different modes of inhalation on airway } \\
\text { deposition of Terbutaline Sulphate } \\
\text { pMDI. }\end{array}$ & $\begin{array}{l}\text { Slow inhalation }(30 \mathrm{~L} / \mathrm{min} \text {. }) \\
\text { increased FEV } \text { by } 30 \% \text { anf }_{1} \text { fast inhalation }(80 \mathrm{~L} / \mathrm{min} \text {.) } \\
\text { increased FEV } \text { by } 15 \% \text {. }_{1} \text { blow inhalation flow rate } \\
\text { from pMDI produced better } \\
\text { clinical effect on FEV } \mathrm{FV}_{1} \text { than } \\
\text { fast inhalation flow rate }\end{array}$ \\
\hline $\begin{array}{l}\text { Barry and } \\
\text { O'Callaghan } \\
(1995 \mathrm{~A})\end{array}$ & $\begin{array}{l}\text { In vitro determination of the optimum } \\
\text { size and shape of spacer devices for } \\
\text { inhalation therapy }\end{array}$ & $\begin{array}{l}\text { Smaller spacers }(<200 \mathrm{~mL} .) \\
\text { provide smaller dose of drug } \\
\text { inhalation. Larger spacers } \\
(750 \mathrm{~mL} .) \text { produced higher } \\
\text { inhalation dose. Spacers }>1 \\
\text { liter are controversial }\end{array}$ \\
\hline $\begin{array}{l}\text { Barry and } \\
\text { O'Callaghan } \\
\text { (1996) }\end{array}$ & $\begin{array}{l}\text { In vitro determination of drug output } \\
\text { from several types of spacers using } \\
\text { various inhalation drugs. }\end{array}$ & $\begin{array}{l}\text { Significant variation in drug } \\
\text { dose for inhalation occurs } \\
\text { when using different drugs } \\
\text { with different spacer devices. } \\
\text { Each typee of spacer should } \\
\text { be evaluated for each } \\
\text { inhalation drug used for } \\
\text { maximum efficacy. }\end{array}$ \\
\hline $\begin{array}{l}\text { Asmus et al. } \\
(2003)\end{array}$ & 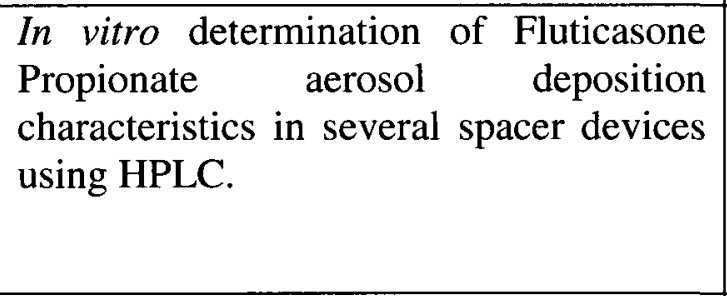 & $\begin{array}{l}\text { Oropharyngeal deposition } \\
\text { from pMDI alone is much } \\
\text { higher than when used with } \\
\text { spacer device. Respirable } \\
\text { dose of Fluticasone varies } \\
\text { with spacer type used. }\end{array}$ \\
\hline $\begin{array}{l}\text { Usmani et al. } \\
(2005)\end{array}$ & $\begin{array}{l}\text { In vivo determination of regional lung } \\
\text { deposition as a function of } \beta \text {-agonist } \\
\text { particle size and inhalation flow rate } \\
\text { using technetium 99-labeled } \\
\text { monodisperesed Albuterol aerosol. }\end{array}$ & $\begin{array}{l}\text { At fast inhalation, small } \\
\text { particles produced higher } \\
\text { lung deposition, more distal } \\
\text { drug penetration and higher } \\
\text { peripheral deposition than } \\
\text { larger particles }\end{array}$ \\
\hline $\begin{array}{l}\text { Crosland } \\
(2008)\end{array}$ & $\begin{array}{l}\text { Determination of spatially resolved } \\
\text { velocity of Ventolin } ₫ \text { pMDI sprays } \\
\text { using a particle image velocimetry. Also, } \\
\text { measurement of spray direction using a } \\
\text { velocity-based calculation method that } \\
\text { uses the average velocity profile of the } \\
\text { spray and a geometry-based calculation } \\
\text { method that uses a commercial spray } \\
\text { software. }\end{array}$ & $\begin{array}{l}\text { Bimodal velocity peaks in } \\
\text { the same location. } \\
\text { Downward deflection of the } \\
\text { spray before returning to the } \\
\text { horizontal plane being more } \\
\text { in the velocity based method } \\
\text { and potentiated by the } \\
\text { coflow. }\end{array}$ \\
\hline
\end{tabular}




\section{Chapter 5: Experimental Setup and Procedure}

Assessment of performance of the add-on devices was carried out using Salbutamol (Albuterol) Sulphate pMDI because Salbutamol Sulphate inhalation is the first line medication used in the symptomatic treatment of bronchial asthma (Haslett et al., 1999 in Davidson's Principle and Practice of Medicine).

\subsection{Study Objectives}

To compare the in vitro aerosol deposition characteristics in three commercially available add-on devices and to determine the deposition pattern in one add-on device at different flow rates using Salbutamol (Albuterol) Sulphate pressurized metered-dose inhaler (pMDI).

\subsection{Experimental Setup}

The experiments were performed to measure the total deposition of Salbutamol aerosol particles in three different add-on devices at flow rates of 30,45 , and $60 \mathrm{~L} / \mathrm{min}$. The deposition pattern of Salbutamol was also determined in one of the add-on devices or valved holding chamber (VHC) at similar flow rates. Figure 5.1 shows a schematic diagram of the apparatus used. One end of the add-on device, the mouthpiece is connected to a filter, which represents the oral cavity and the airways. The drug that deposits in the filter from the add-on device represents the total drug that deposits in the lungs and the oropharynx. Attached to the other end of the filter is a flow meter together with a vacuum pump that withdraws air mixed with aerosol droplets from the pMDI in 
the add-on device through the filter. The flow meter measures the flow rate which is regulated by a flow control valve. The exit nozzle of the pMDI is attached to the other end of the add-on device.

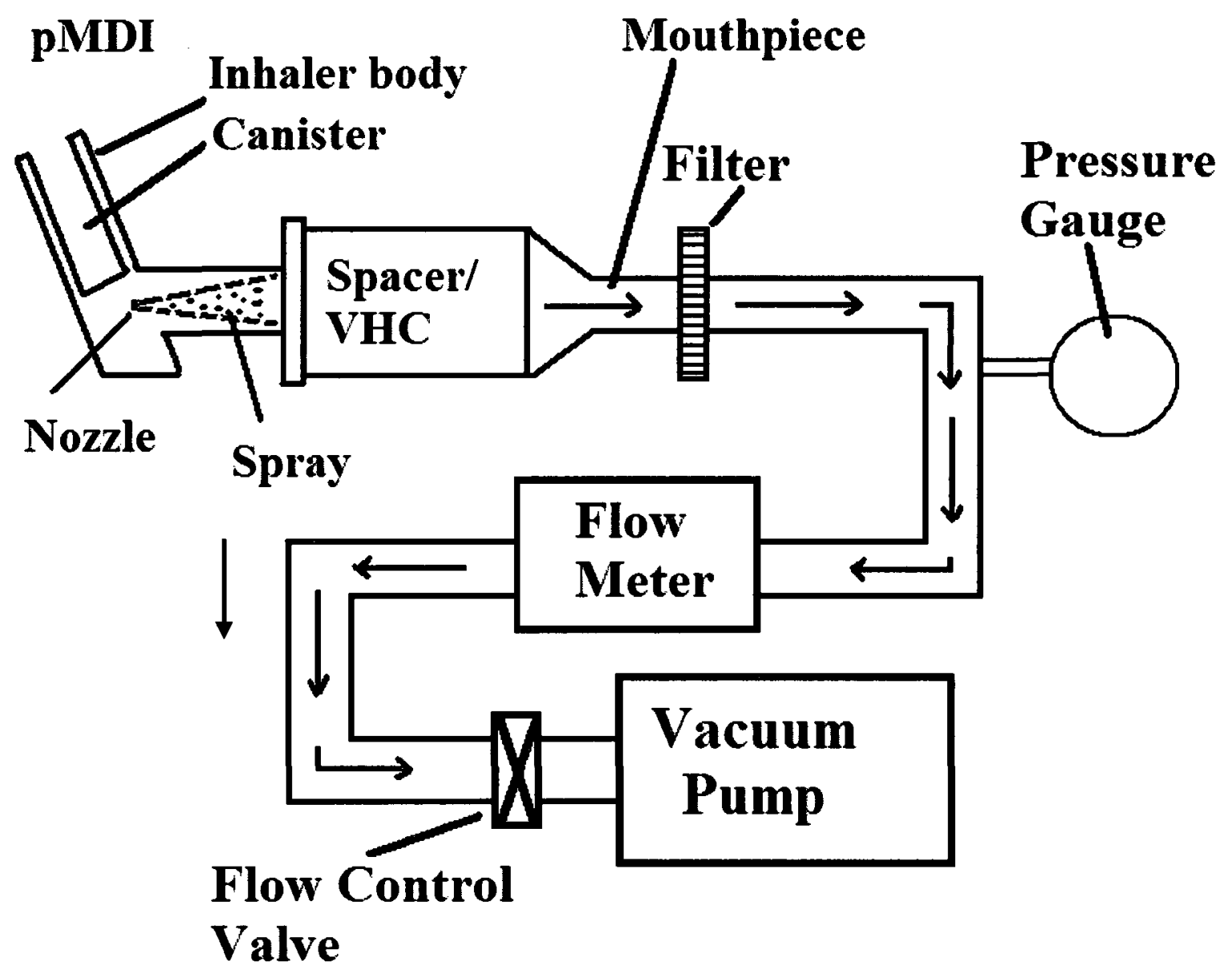

Figure 5.1 Experimental apparatus. 


\subsubsection{Propellant Driven Metered-Dose Inhaler}

Ventolin HFA ${ }^{\mathrm{TM}}$ (GlaxoSmithKline Inc., Montreal, Quebec, Canada) pMDI containing Salbutamol (Albuterol) Sulphate was purchased from the pharmacy at Carleton University (Figure 5.2). According to the instruction leaflet with the pMDI, before administering the drug, the canister must be primed by first shaking the device and then actuating it once by releasing the spray in open air. Priming of the pMDI was carried out each time before use.

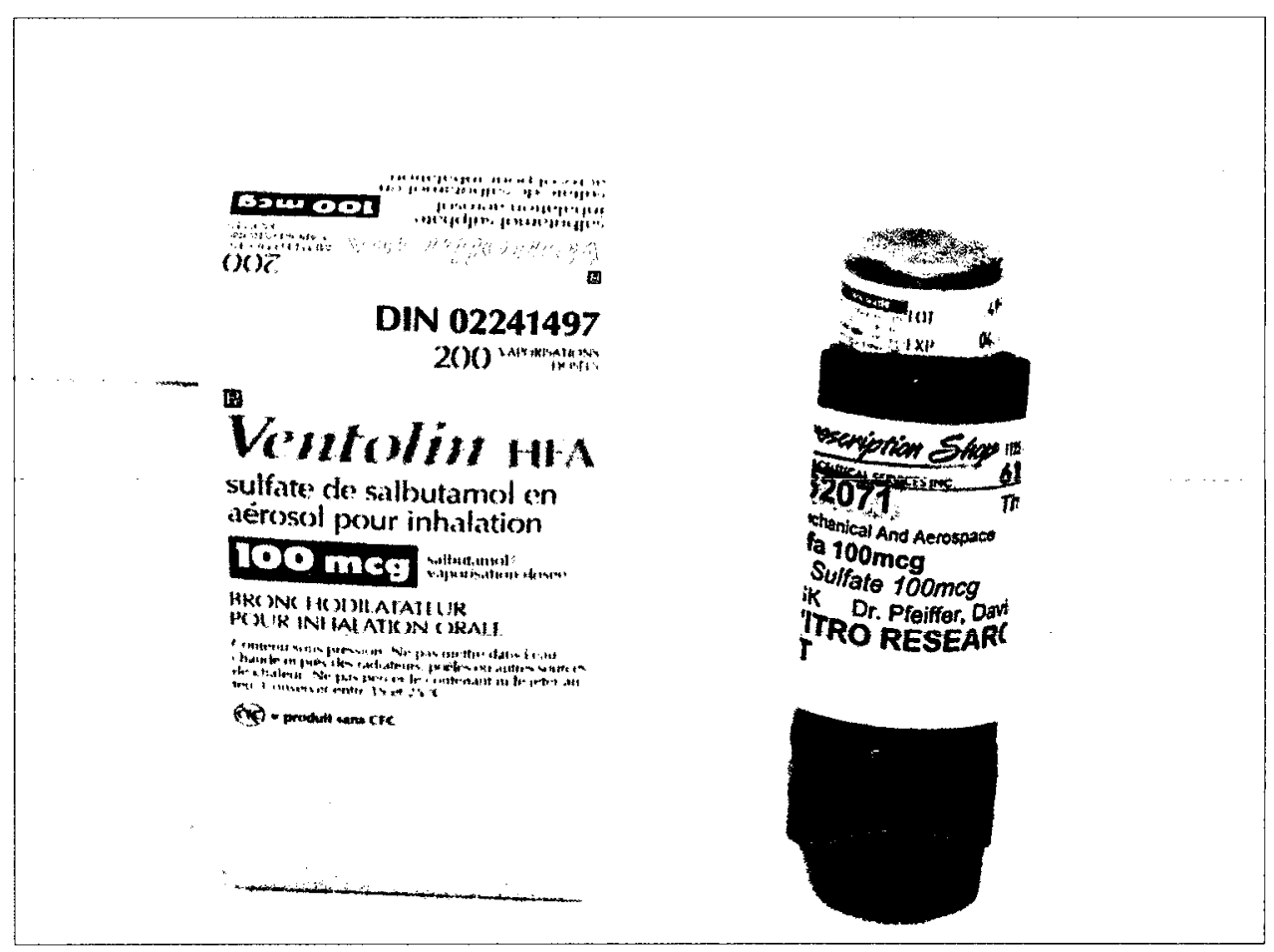

Figure 5.2 Ventolin HFA $^{\mathrm{TM}}$ pressurized metered dose inhaler. 


\subsubsection{The Add-On Devices}

The add-on devices used (Figure 5.3 and Table 5.1) consist of two valved holding chambers (OptiChamber ${ }^{\circledR}$ and PocketChamber ${ }^{\mathrm{TM}}$ ) and a spacer (OptiHaler ${ }^{\circledR}$ ). Throughout the research, these devices will be referred to as add-on devices or spacers unless otherwise specified.

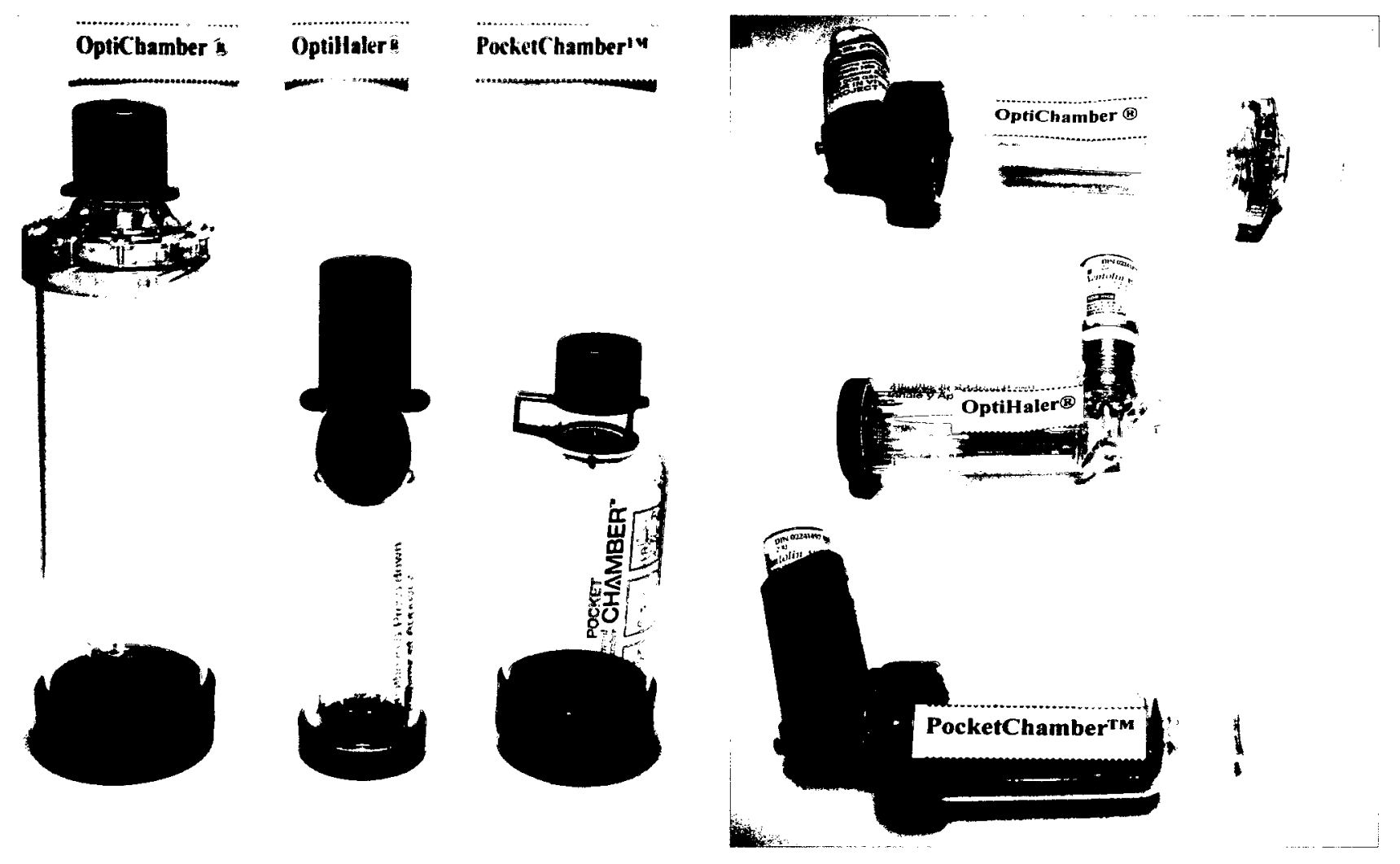

Figure 5.3 Inhalers used in the experiments (OptiChamber ${ }^{\circledR}$, Optihaler ${ }^{\circledR}$, PocketChamber ${ }^{\mathrm{TM}}$ ) with and without pMDI. 
Table 5.1 Add-on devices used and their respective dimensions and volumes

\begin{tabular}{|l|l|l|l|l|}
\hline Add-on Device & Manufacturer & $\begin{array}{l}\text { Length } \\
(\mathrm{cm})\end{array}$ & $\begin{array}{l}\text { Width } \\
(\mathrm{cm})\end{array}$ & $\begin{array}{l}\text { Volume } \\
(\mathrm{ml})\end{array}$ \\
\hline $\begin{array}{l}\text { OptiChamber } \\
\text { Advantage }{ }^{8}\end{array}$ & $\begin{array}{l}\text { Respironics, Cedar Grove, New } \\
\text { Jersey, USA }\end{array}$ & 17.00 & 5.25 & 218 \\
\hline OptiHaler® & $\begin{array}{l}\text { Respironics, Cedar Grove, New } \\
\text { Jersey, USA }\end{array}$ & 13.20 & 3.80 & 70 \\
\hline PocketChamberTM & $\begin{array}{l}\text { Ferraris Medical, Inc., Centre } \\
\text { Drive Orchard Park, New York, } \\
\text { USA }\end{array}$ & 4.750 & 110 \\
\hline $\begin{array}{l}\text { Spacer/VHC devices } \\
\text { manufacturer })\end{array}$
\end{tabular}

\subsubsection{The OptiChamber Parts}

The mouthpiece and the valvular part of the OptiChamber were removed and the cylindrical spacer was cut into two longitudinal halves using an ultra thin electrical saw at the workshop of the Department of Mechanical and Aerospace Engineering, Carleton University (Figure 5.3). 


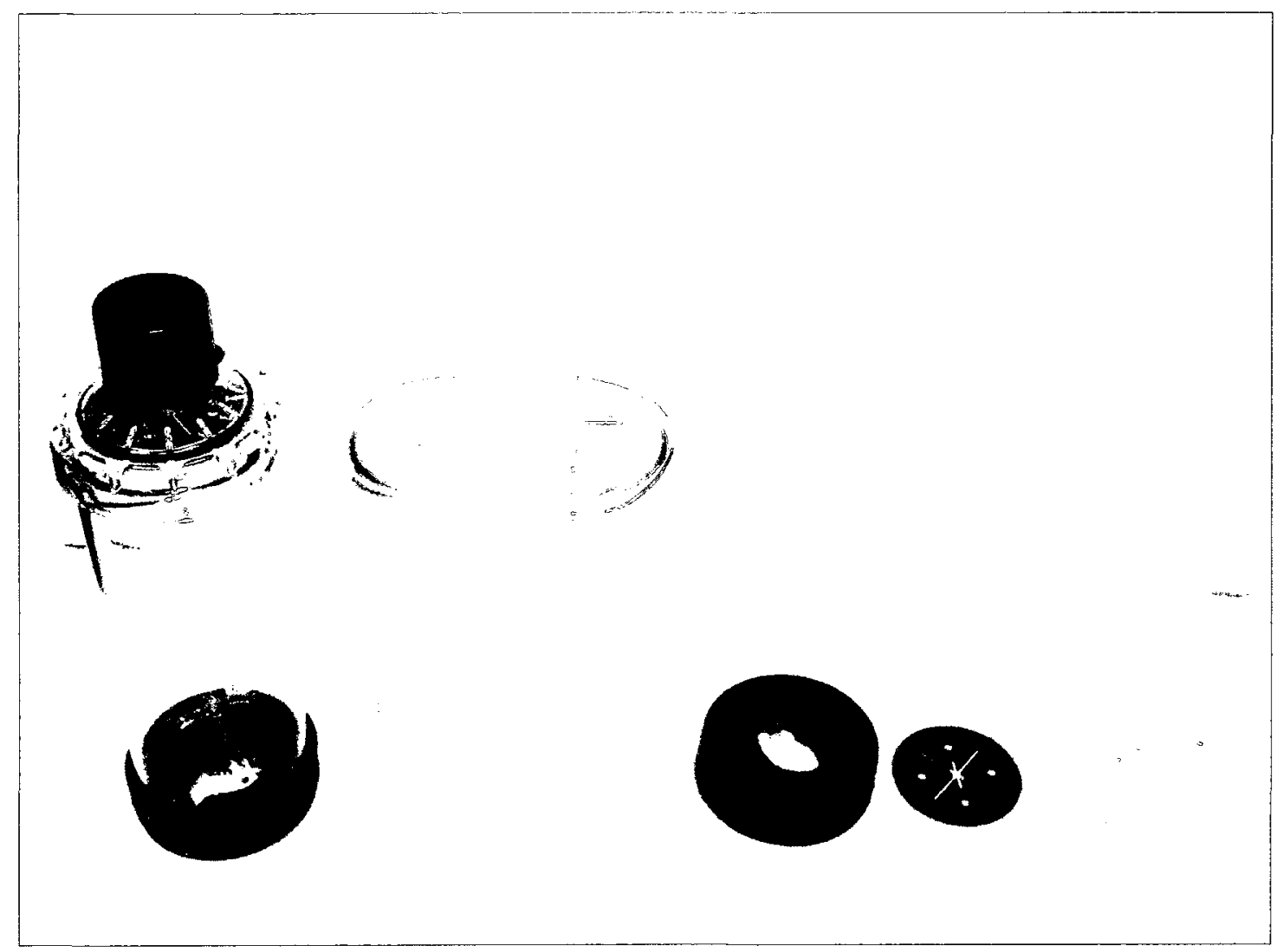

Figure 5.3 Photograph showing different parts of the OptiChamber (two halves, MDI inlet piece, valve and mouthpiece that fit together).

\subsubsection{The Filter}

A single filter was used downstream of the spacer. The drug captured in the filter by impaction represents the drug deposited in both the upper and lower respiratory tract (see Figure 2.1). For each deposition experiment, a new filter was used. To show that the filter was trapping all of the drug particles, initially two filters attached in series were used in the first three deposition experiments and each filter was washed and assayed for the drug deposition separately (see section 5.4). Drug deposition in the second filter was negligible 
The filters used were the Marquest Respirgard-II 303 Bacterial filters manufactured by Vital Signs Inc. The material used in the filter was spun bound polypropylene.

\subsubsection{The Mass Balance}

An analytical mass balance (Ohaus AV260, Central Carolina Scale, Inc., Sanford, NC) was used to measure the weight of Salbutamol Sulphate released from the pressurized metered-dose inhaler.

\subsubsection{The Mass Flow Meter}

The flow rate was measured using the Brooks Instrument Model 5863S thermal mass flow meter. The equipment manual (Brooks Instrument, 2000) was used to operate the flow meter.

A bypass channel diverts the airflow over a heating element. Two temperature sensing device one placed upstream and the other downstream from the heating element measure the temperature difference upstream and downstream of the heating element. A bridge circuit connects the two temperature sensing devices such that the resistance in each temperature device is proportional to the temperature in the device. Therefore, the temperature difference can be determined from the difference in resistance between the two temperature devices. The voltage output signal which is given by the mass flow meter is proportional to the mass flow rate. The signal was fed into a National Instruments data acquisition card, which was read by the LabView software.

The maximum flow rate that can be recorded by the flow meter is 150 SLPM (Standard litres per minute of air at $0^{\circ} \mathrm{C}$ and $101.325 \mathrm{kPa}$ ). For the full scale reading, the 
flow meter has a bias error of $0.2 \%$ while for the flow range used in the experimental procedure, the bias error is about $0.7 \%$. A drift and oscillation occurs in the set flow rate reading during the experimental procedure resulting in a bias error in the gauge reading of about $0.2 \%$.

\subsubsection{The Vacuum Pump}

A Welch dry vacuum pump Model 2585B is used to provide for the airflow. The airflow is controlled by a control valve situated downstream of the pump together with a flow meter. The pump has a maximum suction rate of $200 \mathrm{~L} / \mathrm{min}$.

\subsubsection{The Spectrophotometer}

Early spectroscopy originated in 1666 with Newton's discovery of the solar spectrum. In 1823, Fraunhofer discovered the wavelengths of solar spectrum lines (Ebdon, 1982). This method is used to determine concentrations of various chemicals which can give colours either directly or after addition of some other chemicals. The light absorption of the compound is measured in a spectrophotometer. Some compounds absorb light other than the visible range of the spectrum including the UV and infra-red regions.

\subsubsection{Theory}

Absorption spectroscopic methods of analysis depend on the fact that certain compounds absorb light radiation of a specific wavelength. The method is based on measuring the amount of light radiation absorbed by the sample of the compound to be analyzed. The light radiation being absorbed is directly related to the concentration of the coloured 
compound in the sample. The wavelength $(\lambda)$ of maximum absorption for different compounds is known. Equally a minimum amount of light is transmitted through the compound (Riddle, 2005).

\subsubsection{The Beer-Lambert Law}

The absorbance A (also known as optical density) and transmission $\mathrm{T}$ (also known as Transmittance) of light through a sample can be calculated by measuring light intensity entering and leaving the sample (Hardesty, 2008).

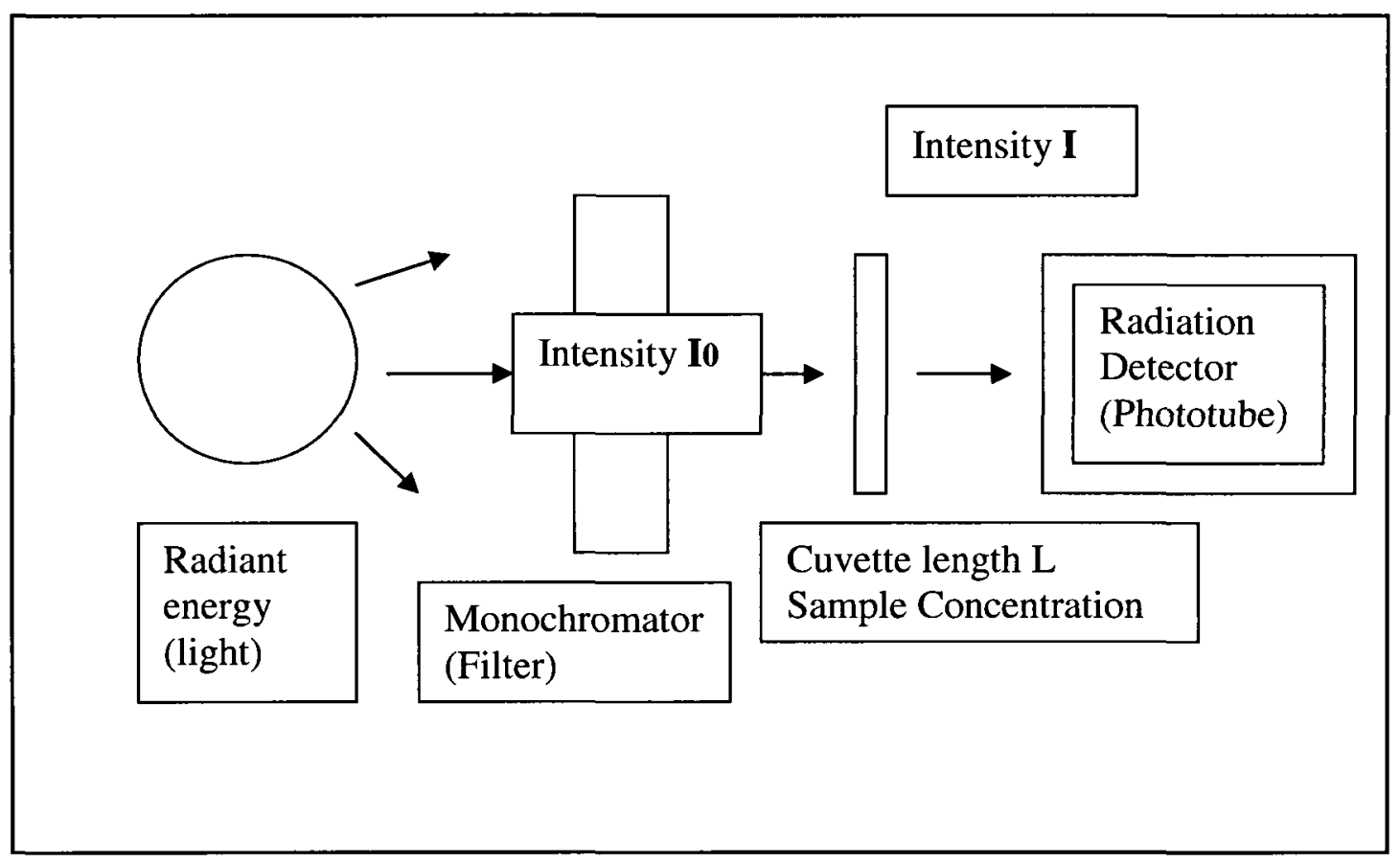

Figure 5.4 Schematic diagram of a spectrophotometer.

Light energy with an Intensity ' $\mathrm{L}_{0}$ ' passes through a sample having a concentration ' $\mathrm{C}$ '. Some of the light energy is absorbed by the sample (Figure 5.4). The amount of light 
energy leaving the sample has an Intensity 'I'. Therefore the terms can be defined as follows:

" $\mathrm{L}_{0}$ " is the light Intensity entering the sample

"I" is the light Intensity leaving the sample

" $\mathrm{C}$ " is the concentration of analyte in the sample

"L" is the length of the light path in glass sample cuvette

" $\mathrm{K}$ " is a constant for a particular solution of the sample at a certain wavelength

The Beer-Lambert Law is given by the following equations:

Light Absorbance $(\mathrm{A})=\log \left(\mathrm{I}_{0} / \mathrm{I}\right)=\mathrm{KCL}$

Light Transmission $(\mathrm{T})=\mathrm{I} / \mathrm{I}_{0}=10^{-\mathrm{KCL}}=10^{\mathrm{A}}$

According to Beer-Lambert Law, a graph of absorbance (A) against the concentration (C) of the analyte in the sample yields a straight line that passes through the origin. Uncertainty in the intensity of the transmitted light ( $\mathrm{T}$ ) results in uncertainty in the absorbance proportional to $10^{\mathrm{A}}$. The uncertainty increases rapidly as the absorbance (A) becomes greater than 1 . The precision error of absorbance (A) becomes a significant fraction in low absorbance. 


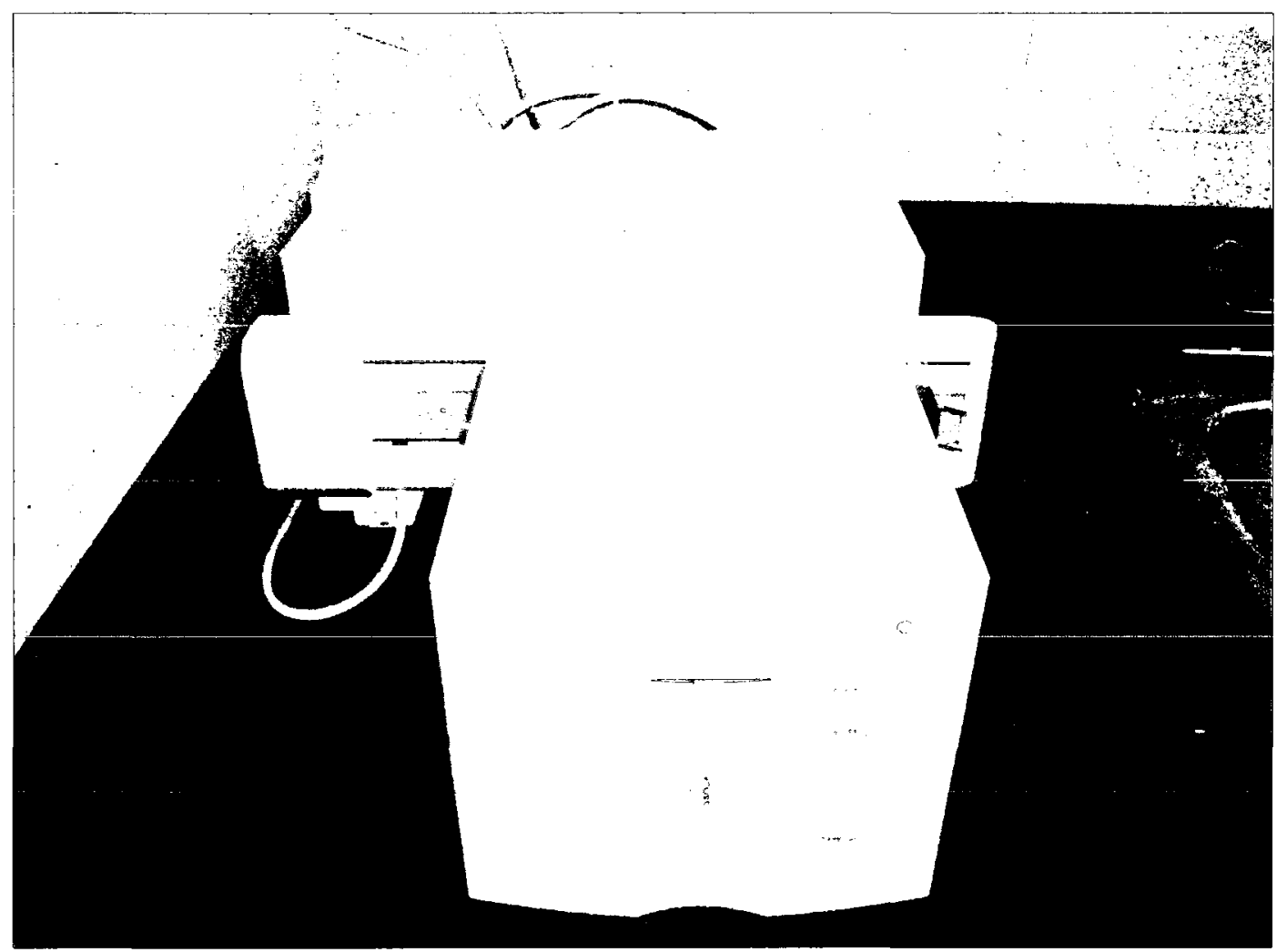

Figure 5.5 Agilent 8453 UV-visible Spectroscopy System.

The basic components of the spectrophotometer instrument (Figures 5.4 and 5.5) used to measure the absorption of radiant energy (Riddle, 2005) include:

(i) A stable source of radiant energy (Light);

(ii) A wavelength selector to isolate a desired wavelength from the source (filter or monochromator);

(iii) A cuvette which is a transparent container that holds the sample and the blank;

(iv) A phototube, which is a radiation detector that converts the radiant energy received to a measurable signal; 
(v) A readout device that displays the signal from the detector.

Light radiation enters the cuvette containing the sample to be analyzed. The energy that has passed through the sample is measured by the detector. The amount of light absorbed by the sample is calculated by the readout device and displays the signal from the detector as absorbance (Riddle, 2005).

Monochromatic light is required to produce a linear relationship between absorbance and concentration in accordance with Beer-Lambert Law. In addition, a narrow band of light is needed to provide a greater selectivity such that compounds with absorption peaks in other nearby wavelengths are less likely to cause interference. It also increases the sensitivity as it produces greatest change in absorbance with every increment change in concentration of the compound to be analyzed. The radiation wavelength is restricted by both the filters and the monochromators (Figure 5.4).

\subsection{General Measurement Procedures}

As explained above, the Beer-Lambert Law forms the basis of the measurement procedure. The amount of light radiation absorbed by a compound is directly related to the concentration of the compound. The general measurement procedure consists of five steps:

(1) Samples were prepared to make coloured compound.

(2) A series of standard solutions of known concentrations were prepared and treated in the same manner as the sample prepared for making coloured compounds.

(3) The spectrophotometer was set to $\lambda$ of maximum light absorption. 
(4) Light absorbance of standards was measured.

(5) Standard curve was then plotted of absorbance (A) against concentration (C). Once the standard plot was constructed, it was simple to find the concentration of an unknown sample: The absorption of the unknown samples was measured, and from the standard plot, the related concentration was then obtained.

\subsection{Measurement of Deposition}

\subsubsection{Assay of Salbutamol Sulphate}

The assay procedure was based on that of Habib and colleagues on the spectrophotometer determination of Salbutamol Sulphate (Habib et al., 2005).

\subsubsection{Wash Procedure}

A solution containing $20 \%$ anhydrous ethanol in distilled water was prepared. The complete add-on devices used were washed by pouring $20 \mathrm{~mL}$ of the ethanol solution into each device and shaking the device repeatedly with the same ethanol solution. The total drug deposition in each device was determined by measuring the absorption of each wash solution between $200-350 \mathrm{~nm}$ against a blank of $20 \%$ anhydrous ethanol in distilled water.

The two halves of the OptiChamber were each washed repeatedly with the same 20 $\mathrm{mL}$ of the ethanol solution by using a $10 \mathrm{~mL}$ glass pipette for the repeated wash. The valvular piece and the mouthpiece of the same spacer were each washed separately by shaking them repeatedly in $20 \mathrm{~mL}$ of the ethanol solution. 
The filter represents the drug deposition in both the upper and lower airways including the oral cavity and the drug, which has impacted on the oropharynx. The filter was washed with $20 \mathrm{~mL}$. of the ethanol solution. The washing involves the use of a 10 $\mathrm{mL}$ glass pipette for repeated withdrawal of the ethanol solution from the filter and repeatedly washing the filter with the same wash solution. Each filter was repeatedly washed (ten times) with the same wash solution to ensure that most of the drug in the filter has been washed out of the filter by the same wash solution. The amount of Salbutamol Sulphate deposited in each filter was determined by measuring the absorption of the wash solution between $200-350 \mathrm{~nm}$ against a blank of $20 \%$ anhydrous ethanol in distilled water.

\subsection{Procedure for the Construction of the Standard Curve}

Weight of empty $250 \mathrm{~mL}$ Erlenmeyer flask=119.7809 g.

Weight of flask +100 actuations of Salbutamol Sulphate $=119.7942 \mathrm{~g}$.

Weight of Salbutamol Sulphate $=119.7932-119.7809=0.0123 \mathrm{~g} / 100$ actuations.

There are $12.30 \mathrm{mg}$ of Salbutamol Sulphate present in 100 actuations.

Amount of Salbutamol Sulphate in each actuation $=0.123 \mathrm{mg}$ or $123 \mu \mathrm{g}$.

The weight of 100 Salbutamol Sulphate actuations was diluted with $1000 \mathrm{~mL}$ of $20 \%$ anhydrous ethanol in distilled water and the absorption of the resulting analyte was measured between $200-350 \mathrm{~nm}$ against a blank of $20 \%$ anhydrous ethanol in distilled water. Further dilutions of the analyte were carried out and the corresponding absorptions were measured. 
A standard calibration curve was plotted showing the linear variation of the absorption with the concentration of the analyte.

\subsection{Uniformity of pMDI Actuation Dose.}

1) The pMDI was primed once before each actuation.

2) Eight pMDI actuations were collected directly into each filter.

3) According to the label on the pMDI, a maximum of 200 single actuation doses can be used.

4) A total of 16 actuations were used for each sample collected in each filter (each actuation is preceded by priming the pMDI once).

5) A total of 12 filters were used to collect the samples.

6) Accordingly, the numbers of doses used from the pMDI were 192 (16 doses in each of the 12 filters).

7) The Salbutamol Sulphate in each of the 12 filters used was washed with $15 \mathrm{~mL}$ of $20 \%$ solution of anhydrous ethanol in distilled water using the pipette suction method (as explained in section 5.4.2).

8) The absorption of each Salbutamol Sulphate sample was measured between 200 - 350 nm against a blank of $20 \%$ solution of anhydrous ethanol in distilled water. 


\subsection{Determination of Salbutamol Sulphate Deposition in Different}

\section{$\underline{\text { Add-On Devices at Various Flow Rates }}$}

Twenty consecutive doses of Salbutamol Sulphate pMDIs were actuated in each of the three types of spacers using flow rates of 30,45 , and $60 \mathrm{~L} / \mathrm{min}$ respectively priming the pMDI once before each actuation. Salbutamol Sulphate aerosol deposition was determined in each spacer as a whole by shaking the spacer with $20 \mathrm{~mL}$ of $20 \%$ ethanol anhydrous in distilled water. The absorption of each analyte from each spacer sample was then determined.

\subsection{Determination of Salbutamol Sulphate Deposition in Different Parts of the OptiChamber at Various Flow Rates}

The two halves of the OptiChamber were labelled as upper and lower halves, respectively, and assembled together on the pMDI inlet piece. The two halves were joined together accurately along the split line and held together tightly using cardboard glue tape. The mouthpiece with the valve was then screwed at the outlet of the joined halves of the VHC. The mouthpiece and the two halves were then tightly taped together. Twenty consecutive doses of Salbutamol Sulphate were then actuated in the assembled OptiChamber at each of the above specified flow rates, priming the pMDI once before each individual actuation. The OptiChamber was dismantled each time and the Salbutamol Sulphate deposition in each part of the spacer was washed with $20 \mathrm{~mL}$ of ethanol solution using a $10 \mathrm{~mL}$ pipette. The Salbutamol Sulphate deposition in each washing for each flow rate was determined as mentioned above. 


\section{Chapter 6: Measurement of Uncertainty}

\subsection{Experimental Errors}

Except for the experimental procedures to construct the calibration curve and the procedure to determine the dose uniformity of the pMDI, all experiments that determined the deposition of Salbutamol Sulphate in the spacers and filters involved the use of 20 pMDI actuations and $20 \mathrm{~mL}$ ethanol wash solution.

In Appendix D, tables D.1, D.2 and D.3, the mean total deposition of Salbutamol Sulphate (spacer and filter) in all flow rates was $102.887 \mu \mathrm{g} / \mathrm{mL}$.

According to the data for the construction of the calibration curve (Appendix A, table A.1), the total deposition in spacer and filter should be $123 \mu \mathrm{g} / \mathrm{mL}$.

Therefore experimental errors have caused the loss of approximately 123 $102.887=20.365 \mu \mathrm{g} / \mathrm{mL}$ of Salbutamol Sulphate in deposition, in other words, a loss of $(20.365 / 123) \times 100=16.557 \%$ in Salbutamol Sulphate dose

In Appendix F, tables F.1, F.2 and F.3, the mean total deposition of Salbutamol Sulphate (spacer and filter) in the re-assembled OptiChamber in all flow rates was 92.056 $\mu \mathrm{g} / \mathrm{mL}$.

According to the data for the construction of the calibration curve (Appendix A, table A.1, the total deposition in spacer and filter should be $123 \mu \mathrm{g} / \mathrm{mL}$.

Therefore experimental errors have caused the loss of approximately $123-92.056$ $=30.944 \mu \mathrm{g} / \mathrm{mL}$ of Salbutamol Sulphate in deposition, in other words, a loss of $(30.944 / 123) \times 100=25.178 \%$ in Salbutamol Sulphate dose. 


\subsection{Types of Experimental Errors}

The procedure to analyse uncertainty in the results obtained in this research work is based

on the ANSI/ASME, Measurement Uncertainty, Part 1 (1985). During experimental procedure, errors occur in the data measured. The total error that arises in these experimental measurements can be divided into two parts, a bias error and a random or precision error. To obtain an accurate measurement, both types of error must be minimised.

\subsection{Bias Error}

A constant error that occurs when the same tests are repeated using the same technique and under the same ambient conditions. Bias error arises as a result of instruments used in experimental procedures. It is the sum of different bias errors occurring in the experimental procedure. Some of these errors are known and may be corrected or estimated while others are unknown. A bias error ranges equally between a positive value and an equal negative value around the measurement concerned. Therefore, a bias error is given a bias limit that ranges between the same negative and positive values. Different bias limits in the same experimental procedure can be combined by adding the square of each individual bias error and determining the square root of the sum. The propagated bias error is given by equation (6.1) below.

$$
U=\sqrt{U_{1}^{2}+U_{2}^{2}+\cdots U_{N}^{2}}
$$

Where $\mathrm{U}_{1}, \mathrm{U}_{2}, \ldots, \mathrm{U}_{\mathrm{N}}$ are individual bias limits in the same experimental procedure. 


\subsubsection{Estimation of Bias Error in the Deposition Fraction of Salbutamol Sulphate}

The deposition fraction (DF) can be written as

$D F=\frac{V o l_{\text {spacer }} A_{\text {spacer }}}{\left(\operatorname{Vol}_{\text {spacer }} A_{\text {spacer }}+\text { Vol } l_{\text {filter }} A_{\text {fitter }}\right)}$

Where the suffix $\mathrm{Vol}$ represents the volume of the respective wash solution and $A$ being the respective absorbance of the wash solution. The deposition fraction (DF) can be represented as

$$
D F=\frac{m_{\text {spacer }}}{\left(m_{\text {spacsp }}+m_{\text {fitesp }}\right)}
$$

Where, $m_{\text {spacer }}$ is the particle mass deposited in the spacer and $m_{\text {filter }}$ is the particle mass deposited in the filter. Using equation (6.1),

$$
U=\sqrt{U_{1}^{2}+U_{2}^{2}+\cdots U_{N}^{2}}
$$

the bias limit for the deposition fraction (DF) can be written as

$U_{D F}=\sqrt{\left(\frac{U m_{\text {spacer }} \partial D F}{\partial m_{\text {spacer }}}\right)^{2}+\left(\frac{U m_{f i l e r} \partial D F}{\partial m_{f i l t e r}}\right)^{2}}$

Substituting for

$$
\begin{aligned}
& \frac{\partial D F}{\partial m_{\text {spaesr }}} \\
& \frac{\partial D F}{\partial m_{\text {spacer }}}=\frac{m_{\text {filtep }}}{\left(m_{\text {spacer }}+m_{\text {fiter }}\right)^{2}} \\
& \frac{\partial D F}{\partial m_{\text {spacsr }}}=\frac{m_{\text {filter }}}{\left(m_{\text {spacer }}+m_{\text {fater }}\right)^{2}}
\end{aligned}
$$




$$
=\frac{D F(1-D F)}{m_{\text {spacer }}}
$$

Substituting for

$$
\begin{aligned}
& \frac{\partial D F}{\partial m_{\text {filter }}} \\
& \frac{\partial D F}{\partial m_{\text {fiter }}}=\frac{-m_{\text {spacer }}}{\left(m_{\text {spacer }}+m_{\text {filter }}\right)^{2}} \\
& =\frac{-D F}{\left(m_{\text {spacer }}+m_{\text {filtsr }}\right)} \\
& =\frac{D F(1-D F)}{m_{\text {filter }}} \\
& \frac{U_{D F}}{D F}=(1-D F) \sqrt{\left(\frac{U m_{\text {spacer }}}{m_{\text {spacer }}}\right)^{2}+\left(\frac{U m_{\text {filter }}}{m_{\text {fitter }}}\right)^{2}}
\end{aligned}
$$

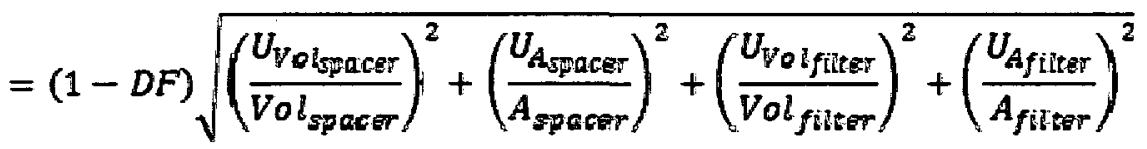

Bias limit is estimated in

(i) Washing solution in the spacer $U$ Vol $_{\text {spacer }} / V_{\text {spacer }}$ as $0.5 \%$.

(ii) Washing solution in the filter $U V l_{\text {filter }} / V_{\text {ol }} l_{\text {filter }}$ as $0.5 \%$.

(iii) Absorption in the spacer $U A_{\text {spacer }} / A_{\text {spacer }}$ as $2 \%$.

(iv) Absorption in the filter $U A_{\text {filter }} / A_{\text {filter }}$ as $2 \%$.

Therefore bias limit for the deposition fraction (DF) is

$$
\begin{aligned}
\frac{U_{D F}}{D F} & =(1-D F) \sqrt{(0.5 \%)^{2}+(2 \%)^{2}+(0.5 \%)^{2}+(2 \%)^{2}} \\
& =2.9 \%(1-D F)
\end{aligned}
$$

Bias error due to flow meter $=\mathrm{U}_{\text {flow meter }} / \mathrm{Q}_{\text {flow meter }}=0.7 \%$

Bias error due to gauge reading $=\mathrm{U}_{\text {gauge }} / \mathrm{Q}_{\text {gauge }}=0.2 \%$ 
Bias error due to flow meter and gauge reading (flow rate measurement) is

$$
\begin{aligned}
\frac{U_{\text {flow rats }}}{Q_{\text {flow rats }}} & =\sqrt{\left(\frac{U_{\text {flow meter }}}{Q_{\text {flow }}}\right)^{2}+\left(\frac{U_{\text {gaugtes }}}{Q_{\text {gaugs }}}\right)^{2}} \\
& =\sqrt{(0.007)^{2}+(0.002)^{2}} \\
& =0.00728
\end{aligned}
$$

For example, the bias limit for the OptiChamber at $30 \mathrm{~L} / \mathrm{min}$ flow rate can be calculated from equations (6.8) and (6.9), such that,

$\frac{U_{D F}}{D F}=2.9 \%(1-D F)$

where $\mathrm{DF}$ is the average deposition fraction at $30 \mathrm{~L} / \mathrm{min}$

$$
\frac{U_{D F}}{D F}=2.9 \%(1-0.4716)=0.0153
$$

Total bias limit is that due to deposition fraction (DF) and flow rate measurement

$$
\begin{aligned}
& =\sqrt{\left(\frac{U_{D F}}{D F}\right)^{2}+\left(\frac{U_{\text {flow rate }}}{Q_{\text {flow rate }}}\right)^{2}} \\
& =\sqrt{(0.0153)^{2}+(0.00728)^{2}} \\
& =0.0169
\end{aligned}
$$

\subsection{Random Error}

Errors that occur in repeated measurements of the same experimental procedure using the same technique under the same ambient conditions. The results produced are quite different due to the presence of many sources of error ranging from the different handling of the experimental procedure by each individual such as data measurement to instrument 
calibration and others. In this research work, a scattered result for the same experiment was obtained for the deposition fraction measurement of Salbutamol Sulphate.

\subsubsection{Estimation of the Precision Error (Random Error) in the Deposition Fraction of Salbutamol Sulphate}

Standard Deviation $S D=\frac{\sqrt{\sum(x-m)^{2}}}{n-1}$

$x=$ experimental value measured

$m=$ mean

$n=$ number of experiments carried out for each sample

Standard deviation of the mean $=\mathrm{SD} / \mathrm{Vn}$

Precision error $=$ standard deviation of the mean multiplied by the $t$-value for 2 degrees of freedom and 95\% confidence interval, i.e, 2.92 (for analyses of variance (ANOVAs), degree of freedom $\mathrm{df}=\mathrm{n}-1$.

For example, the average deposition fraction (DF) of Salbutamol Sulphate for the OptiChamber at $30 \mathrm{~L} / \mathrm{min}$ is 0.4716 then,

$\mathrm{SD}=0.0261$

$\mathrm{SD}$ of the mean $=0.0261 / \sqrt{ } 3=0.01506$

The $\mathrm{t}$-value for 2 degrees of freedom and $95 \%$ confidence interval is 2.92 therefore, the precision error $=0.01506 \times 2.92=0.044$ 


\subsection{Total Error}

This combines both the bias error and the precision error and is the square root of the sum of the bias error squared and the precision error square such that:

Total Error $=\sqrt{(\text { Bias error })^{2}+{\text { (Precision error })^{2}}^{2}}$

For example, the bias error and the precision error involved in the deposition fraction of Salbutamol Sulphate in the OptiChamber for $30 \mathrm{~L} / \mathrm{min}$ flow rate are 0.025 and 0.044 respectively therefore,

Total Error $=\sqrt{(0.0169)^{2}+(0.044)^{2}}=0.047$

Table 6.1 gives the bias error, the precision error, and the uncertainty for the deposition fraction in the three types of spacers used at various flow rates.

Table 6.1: Bias error, precision error, and the uncertainty for the deposition fraction of Salbutamol Sulphate in different spacers at various flow rates.

\begin{tabular}{|c|l|l|l|l|l|l|l|}
\hline \multirow{4}{*}{ Spacer } & $\begin{array}{c}\text { Flow } \\
\text { Rate } \\
(\mathrm{L} / \mathrm{min})\end{array}$ & $\begin{array}{c}\text { Average } \\
\text { DF }\end{array}$ & $\begin{array}{c}\text { Standard } \\
\text { Deviation }\end{array}$ & $\begin{array}{c}\text { Standard } \\
\text { Deviation } \\
\text { of Mean }\end{array}$ & $\begin{array}{c}\text { Bias } \\
\text { Limit }\end{array}$ & Precision & Uncertainty \\
\hline \multirow{3}{*}{ OptiChamber } & 30 & 0.4716 & 0.0261 & 0.0151 & 0.017 & 0.044 & 0.047 \\
\cline { 2 - 8 } & 45 & 0.4183 & 0.0222 & 0.0128 & 0.018 & 0.037 & 0.041 \\
\cline { 2 - 9 } & 60 & 0.3712 & 0.0272 & 0.0157 & 0.020 & 0.046 & 0.049 \\
\hline \multirow{3}{*}{ OptiHaler } & 30 & 0.6595 & 0.0180 & 0.0104 & 0.012 & 0.030 & 0.033 \\
\cline { 2 - 9 } & 45 & 0.6016 & 0.0184 & 0.0106 & 0.014 & 0.031 & 0.034 \\
\cline { 2 - 9 } & 60 & 0.5459 & 0.0186 & 0.0107 & 0.015 & 0.031 & 0.035 \\
\hline \multirow{3}{*}{ PocketChamber } & 30 & 0.6958 & 0.0420 & 0.0243 & 0.011 & 0.071 & 0.072 \\
\cline { 2 - 8 } & 45 & 0.6395 & 0.02918 & 0.0168 & 0.013 & 0.049 & 0.050 \\
\cline { 2 - 8 } & 60 & 0.5874 & 0.0281 & 0.0162 & 0.014 & 0.047 & 0.049 \\
\hline
\end{tabular}




\section{Chapter 7: Experimental Results}

\subsection{Standard Curve}

Figure 7.1 below shows the linear variation of the absorption of Salbutamol Sulphate with concentration in accordance with Beer-Lambert law (see table A.1, Appendix A for experimental data).

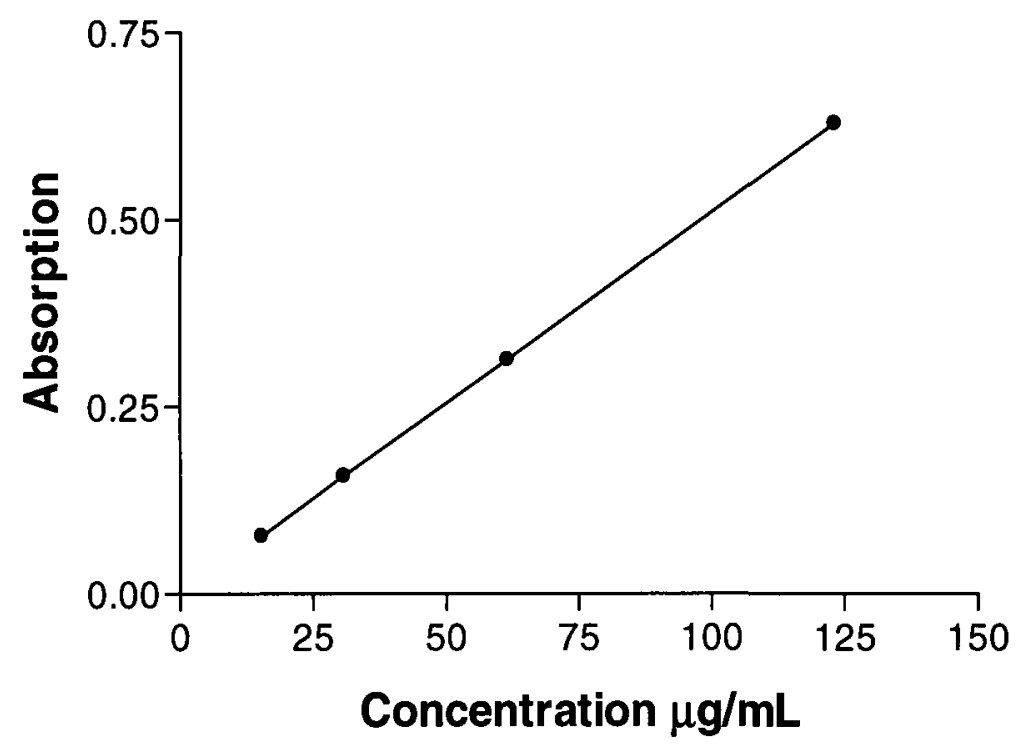

Figure 7.1 Variation of absorption with standard concentrations of Salbutamol Sulphate. 


\subsection{Dose Uniformity}

Figure 7.2 below shows a bar chart of the dose in micrograms per millilitre. Each bar represents eight consecutive actuations (see table B.1, Appendix B for data). Figure 7.2 shows that the dose is approximately uniform.

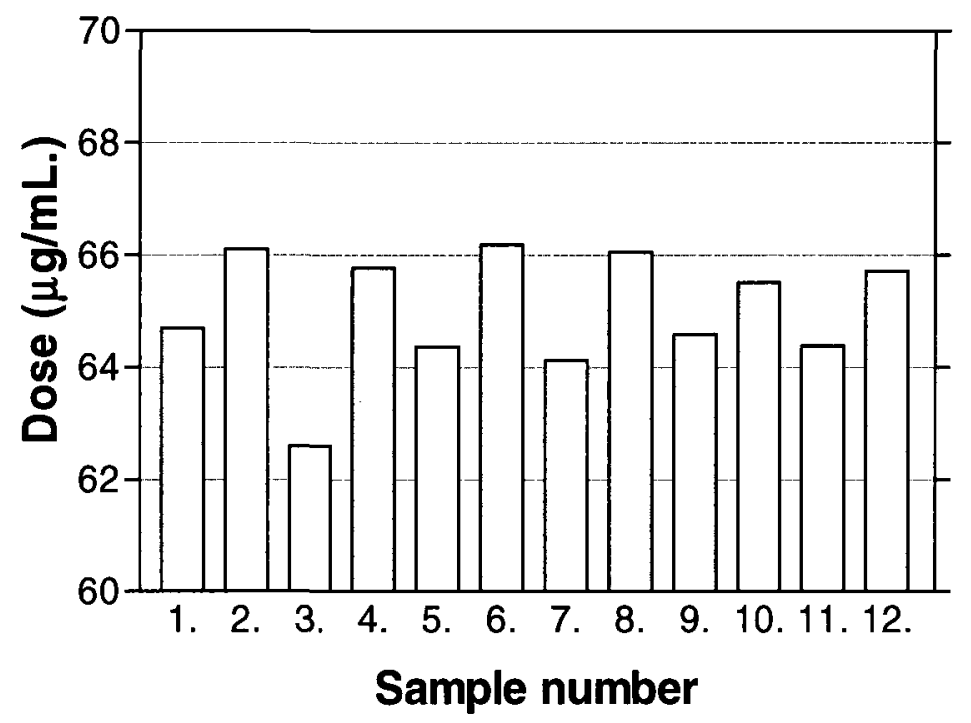

Figure 7.2 Dose uniformity in eight consecutive MDI actuations of Salbutamol Sulphate.

\subsection{Salbutamol Sulphate deposition in Different Add-On Devices}

Figure 7.3 below shows the deposition of Salbutamol Sulphate from a pMDI in the three types of spacers and their filters at $30 \mathrm{~L} / \mathrm{min}$ flow rate (see table C.1-C.3, Appendix C for experimental data). 
Figure 7.3 shows that the deposition of Salbutamol Sulphate in the OptiChamber spacer was slightly less than that of the filter with a deposition of approximately $47 \%$ in the spacer and $53 \%$ in the filter. At this flow rate, Salbutamol Sulphate deposition in the OptiHaler and PocketChamber spacers was higher than their respective filters. In the OptiHaler the mean drug deposition was $66 \%$ in the spacer while in the filter this was 34\%. In case of the PocketChamber, this was $68 \%$ in the spacer and $32 \%$ in the filter, a slightly higher deposition in the PocketChamber spacer than that of the OptiHaler. Drug deposition in the OptiChamber spacer was approximately $30 \%$ less than in the spacers of the OptiHaler and PocketChamber respectively. A higher drug deposition in the OptiChamber filter than those in the OptiHaler and PocketChamber reflects a higher drug deposition in the respiratory tract is obtained by OptiChamber at $30 \mathrm{~L} / \mathrm{min}$ flow rate.

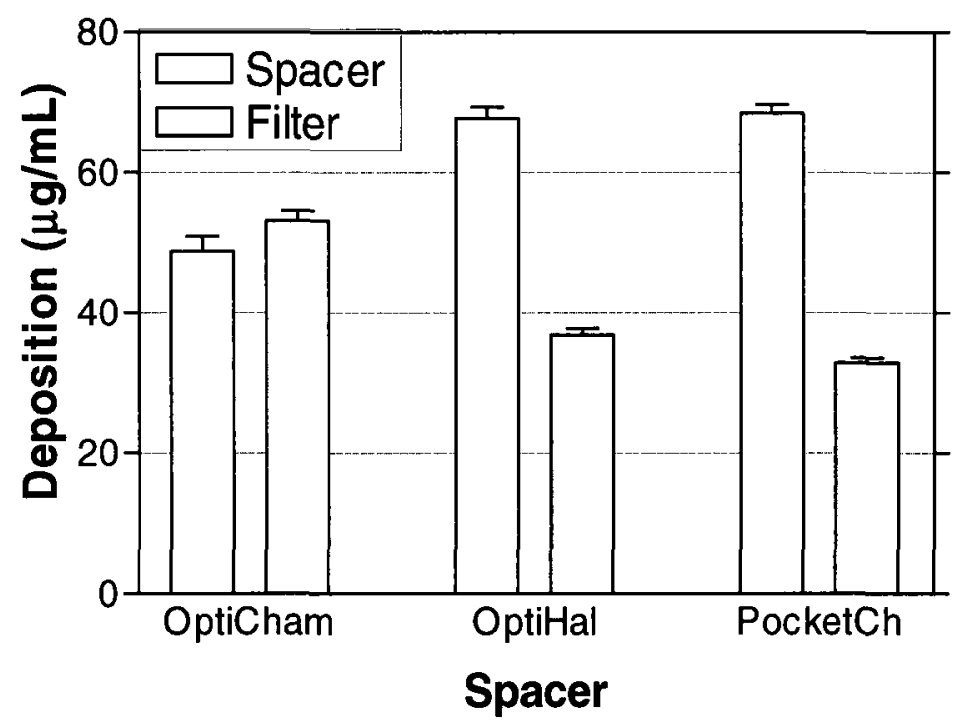

Figure 7.3 Deposition of Salbutamol Sulphate aerosol from pMDI in three types of spacers and their filters at $30 \mathrm{~L} / \mathrm{min}$ flow rate. 
Figure 7.4 below shows the deposition of Salbutamol Sulphate from a pMDI in the three types of spacer and their respective filters at $45 \mathrm{~L} / \mathrm{min}$ flow rate (see table C.1-C.3, Appendix $\mathrm{C}$ for experimental data).

With increase in flow rate, drug deposition in the spacers decreased on the expense of increased drug deposition in the filters. At $45 \mathrm{~L} / \mathrm{min}$ flow rate, Figure 7.4 shows that in the OptiChamber, drug deposition in the spacer decreased to $42 \%$ compared with an increase in filter deposition to $58 \%$. For the relatively smaller volume OptiHaler and PocketChamber, spacer drug depositions were decreased to $60 \%$ and $64 \%$ respectively while the filter drug deposition was increased to $40 \%$ in the OptiHaler and $36 \%$ in the PocketChamber.

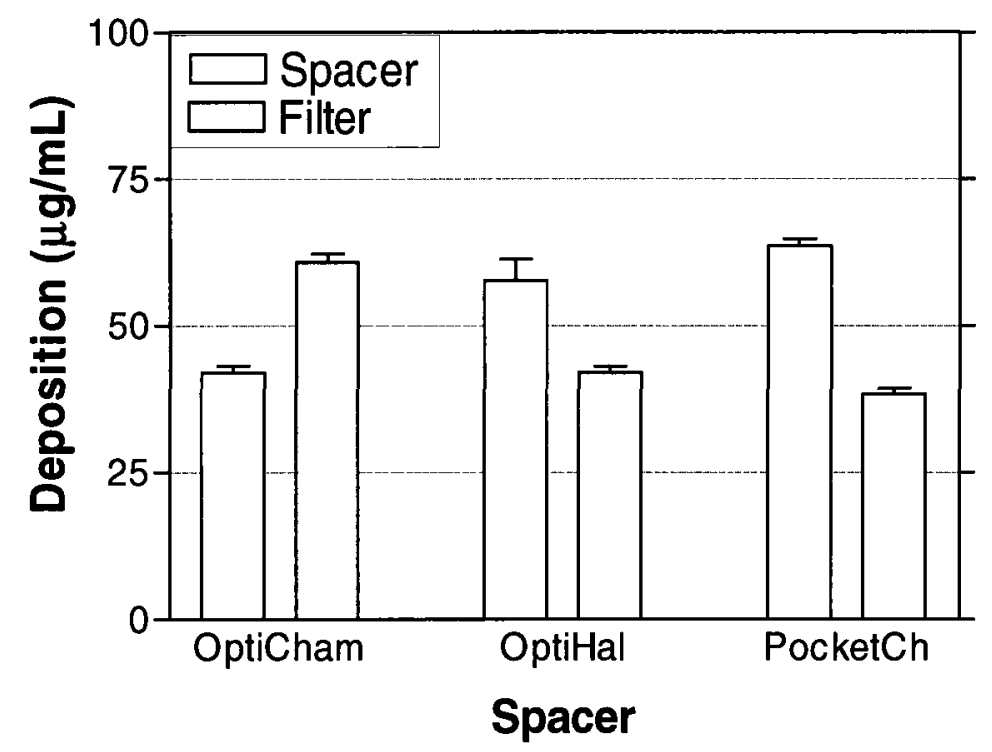

Figure 7.4 Deposition of Salbutamol Sulphate aerosol from pMDI in three types of spacers and their filter at $45 \mathrm{~L} / \mathrm{min}$ flow rate. 
Figure 7.5 below shows the deposition of Salbutamol Sulphate from a pMDI in the three types of spacers and their respective filters at $60 \mathrm{~L} / \mathrm{min}$. flow rate (see table C.1-C.3, Appendix $\mathrm{C}$ for experimental data).

At $60 \mathrm{~L} / \mathrm{min}$, drug deposition in the filters increased such that it became over $30 \%$ more than that of the spacer in case of the OptiChamber. In the relatively smaller volume OptiHaler, drug deposition in the filter approached that in the spacer being about $45 \%$ in the filter and about 55\% in the spacer. For the PocketChamber, deposition in the spacer decreased to about $59 \%$ while increased to about $41 \%$ in the filter. Drug deposition in the PocketChamber spacer was higher than that of the OptiHaler spacer although, deposition in the filter of the PocketChamber was less than that of the OptiHaler.

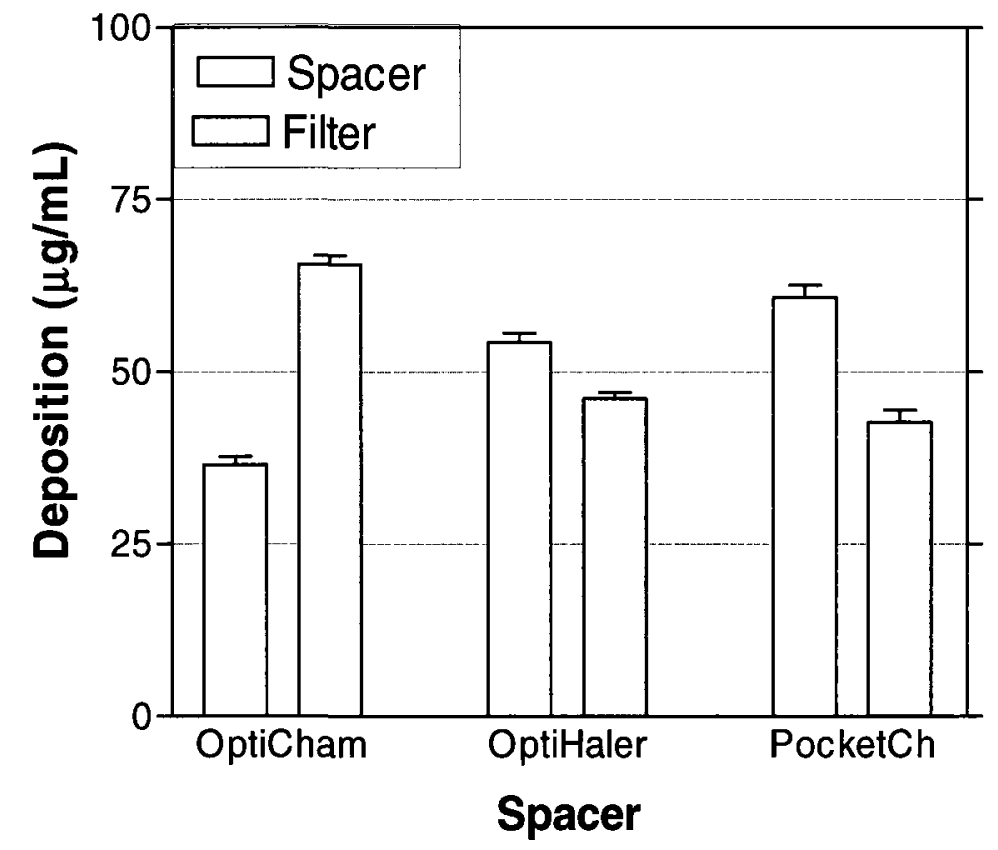

Figure 7.5 Deposition of Salbutamol Sulphate aerosol from pMDI in three types of spacers and their filter at $60 \mathrm{~L} / \mathrm{min}$ flow rate. 
In general, deposition in the relatively large volume spacer such as the OptiChamber is less than that of the filter in all flow rates tested. The difference in drug deposition between the spacer and its respective filter tends to increase with increased flow rate. Deposition in the smaller volume spacers including the OptiHaler and the PocketChamber is higher than their respective filters at all flow rates. The difference in deposition tends to decrease with increased flow rate.

As mentioned in the literature review above by Barry and O'Callaghan (1995A), "small volume add-on devices especially those less than $200 \mathrm{~mL}$ tend to have a reduced drug availability for inhalation." Thus more drug will be deposited in the spacer than the filter. According to Barry and O'Callaghan (1995A), this occurs because of the relatively high velocity aerosol droplets impacting on the internal walls of the small volume add-on device. Droplet impaction on the walls of the spacer decreases with increase in spacer volume thus reducing spacer drug deposition. Since the volume of the OptiHaler is smaller than that of the PocketChamber, it is expected that more drug particles will impact on the walls of the OptiHaler resulting in more drug deposition in the OptiHaler compared with the PocketChamber. This assumption holds true if the design of the spacers are similar. Figure $7.3,7.4$ and 7.5 show that drug deposition in the PocketChamber spacer was more than that in the OptiHaler spacer. This is because the MDI canister holder in the OptiHaler is situated on the side of the main body of the spacer near the mouthpiece. Actuation of the pMDI results in part of the aerosol spray to be sucked into the mouthpiece with the main flow thus reducing drug deposition in the spacer (Figure 7.6). 


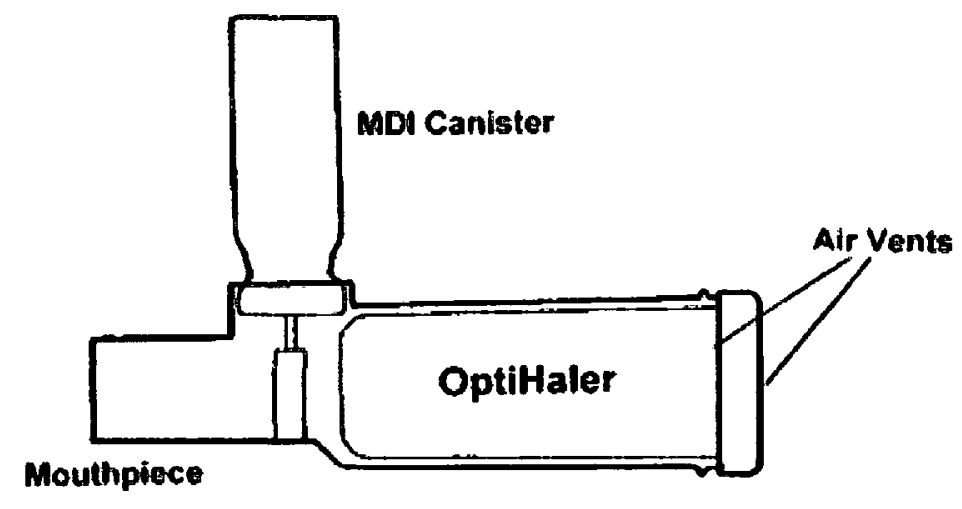

Figure 7.6: Design of the OptiHaler. Source: Foss and Keppel (1999).

If the filter in each type of spacer constitutes the respiratory tract, then according to Usmani et al., (2005), a fast inhalation flow rate produces a higher total lung deposition, a higher oropharyngeal impaction and a higher lung penetration index of the drug. In a similar manner to drug deposition in the respiratory tract, a higher flow rate produced a higher filter deposition in all three types of spacers. This is probably due to break up of large aerosol droplets by aerodynamic forces producing small particles that are easily carried to the filter.

\subsection{Variation of Total Deposition Fraction (TDF) of Salbutamol Sulphate Aerosol Spray with Flow Rate}

The deposition fraction (DF) of the aerosol particles is given by:

$$
D F=\frac{m_{\text {spacer }}}{m_{\text {spacer }}+m_{\text {filter }}},
$$


Where $m_{\text {spacer }}$ is the particle mass deposited in the spacer and $m_{\text {fitter }}$ is the particle mass deposited in the filter. Since the density of the aerosol particles is known, the deposition fraction (DF) can be calculated.

Figure 7.7 below shows the variation of total deposition fraction (TDF) in each type of spacer with the flow rate (see tables D.1-D.2, Appendix D for experimental data). Figure 7.7 shows that the deposition fraction decreases linearly with increase in low rate. Spacers with relatively large volume such as the OptiChamber tend to have a lower deposition fraction because fewer drug particles deposit in the spacer itself. Those spacers with relatively small volume tend to have a higher deposition fraction because of the larger number of particles impacting on the walls of the spacer. Although, the PocketChamber has a volume larger than the OptiHaler, the deposition fraction of the PocketChamber was higher than that of the OptiChamber. This occurs because of the pMDI spray inlet, which is close to the mouthpiece caused some drug loss through the mouthpiece to the filter. 


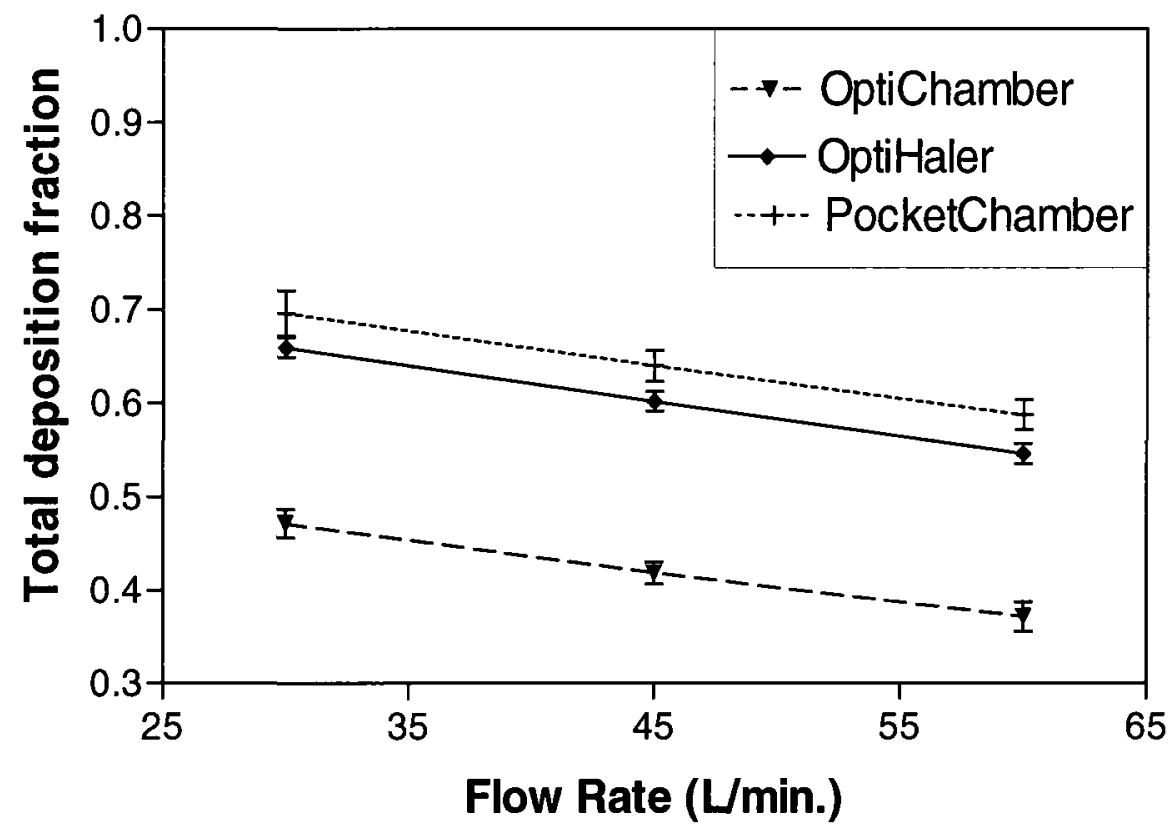

Figure 7.7 Linear variation of the total deposition fraction (TDF) with flow rate for each type of spacer used.

\subsection{Deposition of Salbutamol Sulphate in Different Parts of OptiChamber}

Figure 7.8 below shows the deposition of Salbutamol Sulphate aerosol spray from pMDI in various parts of the OptiChamber at different flow rates (see tables E.1-E.2, Appendix E for experimental data).

Excluding the drug deposition in the filter, Figure 7.8 shows that the highest drug deposition occurred in the lower half of the OptiChamber spacer except at the flow rate of $60 \mathrm{~L} / \mathrm{min}$ where the valvular part of the spacer had the highest drug deposition. At 30 L/min flow rate, the upper half of the spacer had the second highest drug deposition while 
at $45 \mathrm{~L} / \mathrm{min}$, the second highest drug deposition was at the valvular part of the spacer. The high drug depositions obtained in the valvular part of the spacer at flow rates of 60 $\mathrm{L} / \mathrm{min}$ and $45 \mathrm{~L} / \mathrm{min}$ was due to break up of the large aerosol droplets by aerodynamic forces increasing the relative number of smaller drug particles. These smaller drug particles were able to follow the streamwise flow direction causing their impaction at the valvular part of the spacer.

Figure 7.8 also shows that the lowest amount of drug deposition in the filter occurred at $30 \mathrm{~L} / \mathrm{min}$ flow rate while the highest deposition occurred at $60 \mathrm{~L} / \mathrm{min}$ flow rate. This is in agreement with drug deposition in the OptiChamber filter at the specified flow rates shown in Figures 7.3, 7.4 and 7.5. A higher drug deposition with increased flow rate reflects the increased propellant evaporation increasing the relative number of smaller drug particles that are carried further in the flow to be deposited in the filter.

Figure 7.8 shows that the least drug deposition occurred in the spacer inlet piece in all flow rates tested. This is because the pMDI is normally placed in the inlet piece and therefore the spray direction points away from the inlet piece. The lowest drug deposition in the inlet piece was at $60 \mathrm{~L} / \mathrm{min}$ indicating that the smaller drug particles are carried further towards the valvular part of the spacer and to the filter. 


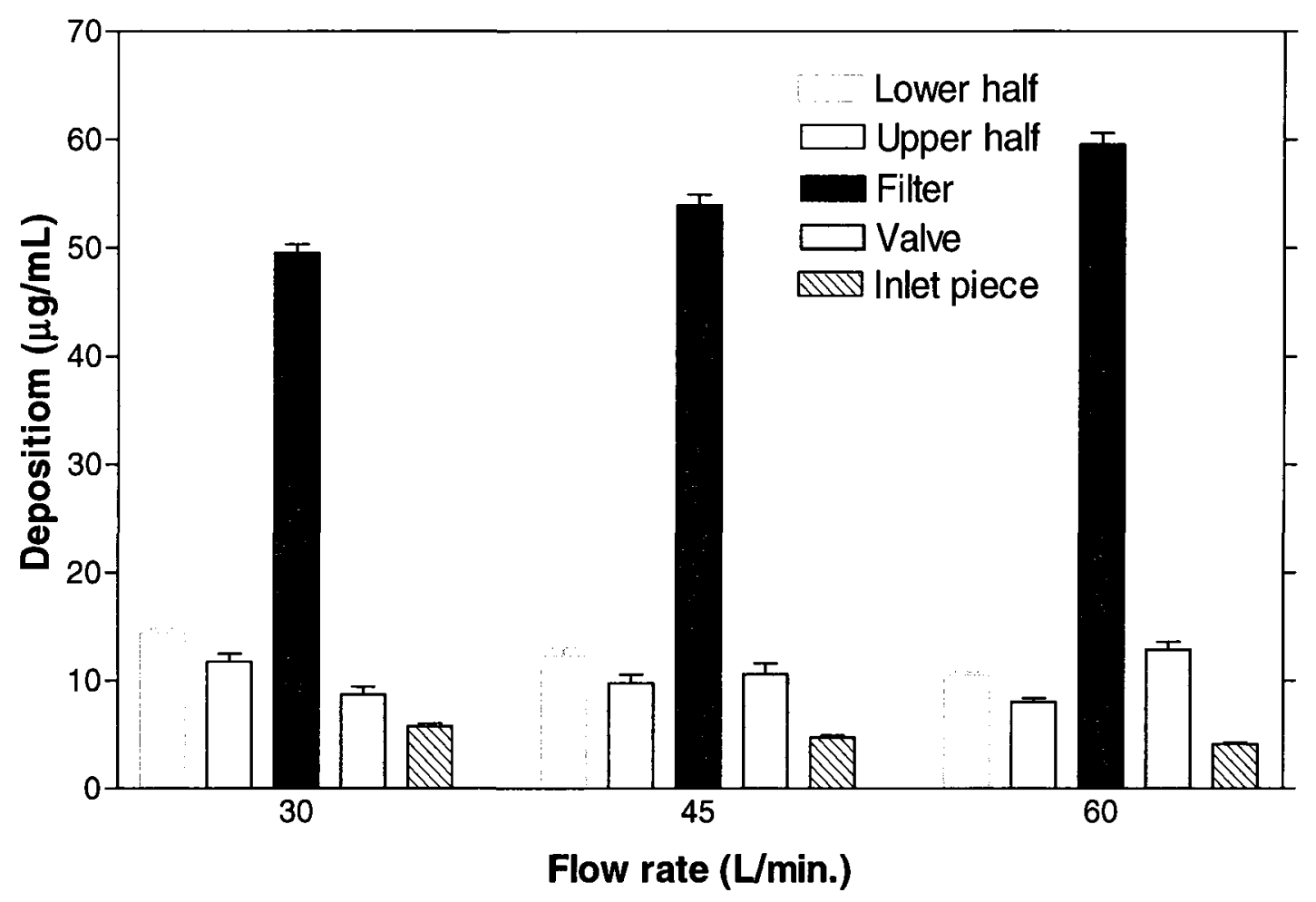

Figure 7.8 Deposition of Salbutamol Sulphate aerosol spray in various parts of the OptiChamber at different flow rates.

Figure 7.9 below compares the deposition of Salbutamol Sulphate aerosol spray from pMDI in the upper and lower halves of an OptiChamber at different flow rates (see tables E.1-E.2, Appendix E for experimental data).

Figure 7.9 shows that the drug deposition in the upper and lower half of the OptiChamber decreases with increased flow rate. This occurred as a result of the increase in relative number of small drug particles due to the break up of large droplets and increased propellant evaporation causing the particles to deposit further towards the valvular part and the filter.

One interesting aspect shown in Figure 7.9 is the higher drug deposition that occurred in the lower half of the OptiChamber spacer compared with that of the upper 
half in all of the flow rates tested. According to Crosland (2008), the direction of spray released from a Ventolin ${ }^{\circledR}$ pMDI had a downward deflection up to $6^{\circ}$ below the horizontal plane probably caused by the nozzle in the canister of the pMDI. A downward deflection of the pMDI spray resulted in aerosol particles impacting on the lower inner surface of the spacer thus increasing the drug deposition on the lower half of the spacer. Therefore, clinical use of Ventolin® pMDI in asthmatic patients or other pulmonary diseases will result in increased drug deposition on the tongue in the oral cavity. Such drug is normally swallowed increasing the potential systemic side effect of the drug.

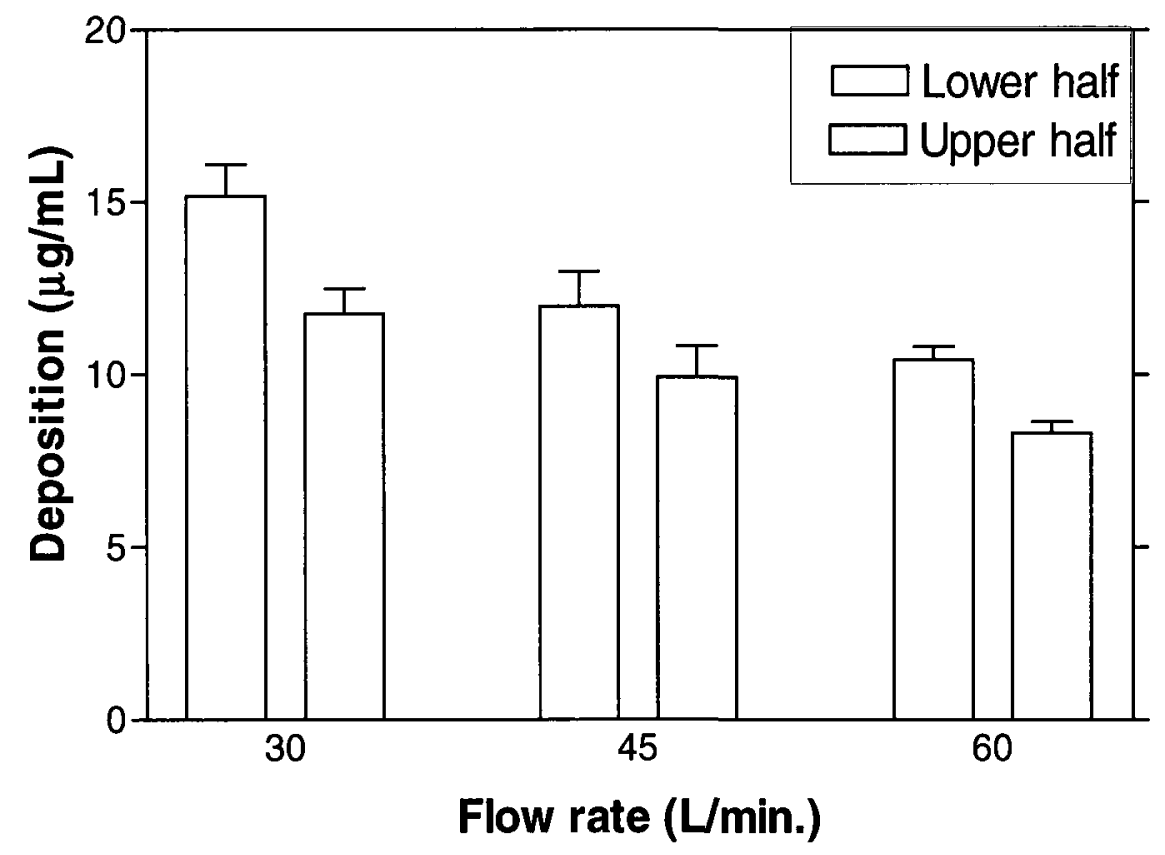

Figure 7.9 Deposition of Salbutamol Sulphate Spray in the upper and lower halves of an OptiChamber. 


\subsection{Deposition fraction of Salbutamol Sulphate in Upper and Lower}

\section{Halves of OptiChamber}

Figure 7.10 below shows the variation deposition fraction of Salbutamol Sulphate pMDI aerosol spray in the upper and lower halves of the OptiChamber with flow rate (see tables F.1-F.3, Appendix F for experimental data).

Figure 7.10 shows that the deposition fraction in both the upper and lower halves of the OptiChamber spacer decrease linearly and in parallel with each other with increase in flow rate. The deposition fraction in the upper half is lower than that of the lower half and is due to the higher drug deposition in the lower half compared with the upper half.

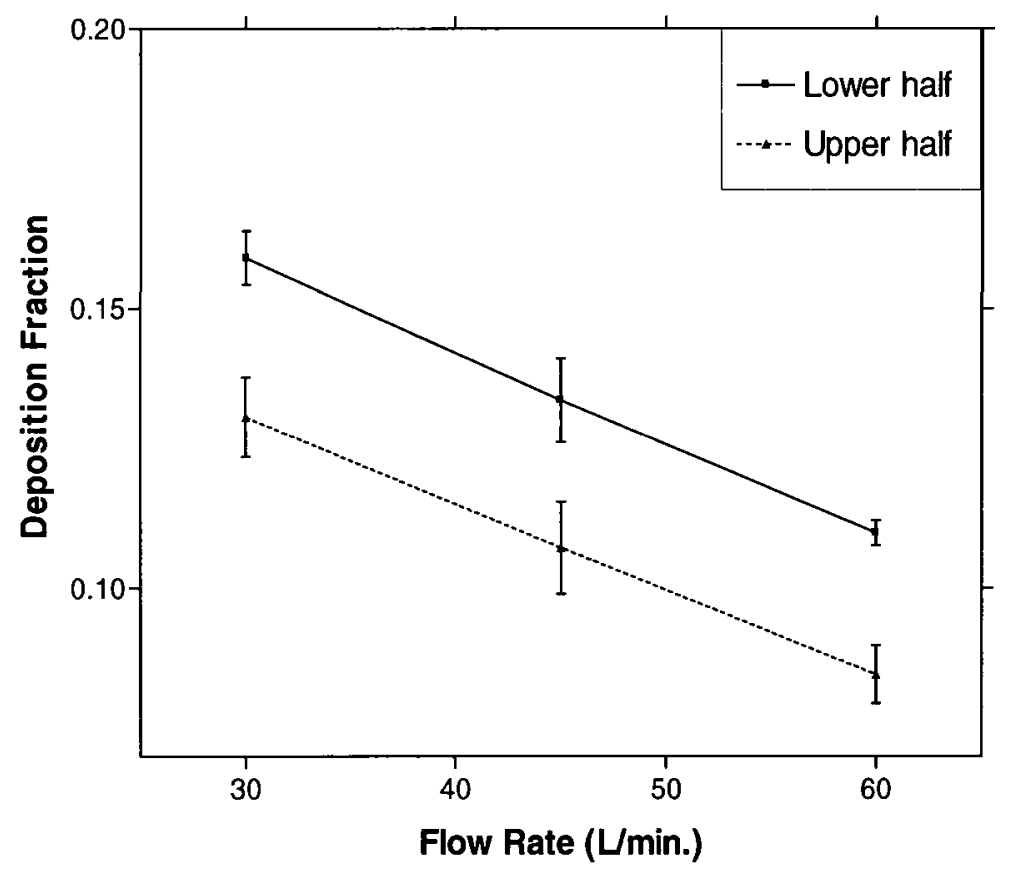

Figure 7.10 Variation of Salbutamol Sulphate deposition fraction in upper and lower halves of OptiChamber with flow rate. 


\section{Chapter 8: $\quad$ Simulations}

A numerical simulation study was carried out to determine whether drug released from a conventional MDI produced a higher drug deposition in the lower half of a conventional cylindrical spacer as that produced experimentally at steady flow rates with a possible explanation to such an outcome. According to the experimental data, a higher drug deposition occurred in the lower half of the spacer compared with the upper half. The deposition tends to decrease with increase in flow rate. Drug deposition in the spacer at a flow rate of $30 \mathrm{~L} / \mathrm{min}$ (similar to spray velocity measurements as those of Crosland, 2008) was numerically simulated using RANS (Reynolds Averaged Navier-Stokes) equations and RANS/EIM (RANS/Eddy Interaction Models).

\subsection{Background}

The volume fraction of drug particles in the air is assumed to be very small such that the effect of the particles on the flow is considered to be insignificant (Elghobashi, 1994). Therefore, the particles in the flow are assumed to have no effect on the single phase fluid motion hence, in such condition the one-way coupling approach is employed. Therefore, when using numerical simulation, the flow-field is solved without the

presence of aerosol particles. The particles are released in the calculated flow domain and tracked by the application of the Lagrangian equation of motion (Wilson, 2008). 


\subsection{Puffer-Spacer Geometry}

A simplified puffer-spacer geometry based on standard devices (pressurized metered dose inhaler: Tilade ${ }^{\circledR}$, Fisons Corporation Limited, Pickering, ON, Canada and an add-on spacer device, OptiChamber ${ }^{\circledR}$, Respironics, Cedar Grove, New Jersey, USA respectively) was adopted here. The solid walls and the unstructured grid were created using ICEM-CFD (Ansys Inc.). The puffer consisted of a canister attached to an Lshaped mouthpiece holder. The spacer has a cylindrical shape measuring $46 \mathrm{~mm}$ in internal diameter and $110 \mathrm{~mm}$ in length (excluding mouthpiece). The adopted geometry is depicted in Figures 8.1. Figure 8.2 shows the middle plane section of the medium sized spacer.

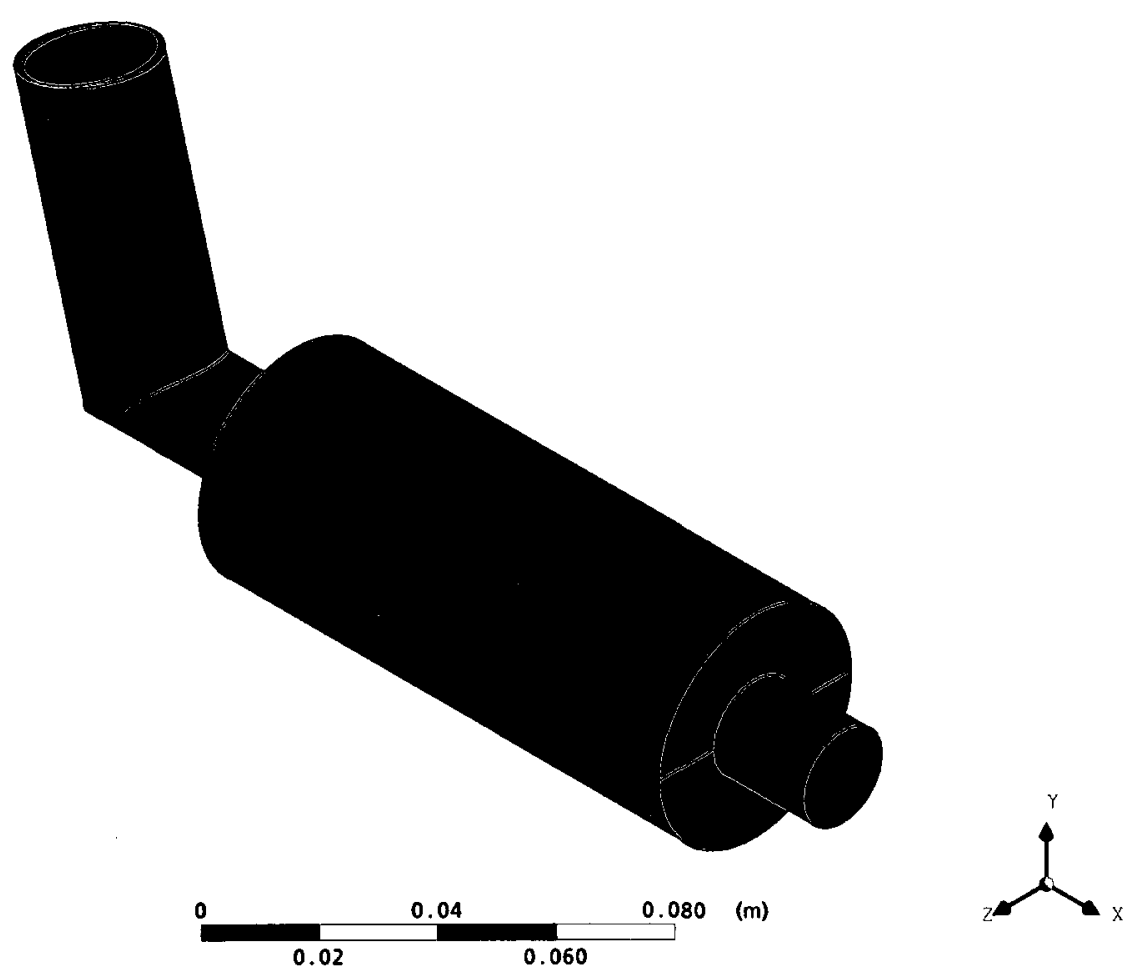

Figure 8.1 View of the puffer attached to the spacer. 


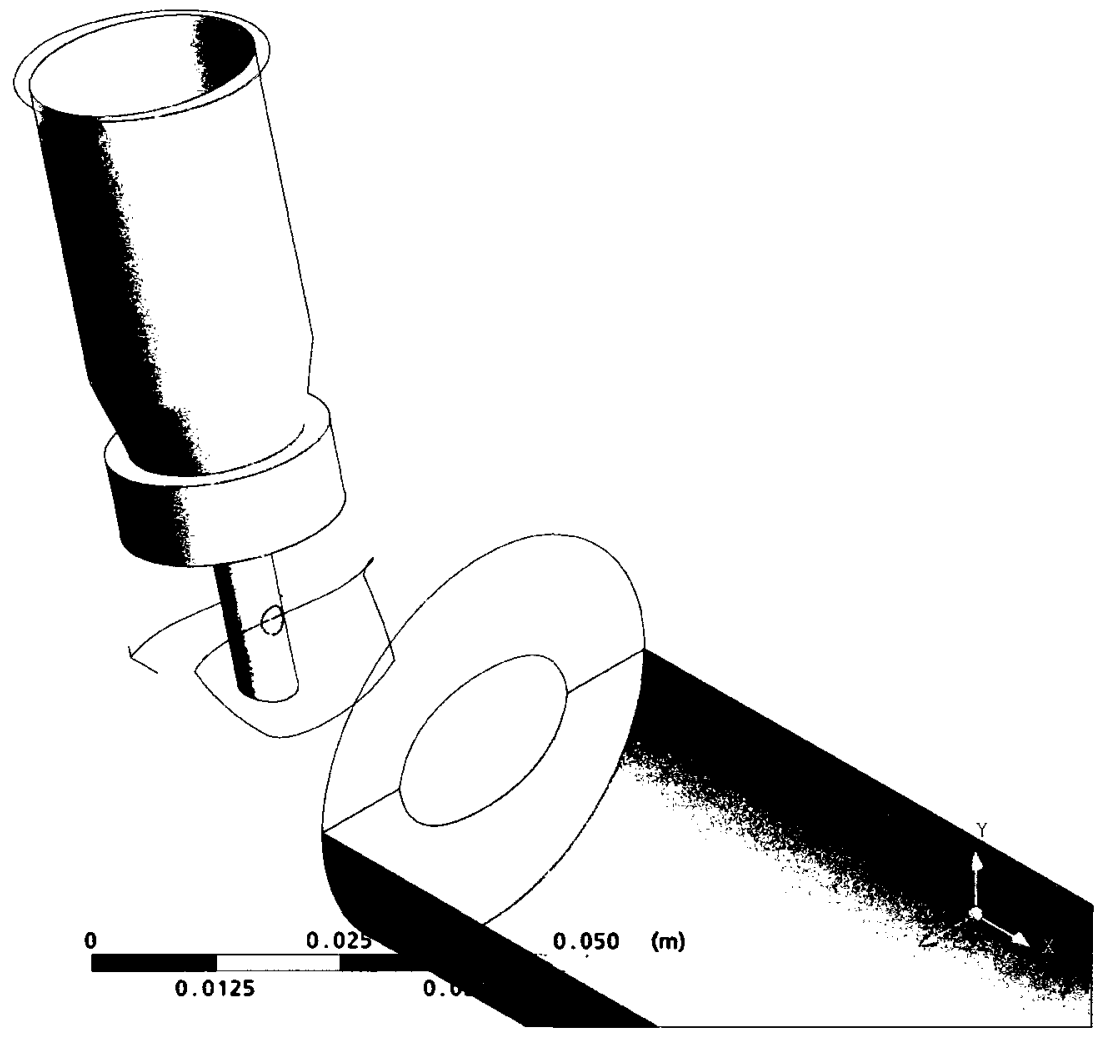

Figure 8.2 View of the canister and the lower part of the spacer.

\subsection{Governing Equations}

The Reynolds averaged Navier-Stokes (RANS) equations were solved using ANSYSCFX 11.0 (Ansys Inc.), along with a shear stress transport (SST) turbulence model (Menter, 1994), which combines the robustness and accuracy of the Wilcox k- $\omega$ turbulence model near the wall and the free-stream independence of the $k-\varepsilon$ model outside the boundary layer (Hoffman and Chiang, 2000).

The Navier-Stokes equations (momentum and continuity) are expressed by 


$$
\frac{\partial u_{i}}{\partial t}+u_{j} \frac{\partial u_{i}}{\partial x_{j}}=-\frac{\partial p}{\partial x_{i}}+\frac{\partial}{\partial x_{j}}\left(v \frac{\partial u_{i}}{\partial x_{j}}\right)
$$

and

$$
\frac{\partial u_{i}}{\partial x_{i}}=0
$$

respectively.

The instantaneous velocity can be defined by

$$
u_{i}=\overline{u_{i}}+u_{i}^{\prime}
$$

where the over-bar represents average and the prime represents a fluctuation component. Here, the subscript $i(i=1,2,3)$ relates to the $(x, y, z)$ coordinates, and $\left(u_{1}, u_{2}, u_{3}\right)$ represents the velocities $(\mathrm{u}, \mathrm{v}, \mathrm{w})$ in a Cartesian coordinate system. After averaging the Navier-Stokes equations, we have the following equation for the momentum equation

$$
\frac{\partial \bar{u}_{i}}{\partial t}+\bar{u}_{j} \frac{\partial \bar{u}_{i}}{\partial x_{j}}=-\frac{\partial \bar{p}}{\partial x_{i}}+\frac{\partial}{\partial x_{j}}\left(v \frac{\partial u_{i}}{\partial x_{j}}-\tau_{i j}\right)
$$

For the continuity equation, we have

$$
\frac{\partial \bar{u}_{i}}{\partial x_{i}}=0
$$

where $\left(\mathrm{x}_{1}, \mathrm{x}_{2}\right.$, and $\left.\mathrm{x}_{3}\right)$ represents $(\mathrm{x}, \mathrm{y}$, and $\mathrm{z})$ in a Cartesian coordinate system. Using the Boussinesq Eddy Viscosity Model (EVM), the Reynolds Stress, which appears in Eq. (4) after averaging, is approximated as

$$
\tau_{i j}=\overline{u_{i}^{\prime} u_{j}^{\prime}}=\frac{2}{3} k \delta_{i j}-v_{t}\left(\frac{\partial \overline{u_{i}}}{\partial x_{j}}+\frac{\partial \overline{u_{j}}}{\partial x_{i}}\right),
$$

where $\delta_{\mathrm{ij}}$ is the Kronecker delta. 


$$
\delta_{i j}=\left\{\begin{array}{l}
0(i \neq j) \\
1(i=j)
\end{array} .\right.
$$

The Reynolds stress term, $\tau_{\mathrm{ij}}$, has to be modelled (closure problem). Menter (1994) proposed the two-equation shear stress transport (SST) turbulent model by combining the standard k- $\varepsilon$ turbulence model (in the outer part of the boundary layer) with the Wilcox $k-\omega$ turbulence model near the wall region, along with limiters for the shear stress transport. In the original two-equation $k-\omega$ turbulence model:

$$
\begin{aligned}
& \frac{D \rho k}{D t}=\tau_{i j} \frac{\partial \overline{u_{i}}}{\partial x_{j}}-\beta^{*} \rho \omega k+\frac{\partial}{\partial x_{j}}\left[\left(\mu+\sigma_{k 1} \mu_{t}\right) \frac{\partial k}{\partial x_{j}}\right], \\
& \frac{D \rho \omega}{D t}=\frac{\gamma_{1}}{v_{t}} \tau_{i j} \frac{\partial \overline{u_{i}}}{\partial x_{j}}-\beta_{1} \rho \omega^{2}+\frac{\partial}{\partial x_{j}}\left[\left(\mu+\sigma_{\omega 1} \mu_{t}\right) \frac{\partial \omega}{\partial x_{j}}\right],
\end{aligned}
$$

The transformed $\mathrm{k}-\varepsilon$ turbulence model is:

$$
\begin{gathered}
\frac{D \rho k}{D t}=\tau_{i j} \frac{\partial \overline{u_{i}}}{\partial x_{j}}-\beta^{*} \rho \omega k+\frac{\partial}{\partial x_{j}}\left[\left(\mu+\sigma_{k 2} \mu_{t}\right) \frac{\partial k}{\partial x_{j}}\right], \\
\frac{D \rho \omega}{D t}=\frac{\gamma_{2}}{V_{t}} \tau_{i j} \frac{\partial \overline{u_{i}}}{\partial x_{j}}-\beta_{2} \rho \omega^{2}+\frac{\partial}{\partial x_{j}}\left[\left(\mu+\sigma_{\omega 2} \mu_{t}\right) \frac{\partial \omega}{\partial x_{j}}\right]+2 \rho \sigma_{\omega 2} \frac{1}{\omega} \frac{\partial k}{\partial x_{j}} \frac{\partial \omega}{\partial x_{j}} .
\end{gathered}
$$

Multiplying Equations (6) and (7) by $F_{1}$ and Equations (8) and (9) by (1- $\left.F_{1}\right)$ and adding equations together, we have the new model:

$$
\begin{gathered}
\frac{D \rho k}{D t}=\tau_{i j} \frac{\partial \overline{u_{i}}}{\partial x_{j}}-\beta^{*} \rho \omega k+\frac{\partial}{\partial x_{j}}\left[\left(\mu+\sigma_{k} \mu_{t}\right) \frac{\partial k}{\partial x_{j}}\right] \\
\frac{D \rho \omega}{D t}=\frac{\gamma}{v_{t}} \tau_{i j} \frac{\partial \overline{u_{i}}}{\partial x_{j}}-\beta \rho \omega^{2}+\frac{\partial}{\partial x_{j}}\left[\left(\mu+\sigma_{\omega} \mu_{t}\right) \frac{\partial \omega}{\partial x_{j}}\right]+2 \rho\left(1-F_{1}\right) \sigma_{\omega 2} \frac{1}{\omega} \frac{\partial k}{\partial x_{j}} \frac{\partial \omega}{\partial x_{j}}
\end{gathered}
$$


where $F_{1}$ is unity near the wall region and zero away from the surface. Let $\phi_{1}$ be any constant in the original model, $\phi_{2}$ be any constant in the transformed model ( $k-\varepsilon$ model), and $\phi$ be any constant in the new model ( $k$ - $\omega$ model), then $\Phi$ can be determined by (Hoffmann and Chiang, 2000),

$$
\phi=F_{1} \phi_{1}+\left(1-F_{1}\right) \phi_{2},
$$

The $\phi_{1}$ constants (SST inner, adjusted from original Wilcox constants) are:

$$
\begin{array}{lll}
\sigma_{k 1}=0.5, & \sigma_{\omega 1}=0.5, & \beta_{1}=0.0750, \\
\beta^{*}=0.09, & \kappa=0.41, & \gamma_{1}=\beta_{1} / \beta^{*}-\sigma_{\omega 1} \kappa^{2} / \sqrt{\beta^{*}},
\end{array}
$$

The $\phi_{2}$ constants (standard $k-\varepsilon$ model) are:

$$
\begin{aligned}
& \sigma_{k 2}=1.0, \quad \sigma_{\omega 2}=0.856, \quad \beta_{2}=0.0828, \\
& \beta^{*}=0.09, \quad \kappa=0.41, \quad \gamma_{2}=\beta_{2} / \beta^{*}-\sigma_{\omega 2} \kappa^{2} / \sqrt{\beta^{*}},
\end{aligned}
$$

The eddy viscosity is limited by the addition of two equations for $\mathrm{k}$ and $\omega$ two equation model (Menter, 1994). The new formula for the eddy viscosity thus becomes (Hoffmann and Chiang, 2000)

$$
v_{t}=\frac{a_{1} k}{\max \left(a_{1} \omega, \Omega F_{2}\right)},
$$

where $\Omega$ being the absolute value of vorticity and $F 1$ is given by:

$$
\begin{aligned}
& F_{1}=\tanh \left(\arg _{1}^{4}\right) \\
& \arg _{1}=\min \left[\max \left(\frac{\sqrt{k}}{0.09 \omega y} ; \frac{500 v}{y^{2} \omega}\right) ; \frac{4 \rho \sigma_{\omega 2} k}{C D_{k \omega} y^{2}}\right] v_{t}=\frac{a_{1} k}{\max \left(a_{1} \omega, \Omega F_{2}\right)}, \\
& C D_{k \omega}=\max \left(2 \rho \sigma_{\omega 2} \frac{1}{\omega} \frac{\partial k}{\partial x_{j}} \frac{\partial \omega}{\partial x_{j}}, 10^{-20}\right),
\end{aligned}
$$

$F_{2}$ is given by: 


$$
\begin{aligned}
& F_{2}=\tanh \left(\arg _{2}^{2}\right), \\
& \arg _{2}=\max \left(2 \frac{\sqrt{k}}{0.09 \omega y} ; \frac{500 v}{y^{2} \omega}\right),
\end{aligned}
$$

\subsection{Meshing and Boundary Conditions}

The unstructured grid has approximately 3,000,000 tetrahedral elements, with biased accumulation of prismatic elements (three layers) towards the wall. Figure 8.3 and 8.4 show a view of the midplane of the geometry and near the canister, respectively. Three grid sizes were tested $(1,000,000,2,000,000$ and 3,000,000 elements).

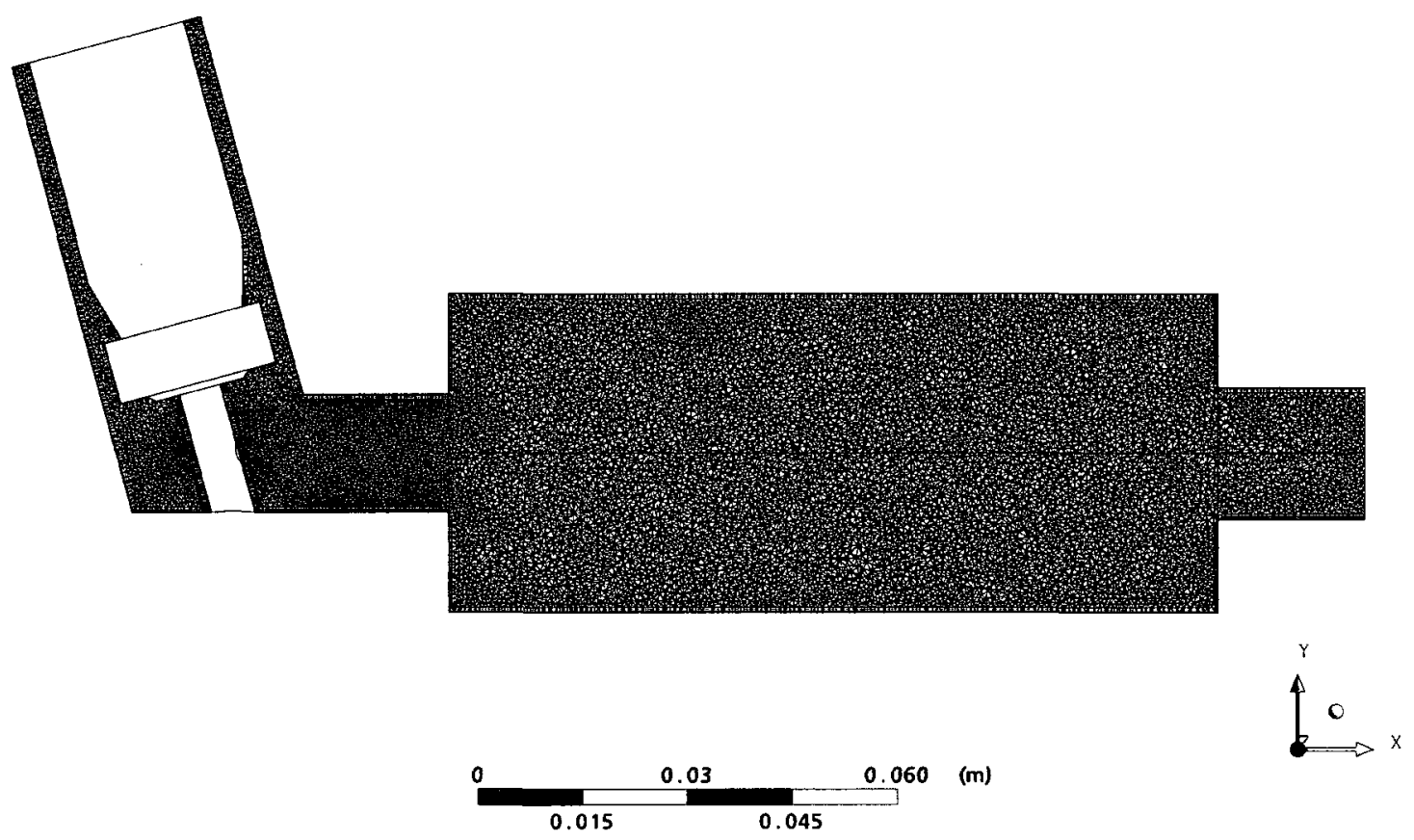

Figure 8.3: Unstructured grid at the mid-plane of the geometry. (The 3-D geometry has approximately 3,000,000 elements). 


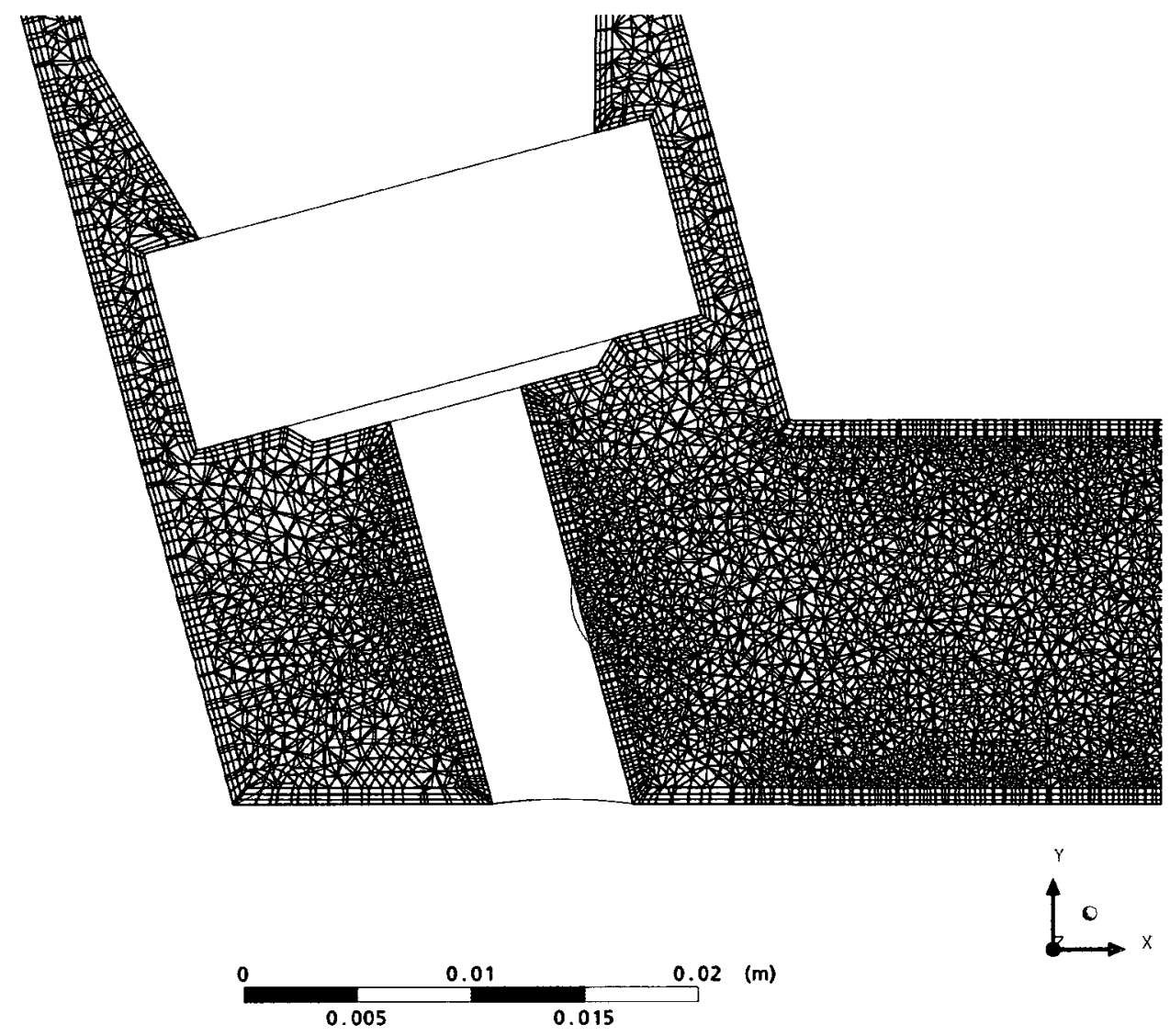

Figure 8.4: Details of the unstructured grid near the canister and nozzle. (The 3-D geometry has approximately $3,000,000$ elements).

Figure 8.5 shows the outlet of the mouthpiece with two lines being located, one horizontal and the other, vertical. Streamwise velocities are illustrated in Figures 8.6 and 8.7 at the horizontal and vertical lines at the mouthpiece outlet, respectively, for the different grid sizes used. 

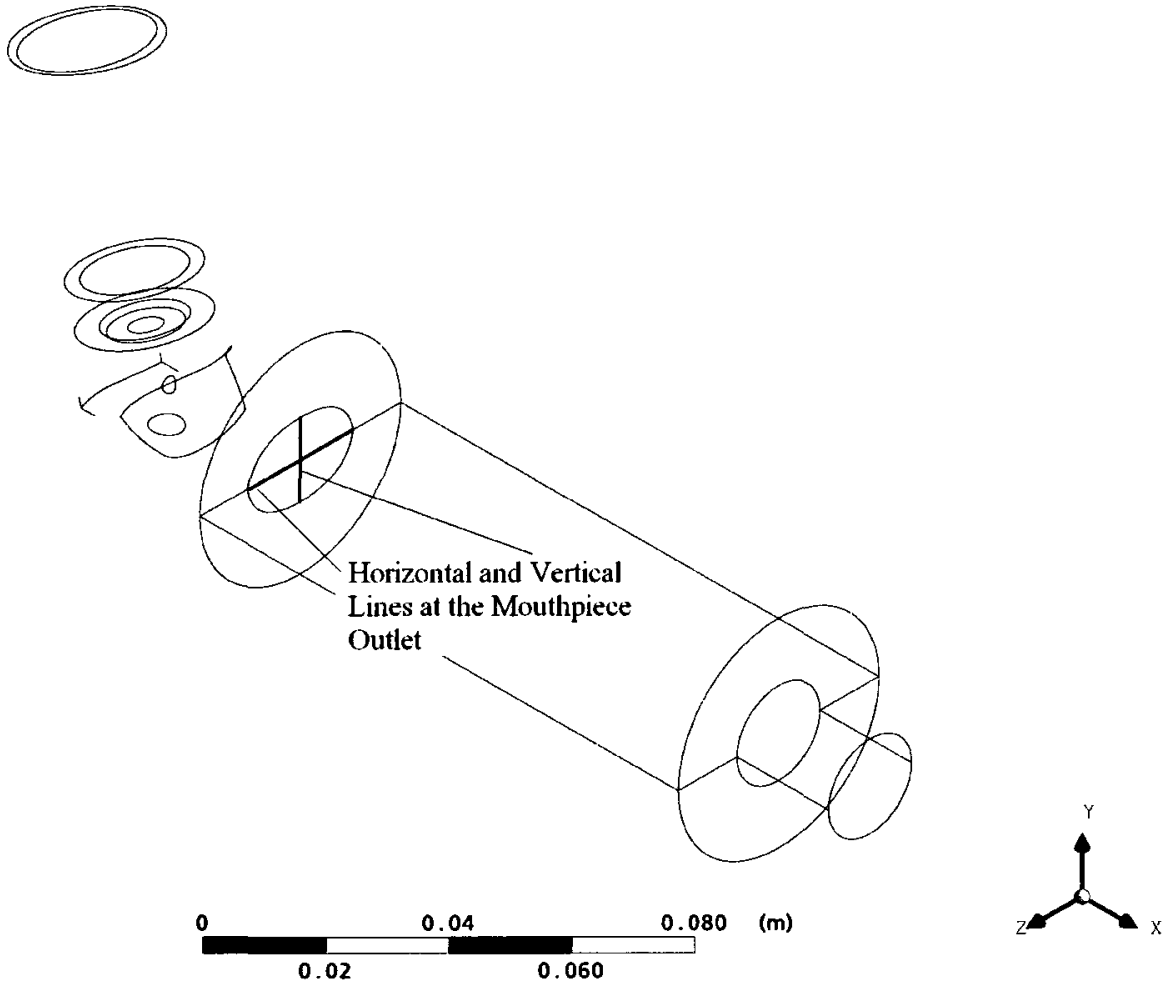

Figure 8.5: The vertical and horizontal lines at the mouthpiece outlet (inlet of the add-on spacer).

Figures 8.6 and 8.7 show that the grid size of $3,000,000$ is satisfactory for the velocity distribution at the pre-determined locations. Discretization of the equations involves the use of a modified linear profile scheme that provides second-order accuracy in most instances. The inlet conditions include a steady mean flow rate of $30 \mathrm{~L} / \mathrm{min}$, a turbulence intensity of $10 \%$ of the mean velocity together with a turbulence length scale of $10 \%$ of the inlet diameter. The average gauge-pressure is considered as zero at the outlet. 


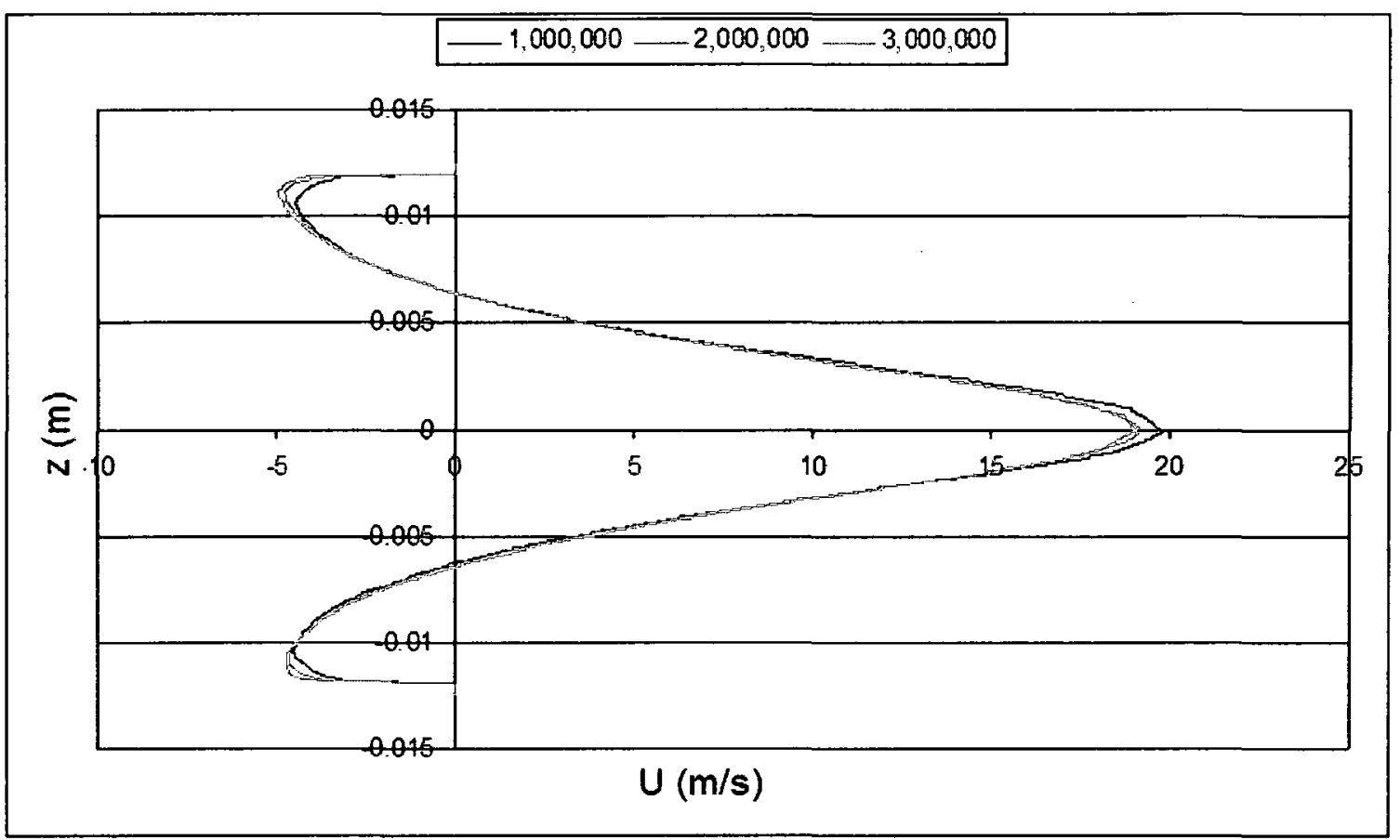

Figure 8.6: Horizontal distribution ( $\mathrm{z}$ direction) of streamwise mean velocities, $U$, for three different grid sizes.

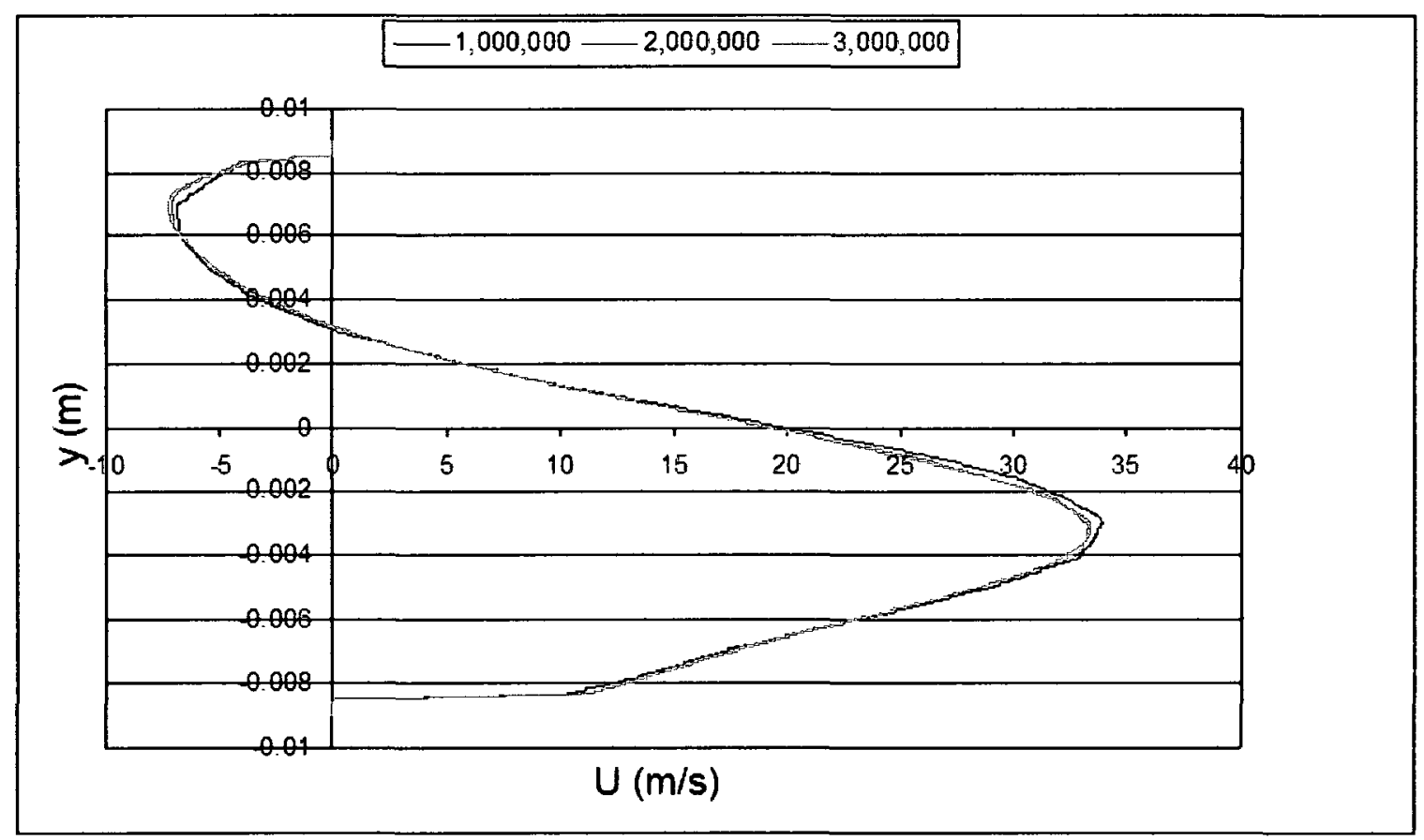

Figure 8.7: Vertical distribution (y direction) of streamwise mean velocities, $U$, for three different grid sizes. 


\subsection{Particle Equation of Motion}

For the case of small particles $(2.5-5 \mu \mathrm{m})$ with low density ratios $\rho_{\mathrm{f}} / \rho_{\mathrm{p}}<<1$ and taking into account only viscous drag and gravity, the three-dimensional Lagrangian equation that describes the motion of particles (for more details, refer to Kim et al. 1998, Mei 1994, Maxey and Riley 1983) in Cartesian coordinate system is given by

$$
\frac{d u_{p i}}{d t}=\frac{\left(u_{i}-u_{p i}\right)}{\tau_{p} / \alpha}-g_{i}\left(1-\frac{\rho_{f}}{\rho_{p}}\right),
$$

where $u_{p i}$ corresponds to the particle velocity components, $u_{i}$ to the instantaneous fluid flow components at the particle location and $\mathrm{g}_{i}$ to the gravitational components. For the case of LES $\bar{u}_{i}$ represents the filtered velocity components. The term

$$
\frac{u_{i}-v_{i}}{\tau_{p} / \alpha}
$$

represents the drag force exerted on the particle. The particle relaxation time is given by

$$
\tau_{p}=\frac{\rho_{p} d_{p}^{2}}{18 \mu_{f}}
$$

and

$$
\alpha=1+0.15 \operatorname{Re}_{p}^{0.687},
$$

In Equation (7.26), $\operatorname{Re}_{\mathrm{p}}$ represents the particle Reynolds number. Initial particle velocities are set equal to the fluid velocity. It is important to note that when RANS equations are used, the instantaneous quantities are composed of a mean part and the fluctuating component

$$
u_{i}=\bar{u}_{i}+u_{i}^{\prime},
$$


where $u_{i}$ will be substituted in Eq. (8.21).

Even though the mean flow velocities are obtained from RANS simulations, the local fluctuating velocities, $\mathrm{u}_{\mathrm{i}}$, have to be obtained though modelling (EIMs, eddy interaction models or random walk models). In the present work, RANS particle simulations without modeling (artificially assuming fluid flow fluctuation velocities to be zero) will be denoted as "mean flow tracking" and particle simulations with modeling will be referred to as "turbulent tracking". In the implementation of "turbulent tracking" in CFX 11.0 (Ansys Inc.), the solver detects if the flow is turbulent at the particle location (during the integration of the particle equation of motion) using the ratio between the turbulent eddy viscosity and the dynamic fluid viscosity. If this ratio exceeds a limit (the default is 5), "turbulent tracking" (turbulent dispersion) is used as described above, but if the ratio is below the limit, then only "mean flow tracking" is used. The standard CFX "turbulent tracking", i.e., the hybrid version having both "turbulent and mean flow tracking", is used in the present analysis. 

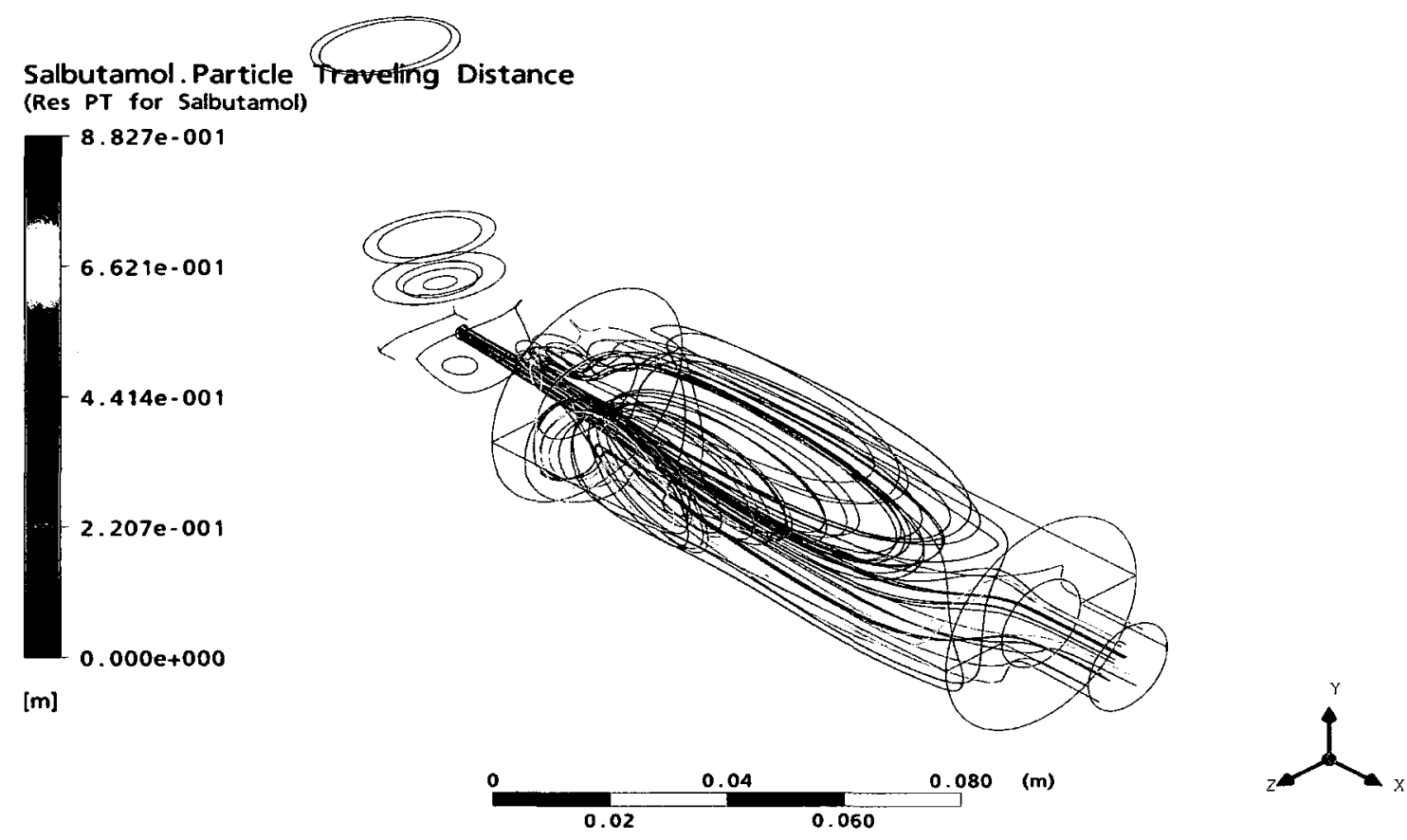

Figure 8.8 Example of meanflow tracking trajectories (20 particles carrying information of the distance travelled by the particles).

\subsection{Lagrangian Particle Tracking}

A large number of particles $(10,000)$ with a diameter of $4.1 \mu \mathrm{m}$ are released in the calculated flow domain and particle depositions are recorded. In EIMs (for details see Gosman and Ionannides, 1981, Schuen et al., 1983, Zhou and Leschziner, 1991, Wang and Stock, 1992, Graham and James, 1996, Hennick and Lightstone, 2000), one particle is allowed to interact successively with various eddies. Each eddy has a characteristic lifetime, length, and velocity scale. The end of interaction between the particle and one eddy occurs when the lifetime of the eddy is over or when the particle crosses the eddy. At this instant, a new interaction of the particle with a new eddy is started. The trajectory 
of this particular particle is obtained by solving the particle equation of motion. The length, time, and velocity a scale of fluid eddies can be obtained from:

$$
\begin{aligned}
& L_{e}=C_{\mu}^{3 / 4} \frac{k^{3 / 4}}{\varepsilon}, \\
& \tau_{e}=\frac{L_{e}}{(2 k / 3)^{1 / 2}}, \\
& u_{e}=\left(\frac{2 k}{3}\right)^{1 / 2},
\end{aligned}
$$

where $\mathrm{C}_{\mu}=0.09, k$ is the turbulence kinetic energy and $\varepsilon$ is the dissipation. For the simple EIMs, the local fluctuating velocities at the beginning of one interaction are obtained by multiplying the root-mean square (RMS) fluid fluctuating velocity by random numbers $\left(\mathrm{N}_{1}, \mathrm{~N}_{2}, \mathrm{~N}_{3}\right)$ generated from a Gaussian probability density function of zero mean and unity standard deviation at the start of eddy-particle interaction.

$$
u_{i}^{\prime}=N_{i}(2 k / 3)^{0.5}
$$

\subsection{Fluid Flow and Particle Deposition Results}

Figure 8.9 and 8.10 show the magnitude of mean velocities and the turbulence kinetic energy at the midplane of the add-on spacer, respectively. The nozzle jet is clearly pointed downwards due to the inlet condition (approximately 6 degree deflection angle, based on Crosland, 2008) as expected. There are also high levels of turbulence kinetic energy surrounding the nozzle jet and extending towards the lower half and up to the

middle cross section (front half) of the add-on spacer. Both the deflection and the higher 
levels of turbulence kinetic energy at the lower half / front half of the add-on spacer may produce more deposition in this region.

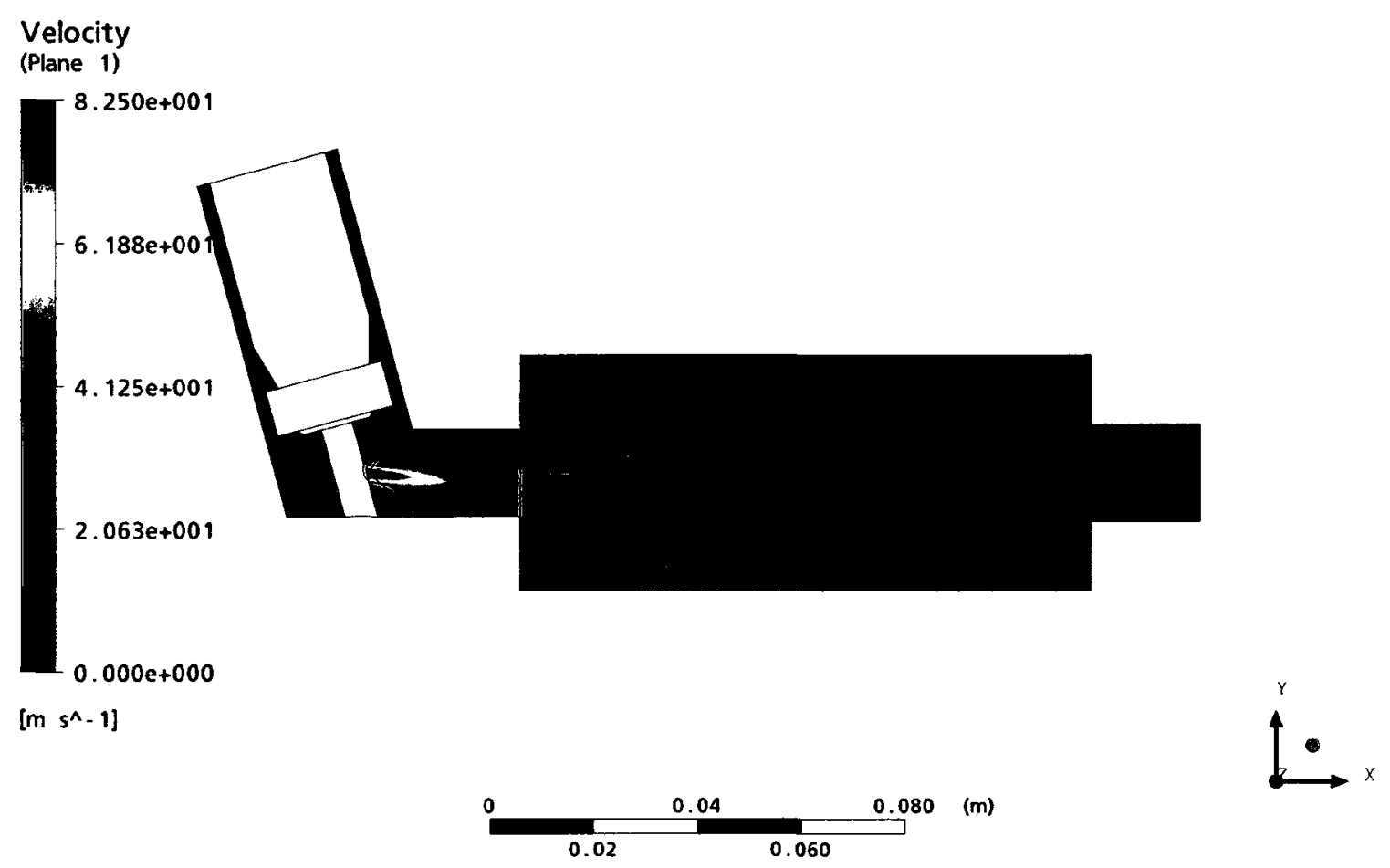

Figure 8.9: Magnitude of mean velocities at the midplane of the geometry. 


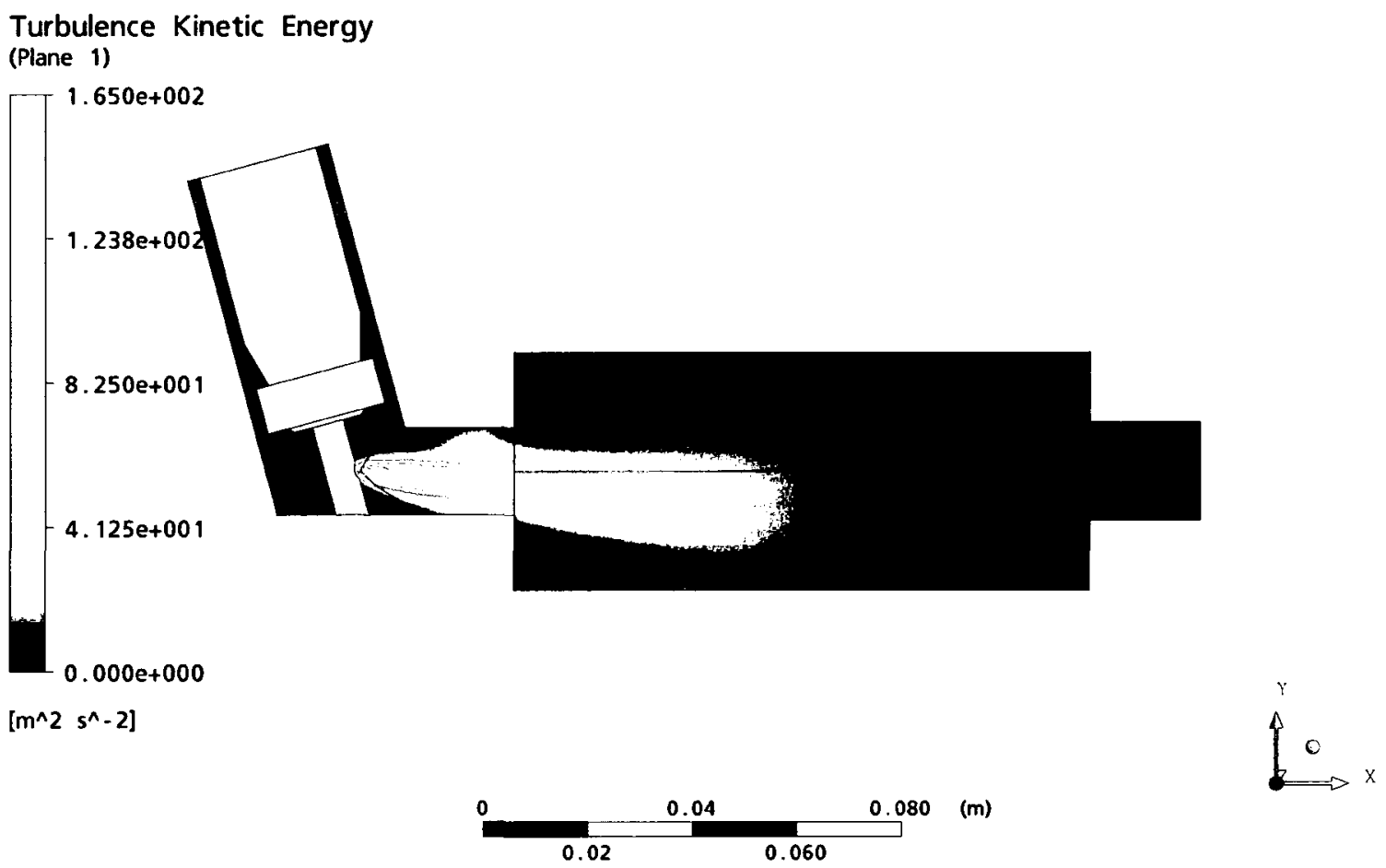

Figure 8.10: Turbulence kinetic energy at the midplane of the geometry.

The magnitude of mean velocities at the mouthpiece outlet cross section is shown in Figure 8.11 , superimposed by the $2-\mathrm{D}$ vector plot which is tangential and therefore, excludes the streamwise velocity component. A downward deflection of the flow causes a partial impingement of the lower half of the mouthpiece. Figure 8.11 also shows that the center of the jet is below that of the mouthpiece. 


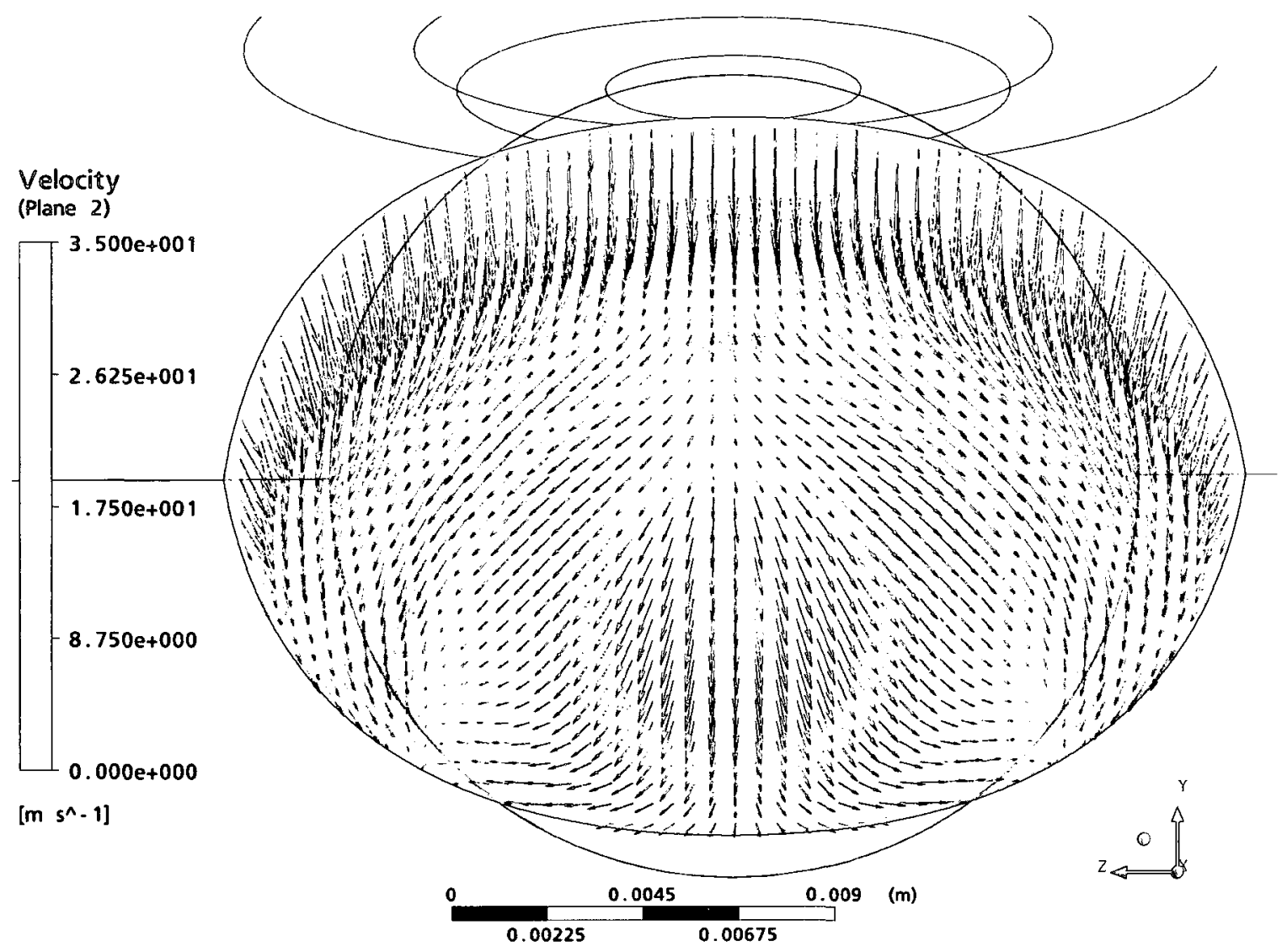

Figure 8.11: 2-D vector plot superimposed to the magnitude of mean velocities at the mouthpiece outlet. 
Ten thousand $(10,000)$ particles of $4.1 \mu \mathrm{m}$ diameter were released in the simulation and the particle deposition in the add-on spacer was calculated in the form of spatial $x-y$ distribution as shown in Figure 8.12.

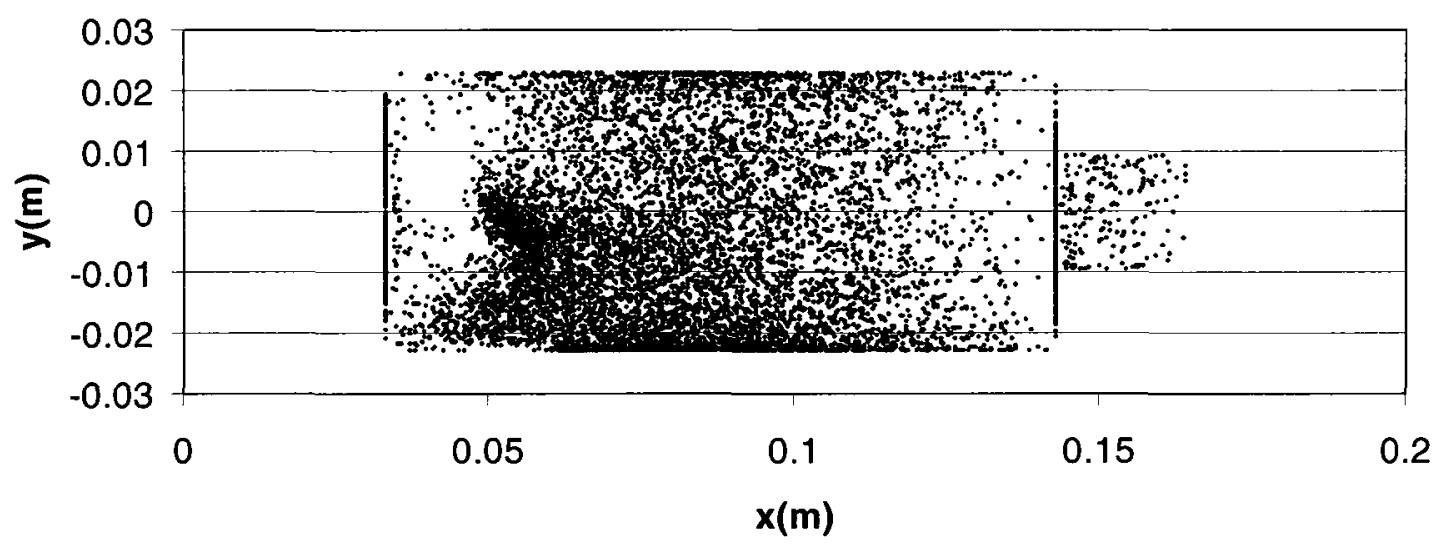

Figure 8.12: Particle deposition distribution (10,000 particles).

The calculated results show that $57.6 \%$ of the particles deposited in the lower half of the add-on spacer, $30.1 \%$ deposited in the upper half while the remainder $12.3 \%$ left the domain through the outlet. The lower half of the add-on spacer had more particle deposition in the front half directly associated with the nozzle jet deflection and higher levels of turbulence kinetic energy distribution. 


\section{Chapter 9: Conclusions}

The following conclusions can be inferred from the present work:

1. Based on the method by Habib et al., (2005)., an assaying procedure was developed and used in the measurement of aerosol medication (Salbutamol Sulphate) deposition in add-on spacers attached to pressurized metered dose inhalers (pMDIs) with a secondary flow of air (simulating steady inhalation).

2. By performing deposition experiments in add-on spacers cut longitudinally in half, it was observed that two thirds of the medication will deposit in the lower half of the spacer (OptiChamber, $30 \mathrm{~L} / \mathrm{min}$ ). To the author's knowledge, this fact was never reported in the open literature. Such higher deposition in the lower half may be related to the downward deflection of the pMDI spray angle during actuation as has been noted by Crosland (2008).

3. Salbutamol Sulphate deposition in the relatively large volume OptiChamber was less than that of the relatively smaller volume OptiHaler and PocketChamber, indicating higher drug availability for inhalation in the large volume add-on spacer.

4. An increase in the flow rate resulted in lesser Salbutamol Sulphate deposition in all the add-on spacer devices used. Increased flow rate caused the breakdown of large aerosol droplets by aerodynamic forces resulting in smaller particles that are carried further with the flow.

5. Numerical simulation by means of RANS and RANS/EIM models together with the SST turbulence model and using a fixed $6^{\circ}$ downward deflection of the spray angle at 30 $\mathrm{L} / \mathrm{min}$ flow rate produced a drug deposition in the lower half twice as that in the upper 
half, indicating a significant influence of the deflection angle on the non-symmetrical deposition of medication in the add-on spacer.

Therefore, a reduction in oropharyngeal deposition requires not only the redesign of add-on spacer devices but also the pressurized metered dose inhaler device. New addon spacer devices should take into consideration the dynamic spray angle (variation of spray angle in time as reported by Crosland, 2008) which occurs with the actuation of the pMDI device at the same time a relative increase in the flow rate with large volume addon spacer may provide smaller drug particles for inhalation, and a lesser oroparyngeal impaction.

\section{Future Work}

Further numerical simulations may be carried out using flow rates of 45 and $60 \mathrm{~L} / \mathrm{min}$ together with a dynamic deflection of spray angle. Experimental studies may be carried out to investigate the drug deposition at different cross sections in the upper and lower halves of the OptiChamber at different flow rates. 


\section{References}

AARC Clinical Practice Guideline (1992) Selection of aerosol delivery device. American Association for Respiratory Care. Respir Care, 37(8):891-897.

Agertoft, L., Pedersen, S. (1994) Influence of spacer device on drug delivery to young children with asthma. Arch Dis Child, 71:217-9.

Anderson, P.J., Wilson, J.D., Hiller, F.C. (1990) Respiratory tract deposition of ultrafine particles in subjects with obstructive or restrictive lung disease. Chest, 97(5):1115-1120.

Asmus, M.J., Liang, J., Coowanitwong, I., Hochhaus, G. (2004) In vitro performance characteristics of valved holding chamber and spacer devices with a Fluticasone metereddose inhaler. Pharmacotherapy, 24(2):159-166.

Barnes, P.J., Basbaum, C.B., Nadel, J.A. (1983) Autoradiographic localization of autonomic receptors in airway smooth muscle: marked differences between large and small airways. Am Rev Respir Dis, 127(6): 758-762.

Barry, P.W., O'Callaghan, C. (1994) Multiple actuations of salbutamol metered dose inhaler into a spacer device reduce the amount of drug recovered in the respirable range. Eur Respir J, 7:1707-9.

Barry, P.W., O'Callaghan, C. (1995 A) The optimum size and shape of spacer devices for inhalation therapy. Journal of Aerosol Medicine-Deposition Clearance and Effects in the Lung, 8(3), 303-305.

Barry, P.W., O'Callaghan, C. (1995B) The effect of delay, multiple actuations and spacer charge on the in vitro delivery of budesonide from the Nebuhaler. Br J Clin Pharmacol, 40:76-8.

Barry, P.W., O'Callaghan, C. (1995C) Video analysis of the aerosol cloud produced by metered dose inhalers. Pharm Sci, 1:119-21.

Barry, P.W., O'Callaghan, C. (1996) Inhalational drug delivery from seven different spacer devices. Thorax, 51:835-40.

Barry, P.W., O'Callaghan, C. (1997) In vitro comparison of the amount of salbutamol available for inhalation from different formulations used with different spacer devices. Eur Respir J, 10: 1345-1348.

Barry, P.W., Robertson, C., O'Callaghan, C. (1993) Optimum use of a spacer device. Arch Dis Child, 69:693-4. 
BNF: British National Formulary (1999) $37^{\text {th }}$ Edition, pp.129. British Medical Association, United Kingdom

Bisgaard, H., Anhøj, J., Klug, B., Berg, E. (1995) A non-electrostatic spacer for aerosol delivery. Arch Dis Child, 73:226-30.

Borgström, L., Nilsson, M. (1990) A method for determination of the absolute pulmonary bioavailability of inhaled drugs: terbutaline. Pharm Res., 7:1068-1070.

Brain, J.D., Valberg, P.A. (1979) Deposition of aerosols in the respiratory tract (review). Am Rev Respir Dis, 120(6):1325-1373.

British Pharmacopoeia (2007) British Pharmacopoeia Commission. The Stationery Office, United Kingdom.

Brown, R.A. Jr, Schanker, L.S. (1983) Absorption of aerosolized drugs from the rat lung. Drug Metab Dispos, 11(4):355-360.

Byron, P., Phillips, E. (1990) Absorption, clearance and dissolution on the lung respiratory drug delivery. Boca Raton FL: CRC, 107-141.

Byron, P. (1976) Some future perspectives for unit dose inhalation aerosols. Drug Dev Ind Pharm, 12:993-1015.

Byron, P.R. (1986) Prediction of drug residence times in regions of the human respiratory tract following aerosol inhalation. J Pharm Sci, 75(5):433-438.

Byron, P. (1987) Pulmonary targeting with aerosols. Pharm Tech, 11: 42-56.

Byron, P.R., Patton, J.S. (1994) Drug delivery via the respiratory tract. J Aerosol Med, $7(1): 49-75$.

Byron, P., Phillips, E. (1990) Absorption, clearance and dissolution on the lung respiratory drug delivery. Boca Raton FL: CRC, 107-141.

Carpenter, M.J., Miller, R.F. (1993). Aerosols for therapy and diagnosis. Eur J Nucl Med, 20(12):1201-1213.

Carpenter, R.L. (1999) Aerosol deposition modeling using ACSL. Drug Chem Tox, 22(1):73-90.

Cates, C.J. (1999) Holding chambers versus nebulizers for beta-agonist treatment of acute asthma. The Cochrane Database or Systematic Reviews.

Chapman, K.R. (1995) The choice of inhalers in adults and children over six. J Aerosol Med, 8(suppl 2):S27-36. 
Chrystyn, H. (1997) Is total particle dose more important than particle distribution? Resp Med., 91(Suppl A):17-19.

Chrystyn, H. (2000) Methods to determine lung distribution of inhaled drugs - could gamma scintigraphy be the gold standard? Br J Clin Pharmacol, 49(6): 525-528.

Clark, A.R. (1991) Metered Atomization for respiratory drug delivery. PhD thesis. Loughborough University of Technology. Loughborough, UK.

Clark, T.J. (1972) Effect of beclomethasone dipropionate delivered by aerosol in patients with asthma. Lancet, 1(7765):1361-1364.

Clarke, D.J., Lipworth, B.J. (1995) Lung bioavailability of salbutamol from a spacer device comparing single versus multiple actuations, delayed inhalation and antistatic treated spacer. Thorax, 50(suppl 2):A79.

Clarke, S.W., Newman, S.P. (1984) Therapeutic aerosols. 2. Drugs available by the inhaled route. Thorax, 39(1):1-7.

Crosland, B.M., Johnson, M.R., Matida, E.A. (2009) Characterization of the spray velocities from a pressurized metered-dose inhaler. Journal of Aerosol Medicine and Pulmonary Drug Delivery, 1(22):1-13.

Crompton, G.K. (1982) Problems patients have using pressurized aerosol inhalers. Eur J Respir Dis, 119:101-4.

Dalby, R.N., Tiano, S.L., Hickey, A.J. (1996) Medical devices for the delivery of therapeutic aerosols to the lungs. In: Hickey AJ, editor. Inhalation aerosols: physical and biological basis for therapy. New York: Marcel Decker, 441-473.

Davies, C.N. (1966) Deposition from moving aerosols. In Aerosol Science, edited by C. N. Davies, p. 408. Academic Press, New York.

Dekker, E. (1961) Transition between laminar and turbulent flow in human trachea. Journal of Applied Physiology, 16, 1060.

Derendorf, H., Huchhaus, G., Meibohm, B., Möllmann, H., Barth, J. (1998) Pharmacokinetics and pharmacodynamics of inhaled corticosteroids. J Allergy Clin Immunol. 101:S440-S446.

Dhand, R., Fink, J. (1999). Dry powder inhalers (review). Respir Care, 44(8):940-951.

Dolovich, M., Rheim, R., Rashid, F., Coates, G., Hill, M., Bowen, B. (1996) Measurement of the particle size and dosing characteristics of a radiolabelled albuterolsulphate lactose blend used in the SPIROS dry powder inhaler. In: Dalby, R.N., Byron, 
P., Farr, S.Y., editors. Respiratory Drug Delivery V. Buffalo Grove: Interpharm Press, 332-335.

Ebdon, L (1982). An Introduction to Atomic Absorption Spectroscopy: A Self-Teaching Approach. London: Heyden.

Effros, R.M., Mason, G.R. (1983) Measurements of pulmonary epithelial permeability in vivo. Am Rev Respir Dis, 127(5 Pt 2):S59-S65.

Elgohbashi, S. (1994) On predictingparticle-laden turbulent flows. Applied Scientific Research, 52, 309-329.

Engel, T., Heinig, J.H., Madsen, F., Nikander, K. (1990) Peak inspiratory flow and inspiratory vital capacity of patients with asthma measured with and without a new drypowder inhaler device (Turbuhaler). Eur Respir J, 3(9):1037-1041.

Everard, M.L, Clark, A.R., Milner, A.D. (1992) Drug delivery from holding chambers with attached facemask. Arch Dis Child, 67:580-5.

Fink, J.B. (2000) Metered-Dose Inhalers, Dry Powder Inhalers, and Transitions. Respir Care, 45(6):623- 635 .

Fink, J.B., Tobin, M.J., Dhand, R. (1999). Bronchodilator therapy in mechanically ventilated patients. Respir Care, 44[1]:3-69.

Finlay, W.H. (2001) The Mechanics of Inhaled Pharmaceutical Aerosols, Academic Press.

Finlay, W.H., Stapleton, K.W., Zuberbuhler, P. (1997) Errors in regional lung deposition predictions of nebulized salbutamol sulphate due to neglect or partial inclusion of hygroscopic effects. Int J Pharm, 149:63-72.

Fletcher, G.E (1975) Factore affecting the atomization of saturated liquids. PhD thesis. Loughborough University of Technology. Loughborough, UK.

Foss, S.A., Keppel, J.W. (1999) In Vitro Testing of MDI Spacers: A Technique for Measuring Respirable Dose Output with Actuation In-Phase or Out-of-Phase with Inhalation. Respir Care, Vol 44 number 12 pp. $1474-1485$

Fuchs, N.A. (1964) The Mechanics of Aerosols. Pergamon Press, New York.

Ganderton, D. (1992) The generation of respirable clouds from coarse powder aggregates. J Biopharm Sci, 3:101-105. 
Gonda, I. (1990) Aerosols for delivery of therapeutic and diagnostic agents to the respiratory tract. Crit Rev Ther Drug Carrier Syst, 6(4): 273-313.

Gonda, I. (1988) Drugs administered directly into the respiratory tract: modeling of the duration of effective drug levels. J Pharm Sci, 77(4):340-346.

Goseman, A.D., Ioannides, E. (1981) Aspects of computer simulations of liquid-fueled compusters, American Institute of Aeronautics and Astronautics, $19^{\text {th }}$ Aerospace Sciences meeting, St. Louis. MO, Jan. 12-15.

Graham, D.I., James, P.W/ (1996) Turbulent dispersion of particles using eddy interaction models. International Journal of Multiphase Flow, 22(1), 157-175.

Habib, I.H.I., Hassouna, M.E.M., Zaki, G. (2005) Simultaneous spectrophotometeric determination of salbutamol and bromhexine in tablets. Microanalysis Chem. Lab., Applied Organic Chem. Department, National Research Centre, Cairo, Egypt.

Hakkinen, A.M., Uusi-Heikkila, H., Jarvinen, M., Saali, K., Karhumaki, L. (1999) The effect of breathing frequency on deposition of drug aerosol using an inhalationsynchronized dosimeter in healthy adults. Clin Physiol, 19(3):269-274.

Hardesty, J.H. (2008) Spectrophotometry and the Beer-Lambert Law: An Important Analytical Technique in Chemistry. Collin County Community College, Dept. of Chemistry.

Haslett, C., Chivers, E.R., Hunter, J., ABoon, N.A. (1999) Davidson's Principle and Practice of Medicine, $8^{\text {th }}$ ed, Churchill Livingstone, pp 304-305.

Health Care Use and Mortality (2000-2001) Asthma Prevalence, National Center for Health Statistics, Centers for Disease Control and Prevention. .

Hennick, E. A., and Lightstone, M. F. (2000) A comparison of stochastic separated flow models for particle dispersion in turbulent flows. Energy \& Fuels, 14, 95-103.

Hill, L.S., Slater, A.L. (1998) A comparison of the performance of two modern multidose dry powder asthma inhalers. Respir Med, 92(1):105- 110.

Hindle, M., Chrystyn, H. (1992) Determination of the relative bioavailability of salbutamol to the lung following inhalation. Br J Clin Pharmacol. 34:311-315.

Hindle, M., Chrystyn, H. (1994) Relative bioavailability of salbutamol to the lung following inhalation using metered dose inhalation methods and spacer devices. Thorax, 49:549-53.

Hoffmann, A., Chiang, S.T. (2000) Computational Fluid Dynamics. Volume III. Fourth Edition Engineering Education System. Wichita. 
Jillavenkatesa, A., Dapkunas, S. J., Lin-Sien L. (2001) Particle Size Characterization, NIST Special Publication 960-1.

Johnson, M. (1996) Pharmacodynamics and pharmacokinetics of inhaled glucocorticoids. Allergy Clin Immunol, 97(1 Pt 2):169-177.

Juntunen-Backman, K., Kajosaari, M., Laurikainen, K., Malinen, A., Kaila, M., Mustala, L., Kaski, U., Linna, O., Marenk, M., Toivanen, P. (2002) Comparison of Easyhaler(R) Metered-Dose, Dry Powder Inhaler and a Pressurised Metered-Dose Inhaler plus Spacer in the Treatment of Asthma in Children. Clinical Drug Investigation. 22(12):827-835.

Kenyon, C.J., Thorrson, L., Borgstrom, L., Newman, S.P. (1996) Reduction in lung deposition of budesonide pressurised aerosol resulting from static charge in plastic spacer devices. In: Drug delivery to the lungs VII. Bristol: The Aerosol Society, 17-8.

Kim, C.S., Trujillo, D., Sackner, M.A. (1985) Size aspects of metered-dose inhaler aerosols. Am Rev Respir Dis.

Kim, I., Elgobashi, S., Sirignano, W. A. (1998) On the equation for spherical-particle motion: effect of Reynolds and acceleration numbers. Journal of Fluid Mechanics, 367, 221-253.

Katzung, B.G. (1989) Basic and Clinical Pharmacology, $4^{\text {th }}$ Edition, Appleton and Lange Publications, San Mateo, California.

Lavorini, F., Fontana, G.A., Pistoles, M. (2006) Drug Delivery to the Lungs - Effects of Spacer Devices, European Respiratory Disease.

Lawford, P., McKenzie, D. (1983). Pressurized aerosol inhaler technique: how important are inhalation from residual volume, inspiratory flow rate and the time interval between puffs? Br J Dis Chest, 77: 276-281.

Lippmann, M. (1977) Regional deposition of particles in the human respiratory tract in Handbook of Physiology Section 9, Reactions to Environmental Agents, Bethesda, Md, American Physiology Society: 213-32

Lippmann, M., Schlesinger, R.B. (1984) Interspecies comparisons of particle deposition and mucociliary clearance in tracheobronchial airways. J Toxicol Environ Health, 13(23):441-469.

Lourenco, R., Cotromanes, E. (1982) Clinical aerosols II. Therapeutic aerosols. Arch Int Med, 142(13):2299-2308.

Martin, D., Jacobi, W. (1972) Diffusion deposition of small-sized particles in the bronchial tree. Health Physics, 23, 23. 
Maxey, M. R., Riley, J. J. (1983) Equation of motion for a small rigid sphere in a nonuniform 7ow. Physics of Fluids, 26(4), 883-889.

Mei, R. (1996) Velocity fidelity of flow tracer particles. Experiments in Fluids, 22, 1-13.

Melchor, R., Biddiscomb, M.F., Mak, V.H.F., Spiro, S.G. (1993) Lung deposition patterns of directly labelled salbutamol in normal subjects and in patients with reversible airflow obstruction. Thorax., 48:289-299.

Menter, F.R. (1994) Two-equation Eddy-viscousity turbulence models for engineering applications. AIAA Journal. Vol. 32 Number 8, pp 1598-1605.

MindFiesta $^{\mathrm{TM}}$ (2009) http://www.mindfiesta.com/respiration

Mitchell, J.P., Nagel, M.W., Rau, J.L. (1999) Performance of large-volume versus small volume holding chambers with chlorofluorocarbon-albuterol and hydrofluoroalkanealbuterol sulphate. Respir Care, 44(1):38-44.

MMWR (2003) Self-reported asthma prevalence and control among adults-United States, 2001. MMWR, 52:357-60.

Morbidity and Mortality. (2002) Chart book on cardiovascular, lung, and blood diseases. National Heart, Lung, and Blood Institute, National Institutes of Health.

Moron, F., Anderson, J. (1980) Fraction of dose exhaled after administration of pressurized inhalation aerosols. mtj Pharmaceutics, 6:295-300.

National Cancer Institute (2009)

http://training.seer.cancer.gov/anatomy/respiratory/passages/

Nelsin, H.S., Loffert, D.T. (1994) Comparison of the bronchodilator response to albuterol response administered by the AeroChamber, the OptiChamber, or by the Metered Dose Inhaler Alone. Annals of Allergy, Vol. 2, Number 4.

Neville, A., Palmer, J.B., Gaddie, J., May, C.S., Palmer, K.N., Murchison, L.E. (1977) Metabolic effects of salbutamol: comparison of aerosol and intravenous administration. Br Med J, 1(6058):413-414.

Newhouse, M.T., Dolovich, M. (1991) Aerosol therapy in children: basic mechanisms of pediatric respiratory disease: cellular and integrative. New York: BC Decker.

Newman, S. (1982) The correct use of inhalers. In: Clark, T., ed. Steroids in Asthma. Auckland, Adis Press, pp. 210-216. 
Newman, S.P. (1985) Aerosol deposition considerations in inhalation therapy. Chest, 88(suppl):152-60S.

Newman, S.P. (1991) Aerosol generators and delivery systems. Respir Care, 36(9):939951.

Newman, S., Clarke, S. (1985) Aerosols in medicine: principles, diagnosis and therapy. In: Moren, F., Newhouse, M., Dolovich, M. editors. Aerosol in therapy. Amsterdam: Elsevier.

Newman, S.P., Newhouse, M.T. (.1996) Effect of add-on devices for aerosol rug delivery: deposition studies and clinical aspects. J Aerosol Med, 9(1):55-70.

Newman, S.P., Pavia, D., Moron, F., Sheahan, N.F., Clarke, S.W. (1981) Deposition of pressurized aerosols in the human respiratory tract. Thorax, 52-5.

Newman, S., Wilding, I. (1996) "The importance of gamma scintigraphy in pharmaceutical development," J. Pharm. Med., Vol. 6, pp 21-33.

Newnham, D.M., McDevitt, D.G., Lipworth, B.J. (1993) Comparison of the extrapulmonary $\beta_{2}$-adrenoceptor responses and pharmacokinetics of salbutamol given by standard metered dose inhaler and modified actuator devices. $\mathrm{Br} \mathrm{J}$ Clin Pharmacol. , $36: 445-450$.

O'Callaghan, C., Barry, P.W. (1997) Spacer devices in the treatment of asthma. BMJ, 314:1061 (12 April).

O'Callaghan, C., Cant, M., Robertson, C. (1994) Delivery of beclomethasone diproprionate from a spacer device: what dose is available for inhalation? Thorax, 49:961-4.

O'Donohue, W.J. Jr. (1996) Guidelines for the use of nebulizers in the home and at domiciliary sites: report of a consensus conference. NAMDRC Consensus Group. Chest, 109(3):814-820.

Olson, D. E., Sudlow, M. F., Horsfield, K., Filley, G. F. (1973) Convective patterns of flow during inspiration. Archives of Internal Medicine, 131, 51.

Owen, P. R. (1969). Turbulent flow and particle deposition in the trachea. In Circulatory and Respiratory Mass Transport: A Ciba Foundation Symposium, edited by Wolstenholme, G.E.W., Knight, J. p. 236. Churchill, London. Little, Brown, Boston.

Patton, J., Platz, R. (1992) Routes of delivery: case studies pulmonary delivery of peptides and proteins for systemic action. Adv Drug Deliv Rev, 8:179-196. 
Pengilly, R.N., Keiner, J.A. (1977) The influence of some formulation variables and valve/actuator designs on the particle size distribution of aerosol sprays. J Soc Cosmet Chem, 28:641-50.

Person, A., Mintz, M.L. (2006) Disorders of the Respiratory Tract, Humana Press, pp. 11-15.

Rajkumari, N.J., Byron, P.R., Dalby, R.N. (1995) Testing of dry powder aerosol formulations in different environmental conditions. Int J Pharmacol., 113:123-130.

Rance, R.W. (1974). Studies of the factors controlling the action of hair sprays: III. The influence of particle velocity and diameter on the capture of particles by arrays of hair fibers. J Soc Cosmet Chem, 25:545-61.

Rees, P.J., Clark, T.J., Morén, F. (1982). The importance of particle size in responses to inhaled bronchodilators. Eur J Respir Dis., 63 (Suppl):73-78.

Reynolds, H.Y. (2004) Respiratory structure and function. In: Goldman L, Ausiello D, eds. Cecil Textbook of Medicine, 22nd ed. W. B. Saunders, Philadelphia, pp. 485-501.

Riddle, P. (2005) Principles of spectrophotometry The Biomedical Scientist.

Russell, R. (1996) Relative Size of Aerosol Particles. Windows to the Universe.

Sackner, M.A., Kim, C.S. (1985) Auxiliary MDI Aerosol Delivery Systems, Chest, 88, 161-170.

Schlesinger, R.B. (1985) Clearance from the respiratory tract. Fundam Appl Toxicol, 5(3):435-450.

Schlesinger, R.B. (1985) Comparative deposition of inhaled aerosols in experimental animals and humans: a review. J Toxicol Environ Health, 15(2):197-214.

Schlesinger, R. B., Lippmann, M. (1976). Particle deposition in the trachea: in vivo and in hollow casts. Thorax. 31(6): 678-684.

Schuen, J. S., Chen, L. D., Faeth, G. M. (1983) Evaluation of a stochastic model of particle dispersion in a turbulent round jet. American Institute of Chemical Engineers (AIChE) Journal, 29(1), 167-170.

Sciarra, J.J., Curie, A. (1978) Simulated respiratory system for in vitro evaluation of two inhalation delivery systems using selected steroids. J Pharm Sci. 67:428-31.

Seale, J.P., Harrison, L.I. (1998) Effect of changing the fine particle mass of inhaled beclomethasone dipropionate on intrapulmonary deposition and pharmacokinetics. Resp Me, 91(Suppl A):9-16. 
Sekihara, T., Olson, D. E., Filley, G. F. (1969) Airflow regimes and geometrical factors in the human airway. Proceedings of the Eleventh Aspen Emphysema Conference, 1968, edited by Mitchell, R.S. p. 103. United States Department of Health, Education and Welfare, Washington DC.

Selroos, O., Halme, M. (1991) The effect of a Volumatic spacer and mouth rinsing on systemic absorption of inhaled corticosteroids from a metered dose inhaler and dry powder inhaler. Thorax, 46:891-4.

Shenfield, G.M., Evans, M.E., Paterson, J.W. (1976) Absorption of drugs by the lungs. Br J Clin Pharmacol., 3:583-589.

Shraiber, A.A., Podvysotsky, A.M., Dubrovsky, V.V. (1996) Deformation and break-up of droplets by aerodynamic forces: Atomization and Spray 6:667-692.

Sivakugan, N. (2000) Soil Classification, James Cook University Geoengineering lecture handout.

Smye, S.W., Jollie, M.I., Littlewood, J.M. (1991) A mathematical model of some aspects of jet nebuliser performance. Clin Phys Physiol Meas, 12(3):289-300.

Snell, J.L., Ganderton, D. (1999) Assessing lung deposition of inhaled medications: Consensus statement from a workshop of the British Association of Lung Research. Respir Med. 93:123-133.

Suarez, S., Gonzalez-Rothi, R.J., Schreier, H., Hochhaus, G. (1998) Effect of dose and release rate on pulmonary targeting of liposomal triamcinolone acetonide phosphate. Pharm Res, 15(3):461-465.

Suarez, S., Hickey, A.J. (2000) Drug Properties Affecting Aerosol Behavior Respir Care, 45(6):652- 666.

Svartengren, K., Lindestad, P.A., Svartengren, M., Philipson, K., Bylin, G., Camner, P. (1995) Added external resistance reduces oropharyngeal deposition and increases lung deposition of aerosol particles in asthmatics. Am J Respir Crit Care Med, 152(1) :32-37.

Terzano, C. (2001) Pressurized Metered Dose Inhalers and Add-on Devices. Pulmonary Pharmacology and Therapeutics 14, 351-366.

The Internet Encyclopedia of Science: Anatomy and Physiology (2009) http://www.daviddarling.info/encyclopedia/A/alveolus.html

Thorsson, L., Edsbacke, S., Conradson, T.B. (1994) Lung deposition of budesonide from Turbuhaler is twice that from a pressurized metered-dose inhaler (P-MDI). Eur Respir $J$, 7(10):1839-1844. 
TSI (2004) PSD 3603 Particle size distribution analyzer instrumentation manual. P/N 1930068, Revision F.

Turner, M.O., Gafni, A., Swan, D., FitzGerald, J.M. (1996) A review and economic evaluation of bronchodilator delivery methods in hospitalized patients. Arch Intern Med, 156(18):2113-2118.

University of Michigan Health System (2009)

www.med.umich.edu/llibr/guides/asthma.htm

Usmani, O.S., Biddiscombe, M.F., Barnes, P.J: (2005) Regional Lung Deposition and Bronchodilator Response as a Function of $\beta$-Agonist Particle Size. American Journal of Respiratory and Critical Care Medicine Vol 172. pp. 1497-1504.

Valberg, P.A., Brain, J.D., Sneddon, S.L., Le Mott, S.R. (1982) Breathing patterns influence aerosol deposition sites in excised dog lungs. J Appl Physiol, 53(4):824-837.

Wang, L.P., Stock, D. E. (1992) Stochastic trajectory models for turbulent diffusion: Monte Carlo process versus Markov chains. Atmosphere Environment, 26A, 1599-1607.

Wiener, M.V. (1958) How to formulate aerosols to obtain the desired spray pattern. Soc Cos Chem, 9:289-297.

Wigley, G., Versteeg, H.R., Hodson, D. (2002) Near-oriifice PDA measurements and atomization mechanism of a pharmaceutical pressurized metered-dose inhaler. Proceedings of the $18^{\text {th }}$ Annual Conference on Liquid Atomization and Spray Systems, pp. 165-170.

Wildhaber, J.H., Devadason, S.G., Eber, E., Hayden, J., Everard, M.L., Summers, Q.A. (1996) Effect of electrostatic charge, flow, decay and multiple actuations in the in vitro delivery of salbutamol from different small volume spacers for infants. Thorax, 51:985-8.

Wilson, S.R. (2008) Aerosol deposition measurements as a function of Reynolds number for turbulent flow in a ninety-degree pipe bend., Department of Mechanical and Aerospace Engineering, Carleton University, Ottawa, Canada.

Yao, FSF., Malhotra, V., Fontes, ML. (2008) Yao and Artusio's Anesthesiology:

Problem-Oriented Patient Management, $6^{\text {th }}$ ed, Lippincott Williams and Wilkins, pp 8.

Yu, C.P., Diu, C.K. (1983) Total and regional deposition of inhaled aerosols in humans. J Aerosol Sci, 14:599-609.

Yu, J., Chien, Y.W. (1997) Pulmonary drug delivery: physiologic and mechanistic aspects. Crit Rev Ther Drug Carrier Syst, 14(4):395-453. 
Zainudin, B.M. (1993) Therapeutic aerosol: principles and practices. Med J Malaysia, 48(3):259-268.

Zak, M., Madsen, J., Berg, E., Bulow, J., Bisgaard, H. (1999) A mathematical model of aerosol holding chambers. J Aerosol Med, 12(3):187-196.

Zanen, P., Go, T.L., Lammers, J-W.J. (1994) The optimal particle size for $\beta_{2}$-adrenergic aerosols in mild asthmatics. Int J Pharm., 107:211-217.

Zanen, P., Go, T.L., Lammers, J-W.J. (1996) Optimal particle size for $\beta_{2}$-agonist and anticholinergic aerosols in patients with severe airflow obstruction. Thorax., 51:977-980.

Zhou, Q., Leschziner, M. A. (1991) A time correlated stochastic model for particle dispersion in anisotropic turbulence. 8th Symposium on turbulent shear 9ows. Technical University of Munich. 


\section{Appendices for Experimental Data}

\section{Appendix A: Standard Curve}

Table A.1 below shows the variation of Salbutamol Sulphate absorption with concentration.

Table A.1 Variation of absorption with concentration of Salbutamol Sulphate

\begin{tabular}{|l|l|l|l|}
\hline $\begin{array}{l}\text { Weight } \\
(\mu \mathrm{g})\end{array}$ & $\begin{array}{l}\text { Volume } \\
(\mathrm{ml})\end{array}$ & $\begin{array}{l}\text { Salbutamol } \\
(\mu \mathrm{g} / \mathrm{ml})\end{array}$ & $\begin{array}{l}\text { Absorption } \\
(\text { at 280 nm })\end{array}$ \\
\hline 12300.000 & 100.000 & 123.000 & 0.630 \\
\hline 12300.000 & 200.000 & 61.500 & 0.313 \\
\hline 12300.000 & 400.000 & 30.750 & 0.158 \\
\hline 12300.000 & 800.000 & 15.375 & 0.078 \\
\hline
\end{tabular}

\section{Appendix B: Dose Uniformity}

Table B.1 below shows the absorption and dose of 12 samples of Salbutamol sulphate. Each sample contains eight consecutive Salbutamol Sulphate pMDI actuations.

Table B.1 Absorption and dose of eight consecutive salbutamol sulphate actuations in twelve samples

\begin{tabular}{|l|l|l|l|l|l|l|}
\hline Sample \# & 1 & 2 & 3 & 4 & 5 & 6 \\
\hline Absorption & 0.330 & 0.337 & 0.319 & 0.335 & 0.328 & 0.337 \\
\hline $\begin{array}{l}\text { Dose } \\
(\mu \mathrm{g} / \mathrm{mL} .)\end{array}$ & 64.700 & 66.113 & 62.599 & 65.779 & 64.369 & 66.191 \\
\hline
\end{tabular}

\begin{tabular}{|l|l|l|l|l|l|l|}
\hline Sample \# & 7 & 8 & 9 & 10 & 11 & 12 \\
\hline Absorption & 0.327 & 0.336 & 0.329 & 0.334 & 0.329 & 0.335 \\
\hline $\begin{array}{l}\text { Dose } \\
(\mu \mathrm{g} / \mathrm{mL} .)\end{array}$ & 64.130 & 66.054 & 64.601 & 65.524 & 64.387 & 65.720 \\
\hline
\end{tabular}




\section{Appendix C: Salbutamol Sulphate Deposition in Spacer and Filter at Different Flow Rates}

(1) OptiChamber

Table C.1 : Salbutamol Sulphate deposition in OptiChamber and filter at different flow rates

\begin{tabular}{|l|l|l|}
\hline Flow rate $(\mathrm{L} / \mathrm{min})$. & Spacer deposition $(\mu \mathrm{g} / \mathrm{mL})$ & Filter deposition $(\mu \mathrm{g} / \mathrm{mL})$ \\
\hline 30 & 45.78 & 56.78 \\
& 47.94 & 54.06 \\
& 50.61 & 50.91 \\
\hline 45 & 41.37 & 62.54 \\
& 42.48 & 59.16 \\
& 45.13 & 57.68 \\
\hline 60 & 35.24 & 66.96 \\
& 40.47 & 61.36 \\
& 37.67 & 64.26 \\
\hline
\end{tabular}

(2) OptiHaler

Table C.2 : Salbutamol Sulphate deposition in OptiHaler and filter at different flow rates

\begin{tabular}{|l|l|l|}
\hline Flow Rate & Spacer deposition $(\mu \mathrm{g} / \mathrm{mL})$ & Filter deposition $(\mu \mathrm{g} / \mathrm{mL})$ \\
\hline 30 & 66.73 & 37.11 \\
& 69.74 & 36.34 \\
& 71.85 & 34.04 \\
\hline 45 & 59.81 & 42.77 \\
& 62.13 & 41.07 \\
& 64.13 & 39.32 \\
\hline 60 & 52.71 & 47.05 \\
& 54.49 & 45.70 \\
& 57.10 & 43.89 \\
\hline
\end{tabular}


(3) PocketChamber

Table C.3 : Salbutamol Sulphate deposition in PocketChamberand filter at different flow rates

\begin{tabular}{|l|l|l|}
\hline Flow Rate & Spacer deposition $(\mu \mathrm{g} / \mathrm{mL})$ & Filter deposition $(\mu \mathrm{g} / \mathrm{mL})$ \\
\hline 30 & 72.49 & 29.31 \\
& 66.15 & 34.27 \\
& 69.74 & 31.72 \\
\hline 45 & 61.54 & 39.90 \\
& 69.68 & 37.41 \\
& 67.66 & 34.65 \\
\hline 60 & 57.57 & 45.77 \\
& 61.20 & 42.14 \\
& 63.95 & 39.69 \\
\hline
\end{tabular}

\section{Appendix D: Total Deposition Fraction (TDF) of Salbutamol Sulphate in Spacers at Different Flow Rates}

(1) OptiChamber

Table D.1: Total deposition fraction of Salbutamol Sulphate in OptiChamber

\begin{tabular}{|l|l|l|l|l|}
\hline Flow Rate & $\begin{array}{l}\text { Spacer } \\
\text { deposition } \\
(\mu \mathrm{g} / \mathrm{mL})\end{array}$ & $\begin{array}{l}\text { Filter } \\
\text { deposition } \\
(\mu \mathrm{g} / \mathrm{mL})\end{array}$ & $\begin{array}{l}\text { Total } \\
\text { deposition } \\
(\mu \mathrm{g} / \mathrm{mL})\end{array}$ & $\begin{array}{l}\text { Total } \\
\text { deposition } \\
\text { fraction }(\mathrm{DF})\end{array}$ \\
\hline 30 & 45.78 & 56.78 & 102.56 & 0.446 \\
& 47.94 & 54.06 & 102.00 & 0.470 \\
& 50.61 & 50.91 & 101.52 & 0.498 \\
\hline 45 & 41.37 & 62.54 & 103.91 & 0.398 \\
& 42.48 & 59.16 & 101.64 & 0.418 \\
& 45.13 & 57.68 & 102.82 & 0.439 \\
\hline 60 & 35.24 & 66.96 & 102.21 & 0.345 \\
& 40.47 & 61.36 & 101.83 & 0.399 \\
& 37.67 & 64.26 & 101.93 & 0.370 \\
\hline
\end{tabular}


(2) OptiHaler

Table D.2: Total deposition fraction of Salbutamol Sulphate in OptiHaler

\begin{tabular}{|l|l|l|l|l|}
\hline Flow Rate & $\begin{array}{l}\text { Spacer } \\
\text { deposition } \\
(\mu \mathrm{g} / \mathrm{mL})\end{array}$ & $\begin{array}{l}\text { Filter } \\
\text { deposition } \\
(\mu \mathrm{g} / \mathrm{mL})\end{array}$ & $\begin{array}{l}\text { Total } \\
\text { deposition } \\
(\mu \mathrm{g} / \mathrm{mL})\end{array}$ & $\begin{array}{l}\text { Total } \\
\text { deposition } \\
\text { fraction }(\mathrm{DF})\end{array}$ \\
\hline 30 & 66.73 & 37.11 & 103.84 & 0.643 \\
& 69.74 & 36.34 & 106.08 & 0.657 \\
& 71.85 & 34.04 & 105.89 & 0.678 \\
\hline 45 & 59.81 & 42.77 & 102.58 & 0.583 \\
& 62.13 & 41.07 & 103.19 & 0.602 \\
& 64.13 & 39.32 & 103.45 & 0.620 \\
\hline 60 & 52.71 & 47.05 & 99.76 & 0.528 \\
& 54.49 & 45.70 & 100.19 & 0.544 \\
& 57.10 & 43.89 & 100.99 & 0.565 \\
\hline
\end{tabular}

(3) PocketChamber

Table D.3: Total deposition fraction of Salbutamol Sulphate in PocketChamber

\begin{tabular}{|l|l|l|l|l|}
\hline Flow Rate & $\begin{array}{l}\text { Spacer } \\
\text { deposition } \\
(\mu \mathrm{g} / \mathrm{mL})\end{array}$ & $\begin{array}{l}\text { Filter } \\
\text { deposition } \\
(\mu \mathrm{g} / \mathrm{mL})\end{array}$ & $\begin{array}{l}\text { Total } \\
\text { deposition } \\
(\mu \mathrm{g} / \mathrm{mL})\end{array}$ & $\begin{array}{l}\text { Total } \\
\text { deposition } \\
\text { fraction }(\mathrm{DF})\end{array}$ \\
\hline 30 & 72.49 & 29.31 & 101.80 & 0.741 \\
& 66.15 & 34.27 & 100.43 & 0.659 \\
& 69.74 & 31.72 & 101.47 & 0.687 \\
\hline 45 & 61.54 & 39.90 & 101.45 & 0.606 \\
& 69.68 & 37.41 & 107.09 & 0.651 \\
& 67.66 & 34.65 & 102.31 & 0.661 \\
\hline 60 & 57.57 & 45.77 & 103.35 & 0.557 \\
& 61.20 & 42.14 & 103.35 & 0.592 \\
& 63.95 & 39.69 & 103.64 & 0.613 \\
\hline
\end{tabular}




\section{Appendix E: Deposition of Salbutamol Sulphate in Different Parts of OptiChamber}

(1) Flow rate: $30 \mathrm{~L} / \mathrm{min}$

Table E.1: Salbutamol Sulphate deposition at $30 \mathrm{~L} / \mathrm{min}$ flow rate

\begin{tabular}{|l|l|l|}
\hline Spacer Part & Absorption & Deposition $(\mu \mathrm{g} / \mathrm{mL})$ \\
\hline Lower half & 0.0771 & 15.14 \\
& 0.0693 & 13.60 \\
& 0.0724 & 14.21 \\
\hline Upper half & 0.0537 & 10.54 \\
& 0.0595 & 11.68 \\
& 0.0665 & 13.06 \\
\hline Filter & 0.2444 & 47.97 \\
& 0.2539 & 49.84 \\
& 0.2583 & 50.69 \\
\hline Valve & 0.0509 & 9.98 \\
& 0.0379 & 7.44 \\
& 0.0415 & 8.66 \\
\hline Inlet piece & 0.0314 & 6.15 \\
& 0.0292 & 5.73 \\
& 0.0271 & 5.33 \\
\hline
\end{tabular}

(2) Flow rate: $45 \mathrm{~L} / \mathrm{min}$.

Table E.2: Salbutamol Sulphate deposition at $45 \mathrm{~L} / \mathrm{min}$ flow rate

\begin{tabular}{|l|l|l|}
\hline Spacer Part & Absorption & Deposition $\mu \mathrm{g} / \mathrm{mL})$ \\
\hline Lower half & 0.0701 & 13.76 \\
& 0.0606 & 11.89 \\
& 0.0559 & 10.97 \\
\hline Upper half & 0.0490 & 9.62 \\
& 0.0571 & 11.20 \\
& 0.0435 & 8.54 \\
\hline Filter & 0.2691 & 52.83 \\
& 0.2706 & 53.11 \\
& 0.2846 & 55.87 \\
\hline Valve & 0.0638 & 12.52 \\
& 0.0522 & 10.25 \\
& 0.0463 & 9.09 \\
\hline Inlet piece & 0.0222 & 4.37 \\
& 0.0234 & 4.60 \\
& 0.0261 & 5.14 \\
\hline
\end{tabular}


(3) Flow rate: $60 \mathrm{~L} / \mathrm{min}$

Table E.3: Salbutamol Sulphate deposition at $60 \mathrm{~L} / \mathrm{min}$ flow rate

\begin{tabular}{|l|l|l|}
\hline Spacer Part & Absorption & Deposition $(\mu \mathrm{g} / \mathrm{mL})$ \\
\hline Lower half & 0.0569 & 11.17 \\
& 0.0503 & 9.88 \\
& 0.0521 & 10.23 \\
\hline Upper half & 0.0373 & 7.31 \\
& 0.0436 & 8.55 \\
& 0.0416 & 8.17 \\
\hline Filter & 0.3126 & 61.36 \\
& 0.2943 & 57.76 \\
& 0.3036 & 59.59 \\
\hline Valve & 0.0720 & 14.13 \\
& 0.0657 & 12.89 \\
& 0.0588 & 11.54 \\
\hline Inlet piece & 0.0210 & 4.12 \\
& 0.0208 & 4.08 \\
& 0.0197 & 3.88 \\
\hline
\end{tabular}

\section{Appendix F: Deposition Fraction of Salbutamol Sulphate in Upper and Lower Halves of OptiChamber at Different Flow Rates}

(1) Flow rate: $30 \mathrm{~L} / \mathrm{min}$.

Table F.1: deposition fraction of Salbutamol Sulphate in upper and lower halves of OptiChamber at $30 \mathrm{~L} / \mathrm{min}$ flow rate

\begin{tabular}{|l|l|l|l|l|l|l|l|}
\hline $\begin{array}{l}\text { Lower } \\
\text { Half } \\
\begin{array}{l}\text { Dep. } \\
(\mu \mathrm{g} / \mathrm{mL})\end{array}\end{array}$ & $\begin{array}{l}\text { Upper } \\
\text { Half } \\
(\mu \mathrm{g} / \mathrm{mL})\end{array}$ & $\begin{array}{l}\text { Filter } \\
\text { Dep. } \\
(\mu \mathrm{g} / \mathrm{mL})\end{array}$ & $\begin{array}{l}\text { Valve } \\
\text { Dep. } \\
(\mu \mathrm{g} / \mathrm{mL})\end{array}$ & $\begin{array}{l}\text { Inlet } \\
\text { Piece } \\
\text { Dep. } \\
(\mu \mathrm{g} / \mathrm{mL})\end{array}$ & $\begin{array}{l}\text { Total } \\
\text { Dep. } \\
(\mu \mathrm{g} / \mathrm{mL})\end{array}$ & $\begin{array}{l}\text { Lower } \\
\text { Half } \\
\text { Dep. } \\
\text { Fraction }\end{array}$ & $\begin{array}{l}\text { Upper } \\
\text { Half } \\
\text { Dep. } \\
\text { Fraction }\end{array}$ \\
\hline 15.14 & 10.54 & 47.97 & 9.98 & 6.15 & 89.80 & 0.169 & 0.117 \\
\hline 13.59 & 11.68 & 49.84 & 7.44 & 5.73 & 88.26 & 0.154 & 0.132 \\
\hline 14.21 & 13.06 & 50.69 & 8.66 & 5.33 & 91.95 & 0.1546 & 0.142 \\
\hline
\end{tabular}


(2) Flow rate: $45 \mathrm{~L} / \mathrm{min}$.

Table F.2: deposition fraction of Salbutamol Sulphate in upper and lower halves of OptiChamber at $45 \mathrm{~L} / \mathrm{min}$ flow rate.

\begin{tabular}{|l|l|l|l|l|l|l|l|}
\hline $\begin{array}{l}\text { Lower } \\
\text { Half } \\
\text { Dep. } \\
(\mu \mathrm{g} / \mathrm{mL})\end{array}$ & $\begin{array}{l}\text { Upper } \\
\text { Dep. } \\
(\mu \mathrm{g} / \mathrm{mL})\end{array}$ & $\begin{array}{l}\text { Filter } \\
\text { Dep. } \\
(\mu \mathrm{g} / \mathrm{mL})\end{array}$ & $\begin{array}{l}\text { Valve } \\
\text { Dep. } \\
(\mu \mathrm{g} / \mathrm{mL})\end{array}$ & $\begin{array}{l}\text { Inlet } \\
\text { Piece } \\
\text { Dep. } \\
(\mu \mathrm{g} / \mathrm{mL})\end{array}$ & $\begin{array}{l}\text { Total } \\
\text { Dep. } \\
(\mu \mathrm{g} / \mathrm{mL})\end{array}$ & $\begin{array}{l}\text { Lower } \\
\text { Half } \\
\text { Dep. } \\
\text { Fraction }\end{array}$ & $\begin{array}{l}\text { Upper } \\
\text { Half } \\
\text { Dep. } \\
\text { Fraction }\end{array}$ \\
\hline 13.76 & 9.62 & 52.83 & 12.52 & 4.37 & 93.08 & 0.148 & 0.103 \\
\hline 11.89 & 11.20 & 53.11 & 10.25 & 4.60 & 91.12 & 0.130 & 0.123 \\
\hline 10.97 & 8.54 & 55.87 & 9.09 & 5.14 & 89.61 & 0.122 & 0.095 \\
\hline
\end{tabular}

(3) Flow rate: $60 \mathrm{~L} / \mathrm{min}$.

Table F.3: deposition fraction of Salbutamol Sulphate in upper and lower halves of OptiChamber at $60 \mathrm{~L} / \mathrm{min}$ flow rate.

\begin{tabular}{|l|l|l|l|l|l|l|l|}
\hline $\begin{array}{l}\text { Lower } \\
\text { Half } \\
\text { Dep. } \\
(\mu \mathrm{g} / \mathrm{mL})\end{array}$ & $\begin{array}{l}\text { Upper } \\
\text { Half } \\
(\mu \mathrm{g} / \mathrm{mL})\end{array}$ & $\begin{array}{l}\text { Filter } \\
\text { Dep. } \\
(\mu \mathrm{g} / \mathrm{mL})\end{array}$ & $\begin{array}{l}\text { Valve } \\
\text { Dep. } \\
(\mu \mathrm{g} / \mathrm{mL})\end{array}$ & $\begin{array}{l}\text { Inlet } \\
\text { Piece } \\
\text { Dep. } \\
(\mu \mathrm{g} / \mathrm{mL})\end{array}$ & $\begin{array}{l}\text { Total } \\
\text { Dep. } \\
(\mu \mathrm{g} / \mathrm{mL})\end{array}$ & $\begin{array}{l}\text { Lower } \\
\text { Half } \\
\text { Dep. } \\
\text { Fraction }\end{array}$ & $\begin{array}{l}\text { Upper } \\
\text { Half } \\
\text { Dep. } \\
\text { Fraction }\end{array}$ \\
\hline 11.17 & 7.31 & 61.36 & 14.13 & 4.12 & 98.10 & 0.114 & 0.074 \\
\hline 9.88 & 8.55 & 57.76 & 12.89 & 4.08 & 93.17 & 0.106 & 0.092 \\
\hline 10.23 & 8.17 & 59.59 & 11.54 & 3.88 & 93.41 & 0.109 & 0.087 \\
\hline
\end{tabular}

